\title{
Adverse Neuropsychiatric Events and Recreational Use of Efavirenz and Other HIV-1 Antiretroviral Drugs
}

\author{
Dhwanil A. Dalwadi, Luis Ozuna, Brian H. Harvey, Michelle Viljoen, and John A. Schetz
}

Institute for Healthy Aging, Center for Neuroscience Discovery, Department of Pharmacology and Neuroscience, University of North Texas Health Science Center, Fort Worth, Texas (D.A.D., L.O., J.A.S.); Centre of Excellence for Pharmaceutical Sciences (PharmaCen), Division of Pharmacology, School of Pharmacy, North-West University, Potchefstroom, South Africa (B.H.H.); and Department of Pharmacology and Clinical Pharmacy, School of Pharmacy, Faculty of Natural Sciences, University of the Western Cape, Bellville, South Africa (M.V.)

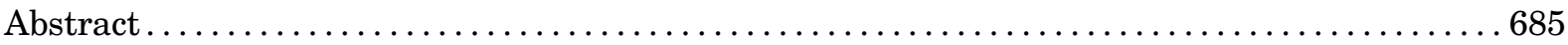

I. Historical Perspective of Antiretroviral Drugs and Highly Active Antiretroviral Therapy .... 685

II. Neuropsychiatric Adverse Event Associated with Antiretroviral Drugs ..................668

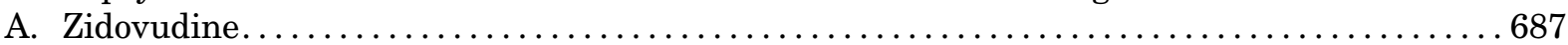

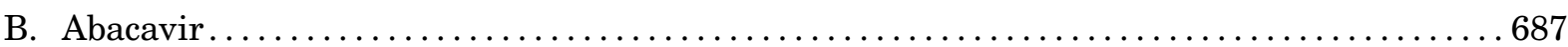

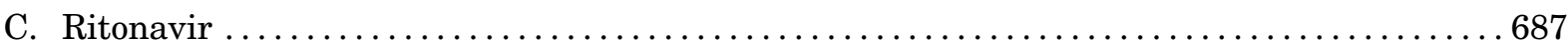

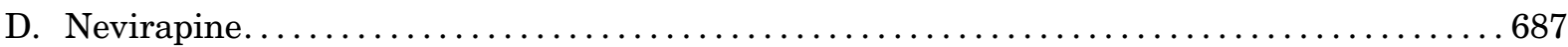

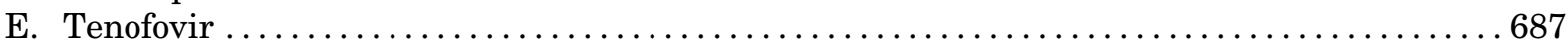

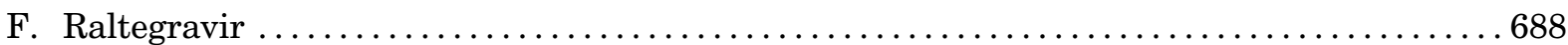

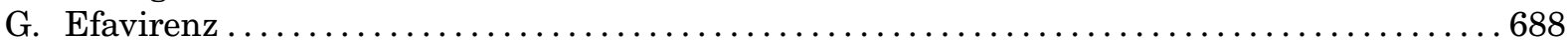

1. Correlation between Efavirenz Plasma Concentrations and Neuropsychiatric

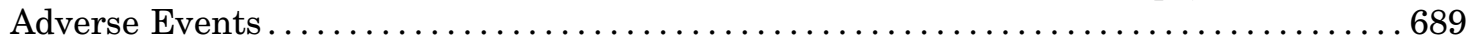

2. Efavirenz Therapeutic Index and Brain Exposure $\ldots \ldots \ldots \ldots \ldots \ldots \ldots \ldots \ldots \ldots \ldots 69 . \ldots \ldots$

3. Longer-Term Neuropsychiatric Adverse Events......................... 689

4. Neuropsychiatric Adverse Events Associated with Efavirenz in Children ............691

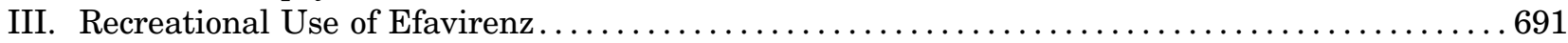

IV. Factors Increasing Efavirenz Plasma Levels ................................ 692

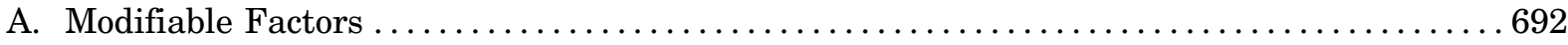

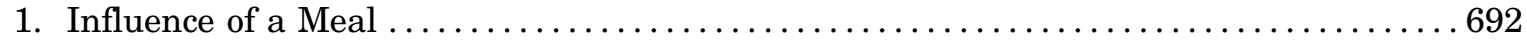

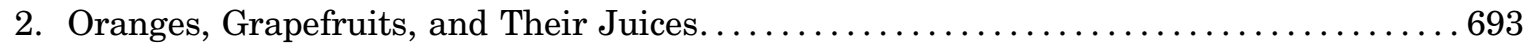

3. Influence of Body Weight/Body Mass Index............................ 693

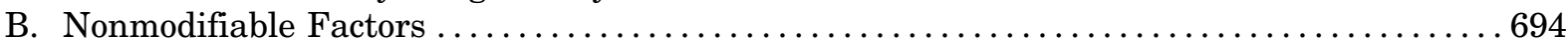

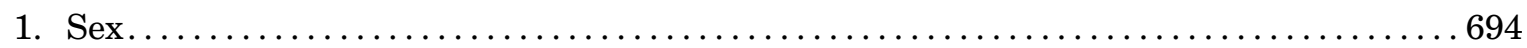

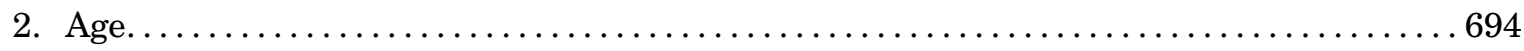

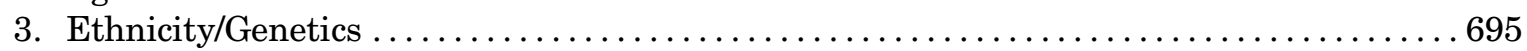

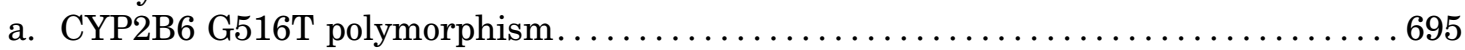

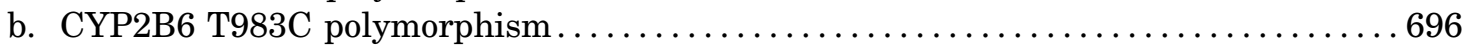

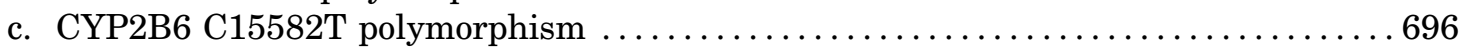

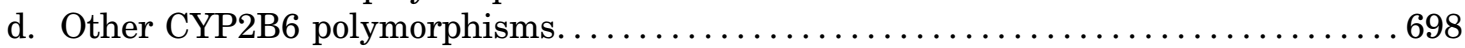

e. Other polymorphisms leading to elevations in efavirenz levels . . . . . . . . . . . . . 698

i. CYP1A2 Polymorphisms ........................................ 699

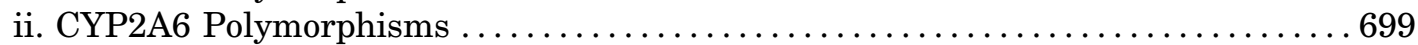

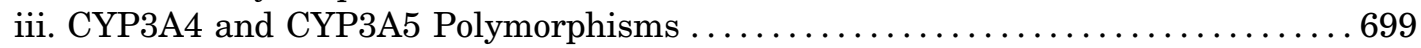

iv. Efflux Transporter Polymorphisms............................... 699

v. ATP Binding Cassette Subfamily B Member 1/Multidrug Resistance Protein

1 Polymorphisms .............................................. 699

vi. UDP-Glucuronosyltransferase Isoform 2B7 Polymorphisms . . . . . . . . . 700

vii. Nuclear Receptor Polymorphisms .................................. 700

Address correspondence to: John A. Schetz, UNT Health Science Center, 3500 Camp Bowie Blvd, Fort Worth, TX 76107. E-mail: John. Schetz@unthsc.edu

https://doi.org/10.1124/pr.117.013706. 


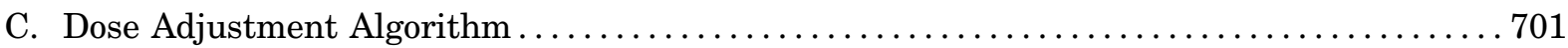

D. Efavirenz Drug-Drug Interactions Leading to Elevated Efavirenz Levels .............. 701

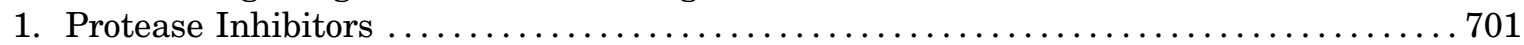

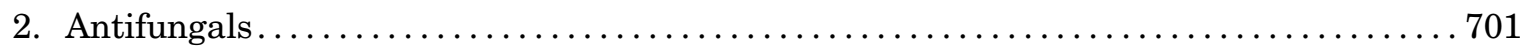

3. Antiplatelet Agents ............................................ 702

V. Molecular Mechanisms and Receptor Pharmacology of Efavirenz..................... 702

VI. Possible Association of Efavirenz with Human Immunodeficiency Virus-Associated

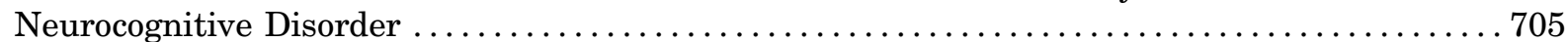

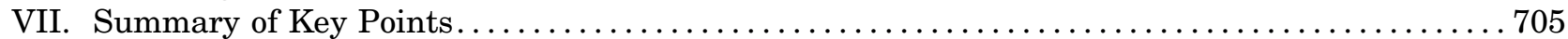

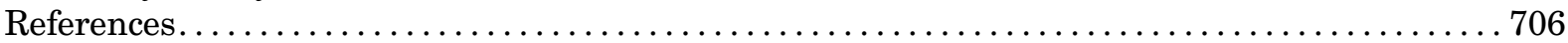

\begin{abstract}
Efavirenz is a highly effective HIV-1 antiretroviral; however, it is also frequently associated with neuropsychiatric adverse events (NPAE) that include abnormal dreams, sleep disturbances, nervousness, anxiety, depression, and dizziness. The incidence of NPAEs upon initiation of treatment with efavirenzcontaining medications is high, exceeding $50 \%$ in most studies. Although the NPAEs tend to decrease after the first month in many patients, they persist for long periods of time in others. Efavirenz-based treatment is generally well-tolerated in children, although some experience persistent concentration problems, as well as sleep disturbances, psychotic reactions, and seizures. In an effort to link basic with clinical research, parameters associated with efavirenz brain exposure are discussed, and factors that increase efavirenz levels are explored in depth as they are expected to contribute to NPAE risk. These include
\end{abstract}

the role of modifiable and nonmodifiable risk factors such as diet, weight, and drug-drug interactions and sex, age, and ethnicity/pharmacogenetics. In addition to NPAEs, this review explores what is known about antiretroviral (ARV) drugs being used for recreational purposes. Although multiple ARV drugs are covered, special attention is devoted to efavirenz given that the majority of reports of NPAEs and illicit use of ARV drugs concern efavirenz. The evolving molecular mechanistic basis of NPAEs and abuse of efavirenz point to a complex and polymodal receptor pharmacology. Animal studies to date primarily point to a serotonergic mechanism of action. Recently emerging associations between HIV-associated neurocognitive disorder and efavirenz use, and possible contributions of the mitochondrialimmune-inflammatory-redox cascade are explored in the context of the signaling mechanisms that appear to be involved.

\section{Historical Perspective of Antiretroviral Drugs} and Highly Active Antiretroviral Therapy

Since the first clinical observation of AIDS in 1981, HIV/AIDS has become a global pandemic affecting almost 1 in 200 people worldwide (https://www.avert.org/globalhiv-and-aids-statistics). To date there is no cure for HIV, but with modern treatment regimens, HIV infection has become a matter of morbidity for many rather than mortality (https:// www.avert.org/global-hiv-and-aids-statistics; Palella et al., 1998; Panos et al., 2008). In the absence of therapy, the average time leading to the development of AIDS is approximately 8-10 years, followed soon by death (Porter et al., 1999). The first effective medicine for HIV was the nucleoside reverse transcriptase inhibitor (NRTI) zidovudine (AZT), which was FDA approved in 1987 (Brook, 1987). AZT treatment resulted in higher $\mathrm{CD} 4^{+}$cell counts but did not significantly reduce viral plasma load (Kinloch-De Loes et al., 1995; Niu et al., 1998). Furthermore, a long-term outcome study revealed that AZT monotherapy did not improve the prognosis in HIV patients (Lindback et al., 1999). Subsequently several more NRTIs were developed, but none were able to suppress the virus for long periods of time. Due to poor prognosis and lack of viable treatment options, in 1993 the FDA implemented an accelerated approval pathway for the development of HIV/AIDS drugs (Wilson et al., 2013). In 1995, efavirenz [(4S)-6-chloro-4-(2cyclopropylethynyl)-4-(trifluoromethyl)-2,4-dihydro- $1 H$ 3,1-benzoxazin-2-one] emerged as one of a new class of non-nucleoside reverse transcriptase inhibitors (NNRTI) (Young et al., 1995). Not only did efavirenz prove to be a potent inhibitor of the wild-type HIV-1 reverse transcriptase, but it was also able to inhibit a panel of otherwise NNRTI-resistant HIV-1 reverse transcriptase mutants (Young et al., 1995). Being more potent than other NNRTI monotherapies available at that time (e.g., nevirapine and delavirdine) (Richman et al., 1991; Dueweke et al., 1993; Young et al., 1995), efavirenz underwent accelerated

ABBREVIATIONS: ABC, ATP binding cassette; ACTG, AIDS Clinical Trials Group; ART, antiretroviral treatment; ARV, antiretroviral; AZT, zidovudine; BMI, body mass index; CAR, constitutive androstane receptor; CNS, central nervous system; CPE, cerebral penetration effectiveness; CSF, cerebrospinal fluid; CYP, cytochrome P450; DAT, dopamine transporter; DHHS, US Department of Health and Human Services; DOI, 2,5-Dimethoxy-4-iodoamphetamine; EFV, efavirenz; FDA, Food and Drug Administration; HAART, highly active antiretroviral therapy; HAND, human immunodeficiency virus-associated neurocognitive disorder; HIV, human immunodeficiency virus; 5-HT, serotonin; IDO, indoleamine 2,3-dioxygenase; iNOS, inducible nitric oxide synthase; LSD, lysergic acid diethylamide; MDR, multidrug resistant transporter; NAA/Cr, $N$-acetylaspartate/creatine; NNRTI, non-nucleoside reverse transcriptase inhibitor; NO, nitric oxide; NPAE, neuropsychiatric adverse events; NRTI, nucleoside reverse transcriptase inhibitor; OATP, organic anion transporting polypeptide; 7-OHEFV, 7-hydroxyefavirenz; 8-OH-EFV, 8-hydroxyefavirenz; PI, protease inhibitor; PXR, pregnane X receptors; SNP, single nucleotide polymorphism; TB, tuberculosis; TDF, tenofovir disoproxil fumarate; WHO, World Health Organization. 
evaluation and in 1998 was approved for the treatment of HIV-1 infection based on a controlled 24-week study analyzing plasma HIV RNA levels and $\mathrm{CD} 4^{+}$cell counts (http://www.fda.gov/ForPatients/Illness/HIVAIDS/History/ ucm151079.htm). However, in the 2 years prior to its approval, the approach for treating HIV had changed drastically from monotherapies to drug combinations, a movement first alluded to in a 1995 editorial published by David Ho in The New England Journal of Medicine (Ho, 1995). In 1996, at the 11th International Conference on AIDS held in Vancouver, British Columbia, three crucial studies were presented that changed the course of HIV treatments: 1) nevirapine-based triple drug therapy, 2) indinavir-based triple drug therapy, and 3) boosting saquinavir with ritonavir. Subsequently, two independent studies demonstrated the effectiveness of three-drug combination therapies (Gulick et al., 1997; Hammer et al., 1997). These studies demonstrated that a combination of the protease inhibitor (PI) indinavir and two NRTIs lamivudine and zidovudine significantly slowed the progression of HIV-1 compared with zidovudine and lamivudine monotherapies (Gulick et al., 1997; Hammer et al., 1997). This ushered in the era of highly active antiretroviral therapy (HAART), a triple drug combination therapy approach used to suppress HIV viral replication and progression of HIV disease.

At the inception of HAART, the triple combination regimen often involved two NRTIs and either a PI or a NNRTI; however, HAART has evolved since to also include integrase strand transfer inhibitors, boosted PIs, or entry inhibitors as third or fourth components for both treatment-naive and treatment-experienced adult patients to optimize background therapy, meaning that a new ARV regimen is being applied as resistance has developed to the original ARV regimen (Flexner, 2011). In the latter case, one PI is used as a pharmacokinetic boosting agent to prolong the metabolic half-life of the other PI (Flexner, 2000). In a number of HAART studies, the inclusion of efavirenz in the combination resulted in better outcomes. Until early 2015, the DHHS guidelines recommended efavirenzbased HAART as the preferred first line regimen for treatment-naive patients. However, the April 2015 and subsequent DHHS guidelines no longer recommends efavirenz for treatment-naive patients, although the latest WHO and South African guidelines for adults continue to recommend efavirenz as the preferred NNRTI for HAART (National Department of Health, 2015; WHO, 2016).

Because of its superior virologic efficacy, soon after its approval, efavirenz became the preferred third drug in HAART (Staszewski et al., 1999). In a 48-week randomized, open-label HAART trial consisting of 1216 patients comparing stavudine and lamivudine with either efavirenz, nevirapine, or nevirapine plus efavirenz, virologic failure occurred in $43.7 \%, 37.8 \%$, and $53.1 \%$ of patients, respectively, indicating the NNRTIs efavirenz and nevirapine have similar efficacy (van Leth et al., 2004). However, the nevirapine-based regimen was associated with significant hepatotoxicity, and, of the 25 deaths that occurred during the study two were attributed to nevirapine and the remaining were due to infection or unrelated to the study medication (van Leth et al., 2004). In a 96-week randomized, double-blind study of 1147 HIV-1-infected patients, a triple nucleoside regimen lacking efavirenz was compared with one including efavirenz (Gulick et al., 2004). Specifically, treatment groups were zidovudinelamivudine-abacavir, zidovudine-lamivudine-efavirenz, or zidovudine-lamivudine-abacavir-efavirenz. After 32 weeks, virologic failure occurred in $21 \%$ of patients in the triple nucleoside group compared with $11 \%$ of patients in the combined efavirenz group, $P<0.001$, indicating that two NRTIs plus the NNRTI efavirenz was the superior treatment option compared with three NRTIs (Gulick et al., 2004). In addition, virologic failure was more rapid in the treatment group that lacked efavirenz, $P<0.001$ (Gulick et al., 2004). Consequently, within a short period of time, the three NRTI combination of zidovudine-lamivudineabacavir was removed from the preferred drug list from virtually every HIV treatment guideline (https://www. medscape.org/viewarticle/523119). Replacing it was the NNRTI plus two NRTI-based HAART regimen that became the mainstay of HIV treatment, and efavirenzbased HAART became the preferred first line ARV regimen for treatment-naive patients (Riddler et al., 2008). On the one hand, efavirenz-based regimens have many advantages that include well-established efficacy, potency, convenience (once daily dosing), superior patient compliance, and lower risk of long-term metabolic toxicities compared with PI-based regimens (Staszewski et al., 1999; Gulick et al., 2004). On the other hand, disadvantages include a low genetic barrier to phenotypic resistance (Joly and Yeni, 2000) and high incidences of neuropsychiatric adverse events (NPAEs). The risk of NPAEs in particular prompted efavirenz-based HAART to be moved to the alternative regimens category in the latest update of DHHS guidelines (DHHS, 2017), although the latest WHO and South African guidelines for adults continue to recommend efavirenz as the preferred NNRTI for HAART (National Department of Health, 2015; WHO, 2016).

\section{Neuropsychiatric Adverse Event Associated with Antiretroviral Drugs}

Although less common, NPAEs have also been reported for ARV drugs other than efavirenz. These include the protease inhibitor (PI) ritonavir; the NRTIs zidovudine, abacavir, tenofovir, and emtricitabine, and the NNRTI nevirapine (Fischl et al., 1990; McLeod and Hammer, 1992; Morlese et al., 2002; Wise et al., 2002). The spectrum of reported neuropsychiatric complications includes confusion, anxiety, depression, insomnia, dizziness, agitation, abnormal dreams, hallucinations and delusional, psychotic, paranoid, and manic behaviors (Fischl et al., 1990; 
McLeod and Hammer, 1992; Morlese et al., 2002; Wise et al., 2002). Like efavirenz, all of these ARV drugs penetrate the central nervous system (CNS) to varying degrees (Letendre et al., 2008; Tozzi et al., 2009) and are recommended for preventing or treating HIV-associated neurocognitive disorder (HAND), which is caused by HIV viral invasion into the CNS (Letendre et al., 2008; Tozzi et al., 2009). Letendre et al. (2008) characterized cerebral penetration of ARV drugs based on molecular and pharmacologic properties, cerebrospinal fluid (CSF) concentration measurements, and effectiveness in reducing CSF viral loads or improving HIV-associated cognitive dysfunction. Results revealed that drugs with higher cerebral penetration-effectiveness (CPE) ranks were associated with lower CSF viral loads of HIV (Letendre et al., 2008). Another study showed that HAND patients treated with ARVs having higher CPE ranks and those that achieved virological suppression also showed improvement in their neurocognitive capabilities (Tozzi et al., 2009). According to Tozzi et al. (2009), ARVs with good CPE include zidovudine, stavudine, abacavir, indinavir, efavirenz, nevirapine, and lamivudine, whereas those considered to have low penetration are tenofovir, didanosine, zalcitabine, nelfinavir and saquinavir, ritonavir, tipranavirritonavir, and enfuvirtide.

\section{A. Zidovudine}

Zidovudine is another potent NRTI often used in combination with lamivudine, but it is no longer recommended for use in the United States (DHHS, 2017). Guidelines for ARV use report that zidovudine alone may be used in pregnant women who wish to reduce exposure of ARV drugs to the fetus while still reducing risk of HIV transmission (DHHS, 2017). In a year-long clinical study, up to $5 \%$ of the patients taking zidovudine experienced agitation, confusion, and insomnia (Rachlis and Fanning, 1993). A number of cases have been published describing the onset of dose-related and reversible adverse psychiatric events associated with zidovudine for the treatment of HIV, including depressive and manic syndromes usually accompanied by auditory hallucinations and paranoid delusions (Maxwell et al., 1988; O'Dowd and McKegney, 1988; Schaerf et al., 1988; Wright et al., 1989) and others concerning the recurrence of posttraumatic stress disorder (Moreno et al., 2003).

\section{B. Abacavir}

Abacavir is another NRTI and is a component of the preferred initial combination regimen for treatmentnaive patients that are HLA-B $* 5701$ negative (Department of Health and Human Services, 2017), because hypersensitivity reactions to abacavir have been linked to this major histocompatibility complex class I allele (Mallal et al., 2008). There are several case reports of the induction of neuropsychiatric complications, including depression with suicidal thoughts, anxiety, nightmares, and auditory hallucinations, when patients switch from an ARV regimen lacking abacavir to one containing it (Foster et al., 2003, 2004; Soler Palacin et al., 2006). Furthermore, when abacavir is removed, these side effects subside, and they return upon reinstatement (Colebunders et al., 2002; Foster et al., 2003).

\section{Ritonavir}

A ritonavir-boosted protease inhibitor (PI) plus two NRTIs is the recommended PI-based ARV drug treatment option (DHHS, 2017). Ritonavir potently inhibits cytochrome P450 3A4, thereby "boosting" the effects of other PI drugs that are metabolized by this isoenzyme (Koudriakova et al., 1998). In a comparative study with tipranavir-ritonavir in healthy volunteers, the incidents of nervous system and psychiatric side effects were $32.4 \%$ and $8.8 \%$ and increased to $61.3 \%$ and $25.8 \%$ upon addition of efavirenz (la Porte et al., 2009). Abnormal dreaming was also prominent (14.7\%) (la Porte et al., 2009). Other studies reported high incident rates of adverse CNS side effects for ritonavir alone; this included insomnia ( $\sim 70 \%)$ and psychologic alterations (24\%-30\%) (Merry et al., 1996; Nadal et al., 2000). In the RELAX study of 129 HIV patients who had achieved viral suppression and were experiencing CNS side effects severe enough to warrant switching to a different antiretroviral drug, $7 \%$ of the patients had been taking ritonavir in combination with either darunavir, atazanavir, or lopinavir (Pedrol et al., 2015).

\section{Nevirapine}

Nevirapine is an NNRTI and was a component of one of the alternative treatment regimens, but is no longer part of any alternative regimen options (DHHS, 2017). Use of nevirapine is somewhat limited by frequent incidents (30\%) of life-threatening adverse side effects such as neutropenia (20.7\%), anemia (5.9\%), rash (5.2\%), hepatotoxicity (3.4\%), and headache and neuropathy $(0.3 \%)$ (Coffie et al., 2010). A number of case reports include hallucinations, vivid dreaming, or psychosis in conjunction with depression and delusions that appear soon after initiating nevirapine in patients with no previous history of psychiatric illness or substance use (Morlese et al., 2002; Wise et al., 2002). These CNS disturbances subsided after withdrawal of nevirapine. A 5-year retrospective analysis concluded high incidents of various neuropsychiatric side effects $(16 \%-31 \%)$, including depression, affective disorders, sleep disorders, and cognitive disorders, with no significant differences between nevirapine and efavirenz (von Giesen et al., 2003). However, the RELAX study suggests that nevirapine is better tolerated with respect to NPAEs than efavirenz (Pedrol et al., 2015).

\section{E. Tenofovir}

The WHO and South African guidelines recommend the use of tenofovir disoproxil fumarate (TDF) in fixed 
dose combinations with emtricitabine and efavirenz as a first line treatment (National Department of Health, 2015; WHO, 2016). The latest DHHS (2017) guidelines recommend either TDF or the prodrug tenofovir alafenamide (TAF) if there are concerns of renal or bone toxicity in combination with emtricitabine as the two NRTI backbone components. As discussed above, efavirenz is frequently associated with neuropsychiatric effects, but tenofovir and emtricitabine also appear to elicit some of these effects. For instance, severe NPAEs consisting of nightmares, insomnia, and dizziness developed when tenofovir was added to an efavirenz-containing regimen (Allavena et al., 2006). All these patients had been on an efavirenz-containing treatment regimen for several months with no neuropsychiatric disturbances prior to the addition of tenofovir. In $66 \%$ of the patients, the treatment regimen was changed to remove either TDF or efavirenz, and in all these cases the neuropsychiatric disturbances subsided. The combination of TDF and efavirenz has not been associated with any known pharmacokinetic interaction (Allavena et al., 2006). In other studies of TAF associated with NPAEs, only headaches were reported, which occurred in $7 \%-14 \%$ or patients receiving the drug (Buti et al., 2016; Chan et al., 2016). No studies were found where efavirenz was administered with TAF, hence it is not known whether TAF would trigger NPAE in patients on efavirenz. It is worth noting that TDF is a component of the efavirnez-containing ATRIPLA.

\section{F. Raltegravir}

Raltegravir is a first in class HIV integrase inhibitor that was approved by the FDA in 2007. Early case studies reported incidences of sleep disturbances and depression in patients taking raltegravir, which subsided upon switching to a different antiretroviral drug (Harris et al., 2008; Gray and Young, 2009; Eiden et al., 2011; Lafay-Chebassier et al., 2015). More recently, in the RELAX study of $129 \mathrm{HIV}$ patients experiencing CNS side effects (e.g., sleep disturbances, anxiety, depression, attention disturbances) severe enough to warrant switching to a different antiretroviral drug, four patients $(3.1 \%)$ had been taking raltegravir (Pedrol et al., 2015). Similarly in a study investigating NPAEs associated with dolutegravir, another HIV integrase inhibitor approved in 2013, the frequency of NPAEs was $3 \%-17 \%$, which resulted in approximately $0.6 \%$ of the patients discontinuing the drug (Fettiplace et al., 2017). In the SWITCH-ER study of 57 participants in which raltegravir was compared with efavirenz, $51 \%$ of patients preferred the switch from efavirenz to raltegravir (Nguyen et al., 2011). Although the SWITCH-ER study indicates that raltegravir is better tolerated than efavirenz, there is evidence demonstrating that raltegravir is also associated with NPAEs (23\%), albeit at a lower rate than efavirenz (38\%) (Nguyen et al., 2011). Collectively, all these clinical studies suggest that several ARV drugs, other than efavirenz, appear to carry a risk for neuropsychiatric complications; however, the risk of NPAEs appears to be much less common than for efavirenz.

\section{G. Efavirenz}

Although efavirenz is highly effective in reducing viral load and can conveniently be taken once daily, it is frequently associated with neuropsychiatric complications (Sustiva, 1998; Munoz-Moreno et al., 2009). In the original study involving a standard oral dose of $600 \mathrm{mg}$ daily, treatment with efavirenz for a mean time of 2.1 years was associated with a greater frequency of severe psychiatric symptoms over the control group (Sustiva, 1998). The spectrum of neuropsychiatric complications includes confusion, anxiety, depression, insomnia, dizziness, agitation, bad dreams, hallucinations, and delusional, psychotic, paranoid, and manic behaviors (Sustiva, 1998). The nervous system side effects and their incidents included dizziness (28\%), depression (19\%), insomnia (16\%), anxiety (9\%), impaired concentration (8\%), somnolence (7\%), nervousness (7\%), abnormal dreams (6\%), and hallucinations (1.2\%). Over a 2-year period, approximately $6 \%$ of patients reported severe psychiatric symptoms, including severe depression, aggressive behavior, paranoia, and manic reactions. Delusions and psychosis may also occur (Sustiva, 1998; Foster et al., 2003; Hasse et al., 2005; Lowenhaupt et al., 2007; Cabrera Figueroa et al., 2010). The sleep disorder aspects (Nunez et al., 2001) and especially reports of abnormal dreams (Sustiva, 1998; Clifford et al., 2005) may be related to the recommendation that efavirenz be taken at night before going to bed (DHHS, 2017). In a prospective study of HIV patients designed to evaluate improvement in NPAEs attributed to an ARV drug after that drug was substituted with nevirapine, in the vast majority (90\%) of the 129 cases, efavirenz was the ARV drug responsible for the NPAEs, which included sleep disturbances (75.2\%), anxiety (65.1\%), depression (38.7\%), and attention disturbances (31\%) (Pedrol et al., 2015).

The experience of suicidal tendencies while exposed to efavirenz treatment was only reported in a small number of patients with no causal relationship (Lochet et al., 2003; Gutierrez et al., 2005; Catalan et al., 2011). More recently, a twofold increase in risk of suicidality was reported in four studies from the AIDS Clinical Trials Group (ACTG) in patients on efavirenz-containing regimens $(n=3241)$ compared with antiretroviral treatment (ART) regimens without ( $n=2091$ ) efavirenz (Mollan et al., 2014). A poster presentation from the Strategic Timing of AntiRetroviral Treatment (START) study suggested that there was an increased risk of suicidal behavior, especially in patients with prior psychiatric history (Arenas-Pinto et al., 2016). In contrast, two other large scale studies in which data were mined from The Food and Drug Administration Adverse Drug Reporting System (FAERS) from 1968 to 2012 (Napoli et al., 2014) and the United States administrative claims database for commercially and medicaid-insured patients ( $>12$ years) from 2006 to 2013 
(Nkhoma et al., 2016) showed no evidence of an association between efavirenz use and suicidality among patients. A large meta-analysis of four random controlled studies in the Data collection of Adverse events of anti-HIV Drugs (D:A:D) study also indicated no higher death rates from suicide in patients receiving an efavirenz-based treatment compared with those on regimens without efavirenz (Smith et al., 2014).

Overall, although efavirenz is not the only class of HIV medication associated with NPAEs, it does appear to be associated with the highest incidences. Moreover, a present reality is that efavirenz is increasingly being exploited as a drug of abuse by HIV and non-HIV infected individuals alike, as will be discussed in Recreational Use of Efavirenz. Given that efavirenz is now off patent and available in inexpensive generic forms, such abuse is likely to be even more of a concern in the future.

1. Correlation between Efavirenz Plasma Concentrations and Neuropsychiatric Adverse Events. In numerous studies, an association has been reported between CNS side effects and higher efavirenz plasma concentrations in adults and children (Marzolini et al., 2001; Foster et al., 2003; Clifford et al., 2005; Gutierrez et al., 2005; Hasse et al., 2005; Gatanaga et al., 2007; Lowenhaupt et al., 2007; Cohen et al., 2009; Puthanakit et al., 2009a,b; Cabrera Figueroa et al., 2010; Gounden et al., 2010). In some of these studies, higher efavirenz plasma concentrations were attributed to the slower metabolizing CYP2B6 G516T genotype providing a mechanistic explanation linking higher plasma concentrations to susceptibility to NPAEs. However, other studies were unable to establish an association between efavirenz plasma concentrations and NPAEs or other side effects in adults (Kappelhoff et al., 2005; Rotger et al., 2005; Takahashi et al., 2007; Ramachandran et al., 2009a,b; Read et al., 2009) or children cohorts (Saitoh et al., 2007; Viljoen et al., 2012). Haas and co-workers (2004) found an association between CYP2B6 G516T genotype and CNS symptoms after 1 week $(P=0.036)$ of treatment, but not at week $24(P=$ $0.76)$ in adults from different ethnic groups $(n=202$, randomized to receive efavirenz $600 \mathrm{mg}$ before bedtime). The suggestion offered for the low frequency of side effects after 6 month follow up was the possible development of drug tolerance, which is the reduced responsiveness to a drug following chronic stimulation due to persistently high plasma efavirenz levels.

2. Efavirenz Therapeutic Index and Brain Exposure. Efavirenz has a very narrow therapeutic window. Plasma levels of efavirenz need to be maintained between 1 and $4 \mu \mathrm{g} / \mathrm{ml}$ to keep the HIV-1 virus suppressed to clinically meaningful levels while minimizing the risk for NPAEs (Marzolini et al., 2001). Based upon efavirenz plasma levels in 130 patients with HIV receiving efavirenz-based HAART, no NPAEs were observed at efavirenz plasma concentrations of $<1 \mu \mathrm{g} / \mathrm{ml}$, although virologic failure occurred in $50 \%$ of patients. In contrast, at levels of $1-4 \mu \mathrm{g} / \mathrm{ml}$ efavirenz, virologic failure occurred in $22 \%$ of patients while NPAEs occurred in only $9 \%$. However, virologic failure was similar (18\%) at efavirenz plasma levels $>4 \mu \mathrm{g} / \mathrm{ml}$, although the reported NPAEs jumped to $24 \%$. In another study, patients with plasma efavirenz $>2.74 \mu \mathrm{g} / \mathrm{ml}$ were 5.7 times more likely to experience NPAEs than those patients with plasma efavirenz below those levels (Fig. 1A) (Gutierrez et al., 2005).

Efavirenz is considered to have good CNS penetration (Tozzi et al., 2009), which is in line with it having a low total polar surface area $(29.5 \AA)$ and being relatively lipophilic (clogP $\sim 4.6-4.8$ ). However, efavirenz is present in CSF at low levels (Tashima et al., 1999; Best et al., 2011; Yilmaz et al., 2012) with a mean CSF concentration across studies of approximately $44 \mathrm{nM}$, which corresponds to an estimated CSF penetration of $0.52 \%$ of that of plasma (Tashima et al., 1999; Best et al., 2011; Yilmaz et al., 2012). However, efavirenz has high protein binding ( $\sim 99.8 \%$ in plasma) (Tanaka et al., 2008; Avery et al., 2013). Thus, it follows that CSF levels of efavirenz might be low, because it tends to bind proteins and healthy CSF contains very little protein content compared with blood plasma $(<1 \%)$. Because the concentration of free efavirenz in the aqueous fraction is expected to be low, what is the fate of the remaining efavirenz once it penetrates the brain? If it binds to protein-rich brain tissue, then one would expect that $44 \mathrm{nM}$ in CSF, which would account for approximately $0.2 \%(100 \%-99.8 \%)$ of the efavirenz dose, would correspond to an estimated $22 \mu \mathrm{M}(44 \mathrm{nM} / 0.002)$ in the brain. Studies in rats suggest that efavirenz readily accumulates in the brain to levels that exceed 4.6 times the plasma levels within 1 hour of an intraperitoneal dose of $15 \mathrm{mg} / \mathrm{kg}$ (Fig. 1B) (Dirson et al., 2006). By assuming that a similar level of brain accumulation occurs in humans, then efavirenz plasma levels $>2.74$ $\mu \mathrm{g} / \mathrm{ml}$ would correspond to a brain concentration of $>37.3 \mu \mathrm{M}$. The rapid accumulation of efavirenz in the brain and its very high propensity for protein binding in combination with its narrow therapeutic window seem to be key contributing factors responsible for its CNS-related adverse events. These projected levels of brain efavirenz are well within the range in which physiologic effects were noted for efavirenz in both acute and chronic animal studies, $10-30 \mathrm{mg} / \mathrm{kg}$, depending upon the behavioral measure examined (Romao et al., 2011; Gatch et al., 2013). Clearly, these physicochemical attributes afford efavirenz with distinct advantages over other antiretroviral drugs when treating cerebral HIV infection, but at the same time carries with it a greater risk of inducing NPAEs.

3. Longer-Term Neuropsychiatric Adverse Events. Although it was initially reported that NPAEs were common and usually occurred soon after initiation of therapy with efavirenz (1st or 2nd day), they were 

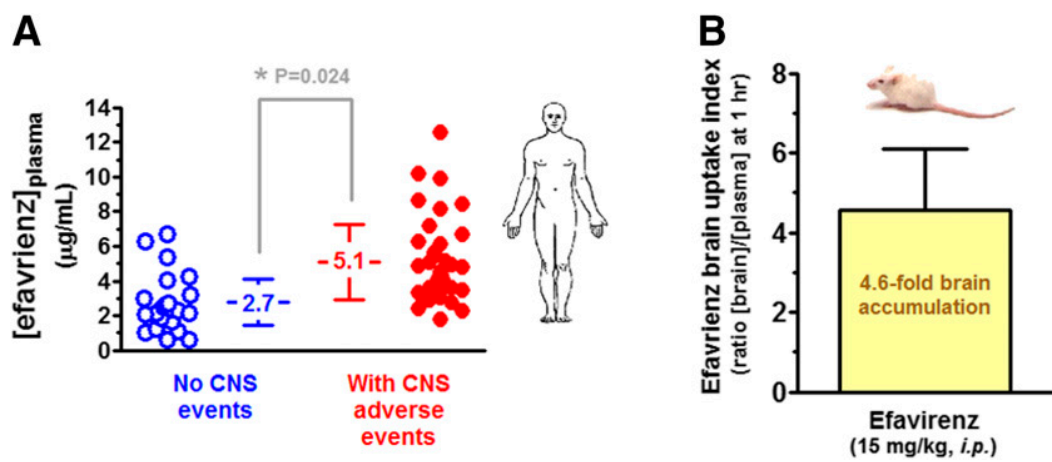

Fig. 1. Brain exposure to efavirenz is high following a single peripherally administered dose; it rapidly accumulates in the CNS. Data adapted and replotted from studies in humans (Gutierrez et al., 2005) and in rats (Dirson et al., 2006). Data are plotted as means \pm S.D. (A) Patients that take a standard dose $(600 \mathrm{mg}$ ) of efavirenz for a long period (average $18 \mathrm{months}$ ) and experience CNS adverse events have significantly higher plasma levels of efavirenz. Furthermore, patients having efavirenz plasma concentrations $>2.74 \mu \mathrm{g} / \mathrm{ml}$ are over five and half times more likely to experience CNS adverse events (Gutierrez et al., 2005). Mean values and statistics are those reported in the original paper (Gutierrez et al., 2005). (B) Efavirenz at a dose within the range that has behavioral effects in rats (Gatch et al., 2013), rapidly accumulated in rat brain to levels that exceed four and half times the plasma levels (Dirson et al., 2006). The brain tissue exposure data are from a study assessing efavirenz uptake into rat brain tissue in the presence of ABCB1 transport blockers or vehicle (designated placebo in the original report) (Dirson et al., 2006). Replotted here is the efavirenz plus vehicle data (a combination of data for both types of vehicles designated Placebo V and Placebo S/Q). Note that similar high levels of brain accumulation (not shown here) occurs in mice [brain]/[plasma] $=2.9 \pm 0.56$ as well (Dirson et al., 2006).

reported to generally resolve after $2-4$ weeks of continuous treatment, although some continued effects of at least moderate severity were noted beyond 4 weeks in 5\%-9\% of the patients (Sustiva, 1998). Across studies, the incidents of neuropsychiatric side effects for efavirenz are high (range 10\%-73\%) exceeding 50\% in most cases (Sustiva, 1998; Molina et al., 2000; Fumaz et al., 2002), Although neuropsychiatric complications tend to decrease after the 1st month, a significant number of cases persist (range 10\%-59\%), as demonstrated by longer term studies, some 2 years in duration (Lochet et al., 2003; Fumaz et al., 2005; Gutierrez et al., 2005; Munoz-Moreno et al., 2009). Furthermore, several recent large clinical studies specifically focusing on tracking NPAEs over long time frames (48-96 weeks) indicated that efavirenz-mediated NPAEs can persist for years (Mills et al., 2013; Nelson et al., 2013; Cohen et al., 2014). In a 48-week, 1368 patient, double-blind international trial of treatment-naive adults (682 patients treated with efavirenz and 386 controls treated instead with rilpivirine), classifying and grading adverse events according to the Medical Dictionary for Regulatory Activities and Division of Acquired Immunodeficiency Syndrome (DAIDS) scales found that the efavirenz-treated group had significantly greater incidents of treatment-related psychiatric ( $23 \%$ vs. $15 \%, P=0.0002)$ and neurologic ( $38 \%$ vs. $17 \%, P<0.0001)$ adverse events, with more discontinuations due to adverse events in the efavirenz group (8\% vs. 3\%, $P=0.0005$ ) (Mills et al., 2013). Both dizziness and abnormal dreams/nightmares possibly related to treatment occurred more frequently in the efavirenz group ( $13 \%$ vs. $8 \%, P<0.01)$. After 96 weeks, with a pool of 1096 treatment-naive patients remaining (546 patients treated with efavirenz and 550 controls treated instead with rilpivirine), more patients in the efavirenz group than in the rilpivirine (control) group discontinued treatment due to adverse events $(8.1 \%$ vs. $3.6 \%, P=0.001$ ), with three quarters due to specifically neurologic or psychiatric adverse events (Nelson et al., 2013). Significantly more grade 2-4 treatment-related psychiatric (27\% vs. $16 \%, P<0.0001)$ and neurologic (37\% vs. $17 \% P<0.0001$ ) symptoms occurred in the efavirenz group, including significantly more dizziness (26\%), abnormal dream/nightmares (15\%), and somnolence (6\%) of any grade. An open-label, international study of 786 treatment-naive patients (392 patients were treated with efavirenz and 394 controls treated instead with rilpivirine) found significantly more discontinuations in the efavirenz group (8.7\% vs. $2.5 \%, P<0.001)$ due to adverse events, with three quarters due to specifically neurologic or psychiatric adverse events. The efavirenz group had greater frequencies of psychiatric $(37.5 \%$ vs. $15.7 \%, P<0.001)$ and neurologic symptoms $(50.5 \%$ vs. $29.7 \%, P<0.001$ ) (Cohen et al., 2014). In the efavirenz group, common psychiatric symptoms included abnormal dreams (24.5\%), depression (8.9\%), and anxiety (8.4\%), whereas common neurologic symptoms included dizziness $(22.2 \%)$, insomnia (14\%), headache $(13.5 \%)$, and somnolence (6.9\%). A small double-blind clinical trial of 38 efavirenz-treated patients experiencing physician assessed ongoing CNS adverse events after 3 months [graded according to the AIDS Clinical Trials Group (ACTG) Division of AIDS scale], demonstrated that switching from efavirenz to etravirine for 3 months significantly reduced the percentage of patients experiencing grade $2-4$ adverse events for any CNS symptom (89\% vs. $60 \%, P=0.009$ ) as well as insomnia (63\% vs. $37 \%, P=0.016)$, abnormal dreaming (57\% vs. $20 \%, P=$ 0.001 ), and nervousness ( $29 \%$ vs. $9 \% ; P=0.046$ ) (Waters et al., 2011). In a case-control study of 32 matched pairs of patients over 6 months, the efavirenz-treated group showed significantly higher total stress scores $(P<$ 0.008) (Rihs et al., 2006), as reported in Depression, Anxiety and Stress Scales (DASS) questionnaires. Additionally, significantly higher levels of severe stress 
$(19 \%$ vs. $0 \%, P<0.014)$ and severe anxiety (19\% vs. $3 \%$, $P<0.059)$ were reported in the efavirenz treatment group, and a significantly higher proportion of patients in the efavirenz group reported unusual dreaming (58\% vs. $32 \%, P<0.049)$. In a systematic review among treatment-naive HIV-infected adults $(n=26,446)$ and children $(n=3975)$ from eight randomized studies and 26 prospective cohorts taking nevirapine or efavirenz, it was concluded that adult patients taking efavirenz are 3.4 (OR 95\%, CI 2.1-5.4) times more likely to experience severe CNS events than when taking nevirapine (Shubber et al., 2013). Taken together it seems clear that CNS adverse events associated with long-term efavirenz treatment significantly impairs quality of life for some and persists in a significant proportion of patients. This is particularly relevant given that life expectancy among individuals infected with HIV has increased dramatically with the implementation of HAART, so much so that according to the Centers for Disease Control, approximately $45 \%$ of all individuals infected with HIV in the United States are over the age of 50 years. Similarly, in most parts of the world, the number of individuals who are HIV positive over the age of 50 years has continually increased since around 2000 (Mahy et al., 2014). This is attributed to HAART therapies allowing people to live longer with HIV, but also leading to increased incidents of HIV-associated NPAEs, especially in the elderly.

4. Neuropsychiatric Adverse Events Associated with Efavirenz in Children. Although initial studies using efavirenz-based treatments in children with HIV infection suggested that NPAEs were not an issue for children, later studies reported that children do experience NPAEs. In the Pediatric AIDS Clinical Trial Group (PACTG) 382 study, efavirenz-based regimens were found to be generally well-tolerated by children infected with HIV (3.8-16.8 years; $n=57$; non-Hispanic white, non-Hispanic black; Hispanic) with the few side effects consisting mostly of rash and, less frequently, fever and NPAEs (Starr et al., 1999). This was one of the first studies to test the safety and efficacy of a then novel combination of efavirenz, nelfinavir, and one or more NRTIs in 57 children of different races. The most common moderate and severe side effects associated with the treatment were rash (30\%), diarrhea (18\%), neutropenia (12\%), and abnormalities in blood biochemistry (12\%). Central nervous system (CNS) side effects were uncommon, but dizziness or light-headedness was reported (14\%), which subsided once the efavirenz was administered at bedtime and not in the morning as per the original study protocol. Treatment was discontinued in $25 \%$ of the children due to various reasons, such as moderate $(7 \%)$ or severe $(2 \%)$ rash, virological failure (11\%), inability to take capsules (2\%), and noncompliance (2\%) (Starr et al., 1999). One child (2\%) was determined to have been on a NNRTI-based regimen previously (Starr et al., 1999). Persistent side effects such as concentration problems, sleep disorders, psychotic reactions, and seizures were reported in $24 \%$ of children in a German cohort ( $n=33$ ) consisting of Caucasians (24), Africans (7), and Asians (2), with median (range) treatment duration of 50 (2-81) months (Wintergerst et al., 2008). A study in Thai children $(n=63$, median age 12.3 (3.1-18.7) years, cross sectional, middose sampling) reported rash (16\%), CNS disturbances (22\%), and psychiatric problems (8\%) during the first few weeks post-HAART initiation (Puthanakit et al., 2009b). In a longitudinal study in black South African children (3-14 years, $n=59$ ), none of the patients stopped their efavirenz-based ART during the first 6 months post-ART initiation due to reported side effects. A few side effects, such as nightmares (7\%), insomnia (2\%), rash, and abdominal cramps were reported during the 1st month post-ART initiation and no association between side effects and efavirenz plasma concentrations at middose sampling was reported (Viljoen et al., 2010, 2012). Importantly, Saitoh and coworkers (2007) pointed out the difficulty in quantifying and assessing neuropsychological side effects in young children, thus the occurrence of NPAEs might be underreported in the very young (Saitoh et al., 2007).

\section{Recreational Use of Efavirenz}

In addition to NPAEs, there are reports of the recreational use of efavirenz. As early as 1999, the People with AIDS Health Group of New York City reported that some users recovering from drug abuse experienced flashbacks, some for prolonged periods of time (more than 2 months), while taking efavirenz (Vazquez, 1999). The nature of the flashbacks corresponded to memories of the high on their previous drug of choice, such as heroin, cocaine, or crack cocaine. There are also a number of survey/focus group reports concerning the recreational use of efavirenz. A 2005 survey of Miami street and club drug users revealed that efavirenz was sought by HIV-negative people for its intoxicating properties (Inciardi et al., 2007). A focus group report with community health workers in South Africa's Western Cape Province concerning the off-label usage of efavirenz documents a firsthand account of theft of ARV drugs from a doctor's office and the recreational use of efavirenz by crushing the pills and smoking them (Larkan et al., 2010). However, most reports of the recreational use of efavirenz have surfaced in the popular news media, where efavirenz was being smoked to achieve a high (http://www.iol.co.za/news/south-africa/thugs-get-high-onstolen-aids-drugs-1.352686\#.VgWQSGBdHct; http://news. bbc.co.uk/2/hi/africa/7768059.stm; https://www.youtube.com/ watch?v=wyuFBmlQS_s; http://www.iol.co.za/news/ south-africa/children-smoking-arvs-report-401139\#. VVz3IKwo670; http//abcnews.go.com/Health/MindMoodNews/ story?id=7227982\&page $=1$ ). In these reports, the common practice seemed to be to sprinkle powdered efavirenz onto dagga (marijuana) and smoking it or mixing it 
with heroin or other substances and smoking the concoction.

Although the origin of the practice of smoking efavirenz is unknown, one might speculate that reports of abnormal dreaming (night terrors) in those taking efavirenz as prescribed, including perhaps experienced intravenous drug users who are at high risk for transmission of HIV, might have led to experimentation. Smoking would be a logical mode of experimentation, given that it is well known that inhalation of volatilized drugs can lead to rapid and high levels of drug exposure. South African substance abuse epidemiologists had at one time monitored reports involving recreational antiretroviral use (C. Parry, personal communication). However, these reports were often difficult to independently verify or interpret given that concoctions go by a number of common street terms, such as nyaope, whoonga (or wunga), plazana, kwape, ungah, sugars, pinch, H, Thai, and BoMkon, yet these various concoctions may or may not contain efavirenz and/or other ARV drugs, and if they do the amounts may vary widely (Grelotti et al., 2013; https://www.npr.org/sections/ health-shots/2012/12/18/167523601/dangers-of-whoongaabuse-of-aids-drugs-stokes-resistance; https://www. liveleak.com/view?i=9e2_1363861329\&comments=1https:// citizen.co.za/news/south-africa/350213/kzn-youth-fallunder-whoonga-spell/; https://www.youtube.com/ watch?v=wyuFBmlQS_; Phungula, 2013).

The true origin of these concoctions varies according to where their use has been reported, e.g., the townships of Tswane during 2000-2006, Durban and surrounding areas in 2010, and subsequently in other urban cities around South Africa, all with detrimental consequences to lives and families (http://www.health24.com/Lifestyle/ Street-drugs/News/Street-drug-nyaope-classified-asillegal-20140403; http://globalhealth.org/whoonga-thecruelest-drug-of-south-african-slums/). Depending on where it is sourced, these concoctions can contain low grade heroin, strychnine, dagga/marijuana, tobacco, rat poison, pool acid, certain household detergents, and other bulking ingredients such as milk powder and bicarbonate of soda, although it may or may not contain antiretroviral agents such as efavirenz (http://www.iol.co.za/ news/crime-courts/nigerian-man-bust-with-nyaope-1.1913335; http://www.health24.com/Lifestyle/Street-drugs/News/ Street-drug-nyaope-classified-as-illegal-20140403). On March 28, 2014, the Drugs and Drug Trafficking Act 140 of 1992 was amended to classify nyaope (street drug) as illicit in South Africa (http://www.health24.com/Lifestyle/ Street-drugs/News/Street-drug-nyaope-classified-as-illegal20140403).

In an account of an experimental first time ingestion of only efavirenz (initially $300 \mathrm{mg}$ stepped up to a full $600 \mathrm{mg}$ dose orally) by an HIV-negative person, efavirenz was reported to have classic psychedelic qualities that are LSD-like, with the acute effects somewhat comparable to mescaline (https:/www.youtube.com/watch?v=wyuFBmlQS_s), thus consistent with a potential attractiveness for its recreational use. Efavirenz also has been reported to synergize with the intoxicating effects of ethanol as ratings of drowsiness significantly increased in human test subjects when efavirenz and alcohol were used together, even in the presence of lower blood alcohol levels (McCance-Katz et al., 2013). Taken together, it seems that relatively recently ARV drugs, including efavirenz, have begun to be more widely appreciated as an emerging category of prescription drugs with illicit uses (Davis et al., 2014a).

There are understandable medical concerns over diversion of efavirenz beyond a new type of drug abuse. Diversion of ARV drugs undermines the treatment of HIV patients whose viral levels will not be effectively suppressed without proper dosing. Suboptimal dosing in patients or improper dosing in HIV-negative individuals at risk for being exposed to HIV may encourage the development of ARV drug resistant strains of HIV. A major concern is that the development of ARV drug-resistant HIV strains, especially in treatment-naive patients, could create a serious public health problem that could negatively impact the global response to the HIV/AIDS pandemic (Gatch et al., 2013; Grelotti et al., 2013; http://abcnews.go.com/Health/ MindMoodNews/story?id=7227982\&page=1).

\section{Factors Increasing Efavirenz Plasma Levels}

The complex interplay between efavirenz pharmacokinetic variability, adherence, and resistance to virologic suppression has been extensively investigated (Pham, 2009). Marzolini and coworkers (2001) were the first to report that virologic failure was observed in $50 \%$ of patients when efavirenz plasma levels fall below $1 \mu \mathrm{g} / \mathrm{ml}$ and that a reversible CNS toxicity was approximately three times more prevalent in patients with efavirenz levels of $>4 \mu \mathrm{g} / \mathrm{ml}$ (Marzolini et al., 2001). Given that efavirenz has a narrow therapeutic window related to NPAEs in the context of virologic efficacy (see Efavirenz Therapeutic Index and Brain Exposure), it is important to appreciate factors that regulate efavirenz plasma levels. These factors fall into two categories: modifiable and nonmodifiable.

\section{A. Modifiable Factors}

Plasma levels of efavirenz are influenced by a number of circumstances leading to substantial interpatient and intrapatient variability. Those that can lead to increases in efavirenz levels include taking efavirenz with a meal, specific dietary features, and low body mass index. Each of these may be modified to maintain optimal efavirenz plasma levels (i.e., between 1 and $4 \mu \mathrm{g} / \mathrm{ml}$ ) to reduce the incidences of CNS toxicity and virologic failure.

1. Influence of a Meal. Taking efavirenz with a meal increases oral absorption (Sustiva, 1998). This enhanced oral absorption is greatest for those taking efavirenz $(600 \mathrm{mg})$ tablets after a high-fat/high-caloric 
meal (1000 kcal with 50\%-60\% from fat) resulting in increases in plasma area under the curve $\left(\mathrm{AUC}_{\infty}\right)$ by $28 \%$ and maximal concentration $\left(C_{\max }\right)$ by $79 \%$ (Sustiva, 1998; DHHS, 2017). To minimize the adverse effects associated with elevated efavirenz plasma levels, physicians instruct patients to take the medication on an empty stomach. However, when mixed with small (i.e., 2 teaspoons) amounts of different types of food the bioavailability of efavirenz is no different than under fasting conditions (Kaul et al., 2010). Daily ingestion of the African potato for 2 weeks and then again on the day of a $600 \mathrm{mg}$ dose of efavirenz did not change efavirenz pharmacokinetics (Mogatle et al., 2008). In a study of 15 adult Ugandan patients with HIV-1, a significant $47 \%$ increase in efavirenz $C_{\max }$ was observed along with an $11 \%$ reduction in clearance when efavirenz was taken in a fixed-dose combination with other ARV drugs (i.e., tenofovir disoproxil fumarate/emtricitabine/efavirenz) and with food containing $19 \mathrm{~g}$ of fat versus fasting conditions (Lamorde et al., 2012).

2. Oranges, Grapefruits, and Their Juices. Although the exact mechanisms are still a topic of some debate, ingesting orange or grapefruit juice can elevate efavirenz plasma levels. In two US trials involving female patients with HIV on a standard $600 \mathrm{mg}$ efavirenz dose enrolled in the Women's Interagency HIV Study, eating oranges or drinking orange juice for 5 days led to a $26 \%-31 \%$ increase in efavirenz plasma levels (Gandhi et al., 2009, 2012). Although the type of oranges used in this study were not specified, it is unlikely that they were the bitter and tart Seville oranges used to make marmalade. This distinction can be critical to a potential mechanistic interpretation since Seville oranges contain different causative ingredients than sweet oranges leading to different interactions with cytochrome P450 3A4 (CYP3A4), P-glycoprotein (Pgp)/multidrug resistant transporter (MDR1), and organic anion transporting polypeptide (OATP) (Saito et al., 2005). Sweet orange juice potently inhibits OATP (Dresser et al., 2002), but this cannot explain increased plasma efavirenz because even if efavirenz was a substrate for OATP, this transporter increases movement of substrates from the intestinal lumen to blood and thus its inhibition would not increase efavirenz levels. Sweet oranges lack causative agents that potently inhibit intestinal CYP3A4 (Takanaga et al., 2000; Honda et al., 2004), although they weakly inhibit both Pgp and MRP2/ABCC2 in a substratespecific manner (Honda et al., 2004). Pgp cannot account for changes in efavirenz concentration because efavirenz is not a substrate for this transporter (Stormer et al., 2002; Dirson et al., 2006; Janneh et al., 2009). Although inhibition of MPR2 by orange juice is relatively weak, it might be germane when one considers that efavirenz has been reported to induce MRP2 expression in colon LS180 cells (Weiss et al., 2009). A 2-day dosing study in rats indicated that orange juice, and the orange juice component hesperidin, reduced mRNA and protein expression of
MRP2 in small intestine and liver (Watanabe et al., 2011). This could be relevant because efavirenz may be a substrate for MRP1/2 (Janneh et al., 2009). More likely though is that the tangertin and nobiletin components of orange juice are strong inhibitors of ABCG2/BCRP (Fleisher et al., 2015). Not only is efavirenz a substrate for this transporter (Peroni et al., 2011), but ABCG2 is located in the intestine wall where, like Pgp, it acts as an efflux transporter pumping substrates back into the intestinal lumen. Potent inhibition of ABCG2 by orange juice may be significant considering that efavirenz also induces the expression of ABCG2 (Weiss et al., 2009).

Although published data are lacking and at least one source lists that no clinically significant interactions are expected (University of Liverpool, HIV Drug Interactions, https://www.hiv-druginteractions.org/checker), a number of other sources indicate possible interactions between grapefruit juice and efavirenz with the end result being possible elevations of plasma levels. These sources include numerous online references when searching grapefruit and efavirenz or Sustiva as key words, including some product information listing efavirenzcontaining formulations (www.medicines.org.uk/emc/ medicine/11284) and a book on adverse drug interactions (Karalliedde et al., 2010). Though clinical trials with citrus fruit containing carbonated beverages (e.g., Sun Drop and Fresca) do not produce a measurable effect like grapefruit juice (Schwarz et al., 2006), it is well established that components in grapefruit juice irreversibly inhibit intestinal CYP3A4 thus reducing first pass intestinal metabolism of orally-administered drugs metabolized by this enzyme (Schmiedlin-Ren et al., 1997; Saito et al., 2005), such as efavirenz. However, a number of its components, including bergamottin, also inactivate CYP3A5 and CYP2B6 and their inhibitory potency for CYP2B6 is greater than for the CYP3A4/5 (Lin et al., 2005). While CYP3A4/5 enzymes are more abundant in intestine and liver than CYP2B6, efavirenz is primarily metabolized by CYP2B 6 and thus inhibition of CYP2B 6 might be expected to have a significant impact. Recently, a number of ingredients in grapefruit juice, including bergamottin, have been shown to be potent inhibitors of ABCG2 (Fleisher et al., 2015) and as mentioned above in the context of orange juice, efavirenz is a substrate for the ABCG2 transporter (Peroni et al., 2011). In light of these findings, clinical investigation on the effects of grapefruit juice on efavirenz pharmacokinetics seems warranted.

3. Influence of Body Weight/Body Mass Index. Body weight and body mass index (BMI) have been shown significantly to affect efavirenz plasma levels. In a prospective study of 41 Brazilian patients infected with HIV, and treated with efavirenz $(600 \mathrm{mg} /$ daily $)$ as part of their antiretroviral therapy and had an undetectable viral load for at least 1 year and no other comorbid disease, body weight $\left(r_{\mathrm{s}}=-0.373, P=0.015\right)$ and BMI $(P=0.001)$ were inversely correlated with efavirenz plasma levels, 
meaning that as body weight increases, efavirenz plasma levels decrease (Poeta et al., 2011). This suggests that individuals with low BMI are at higher risk of CNS toxicity due to higher efavirenz plasma levels, whereas people with high BMI are at higher risk of virologic failure due to suboptimal plasma levels. Other studies seem to corroborate the inverse relationship between efavirenz and body weight, although the presence of comorbid tuberculosis (TB) in some (17\%) or all of the study population (Stohr et al., 2008; Manosuthi et al., 2009; Poeta et al., 2011) may have been a confounder as rifampicin was being coadministered to treat comorbid TB and this anti-TB drug has been reported to reduce peak efavirenz plasma concentrations (Benedek et al., 1998; Lopez-Cortes et al., 2002; Kwara et al., 2011). In healthy volunteers, rifampicin reduced efavirenz's plasma AUC by $26 \%$ and its peak concentration by $20 \%$ (Benedek et al., 1998) and AUC by $18 \%$ and $C_{\max }$ by $16 \%$ (Kwara et al., 2011), whereas in a patient infected with HIV taking rifampicin, the median peak efavirenz concentration decreased by $24 \%$ and trough concentration by $18 \%$. However, other studies have not found a significant influence of rifampicin coadministration on mean efavirenz plasma levels (Friedland et al., 2006; Orrell et al., 2011), although in one of these studies rifampicin almost tripled the intersubject variability in efavirenz plasma concentrations (Friedland et al., 2006).

\section{B. Nonmodifiable Factors}

In addition to modifiable factors, a number of nonmodifiable factors also influence efavirenz plasma levels, including sex, age, pregnancy, renal/hepatic function, race, and genotype (Lang et al., 2001; Burger et al., 2006; Cressey and Lallemant, 2007; Lindfelt et al., 2010; Nemaura et al., 2012).

1. Sex. Several studies have shown that sex is an important determinant of efavirenz plasma concentration and that women consistently have higher plasma efavirenz concentrations than men; this might be attributed to lower BMI of women compared with men (Burger et al., 2006; Nyakutira et al., 2008; Manosuthi et al., 2009; Mukonzo et al., 2009; Poeta et al., 2011). However, other studies have not found efavirenz pharmacokinetics to be affected by sex (Csajka et al., 2003; Pfister et al., 2003; Kappelhoff et al., 2005).

Efavirenz use in pregnant women was not investigated during the early years of its introduction as it was contraindicated and labeled as Category D, meaning positive evidence of human fetal risk (Sustiva, 1998). More recently this view has changed as conflicting safety data are now available indicating that there is no increase in the risk of birth defects among women exposed to efavirenz during the first trimester of pregnancy (Ford et al., 2010). Furthermore, the South African National Department of Health guidelines recommend efavirenz as part of the first line regimen in pregnant women; it is only contraindicated if active psychiatric illness is present (National Department of Health, 2015). A summary of five studies in which 235 women were treated with efavirenz during pregnancy concluded that efavirenz plasma levels were not significantly affected (Cohen et al., 2014), whereas the TSHEPISO study in pregnant women with and without tuberculosis coinfection showed that pregnancy did increase the risk of low efavirenz plasma levels (Dooley et al., 2015). The current first line treatment of pregnant and breastfeeding women in South Africa include efavirenz as part of the fixed dose combination (tenofovir and lamivudine or emtricitabine) with the standard $600 \mathrm{mg}$ dose if the women weighed more than $40 \mathrm{~kg}$ and $400 \mathrm{mg}$ if $<40 \mathrm{~kg}$ (National Department of Health, 2015).

2. Age. Age can affect efavirenz pharmacokinetics. For instance, efavirenz is cleared faster and has a shorter half-life in children (von Hentig et al., 2006; Hirt et al., 2009; Viljoen et al., 2012). Mean efavirenz clearance values (Tables 1 and 2) in children are reported to vary between 0.19 and $0.30(\mathrm{l} / \mathrm{h}) / \mathrm{kg}$ (Fletcher et al., 2008; ter Heine et al., 2008; Wintergerst et al., 2008; Hirt et al., 2009) compared with $0.13-0.17(\mathrm{l} / \mathrm{h}) / \mathrm{kg}$ in adults (Csajka et al., 2003; Pfister et al., 2003; Kappelhoff et al., 2005; Ribaudo et al., 2006; Cabrera et al., 2009). The calculated half-life for efavirenz was 14.7, 12.9, and 13.4 hours in Burkino Faso $(n=48)$, German $(n=11)$, and black South African $(n=60)$ children, respectively (von Hentig et al., 2006; Hirt et al., 2009; Viljoen et al., 2012) compared with 19 hours in adults $(n=235)$ (Csajka et al., 2003). Data for efavirenz in very young children and infants is still extremely limited since it was only FDA approved for infants and children as young as 3 months in May 2013. This initial approval was reaffirmed in 2015 , but with caveats such as CYP2B6 genotyping and measuring efavirenz plasma levels at 2 weeks (http://www. pipelinereport.org/2013/pediatric-ARV; Larru et al., 2014).

It is well known that hepatic function is reduced in the elderly (Woodhouse and Wynne, 1988), and hepatic impairment, for example due to liver disease, has been reported to alter the pharmacokinetics of efavirenz, which undergoes extensive hepatic metabolism (Wyles and Gerber, 2005; Cressey and Lallemant, 2007). Furthermore, higher efavirenz plasma levels are observed at higher transaminase levels, a biomarker for liver dysfunction, yet impaired hepatic function as a result of age or hepatitis status apparently has no significant effect on efavirenz plasma levels (Gandhi et al., 2009; Winston et al., 2013). These finding suggest that rather severe but not more modest changes in hepatic function, will affect efavirenz metabolism. Although renal function is also affected by the aging process (Nitta et al., 2013), the functional status of the kidney is likely to play little if any role in clearance, given that less than $1 \%$ of efavirenz is renally cleared (Sustiva, 1998). This is borne out experimentally, where renal insufficiency 
has been found to have no significant effect on efavirenz plasma levels (Gandhi et al., 2009).

3. Ethnicity/Genetics. Ethnicity is another factor that influences efavirenz plasma levels, with Caucasians having the overall lowest plasma levels per standard dose as an ethnic population and Africans having the highest (Burger et al., 2006; Lindfelt et al., 2010). These differences in plasma levels correlate with ethnic differences in the clearance and metabolism of efavirenz which can have clinical consequences. Efavirenz levels that are too low $(<1 \mu \mathrm{g} / \mathrm{ml})$ put patients at risk of virologic failure, whereas those that are too high $(>4 \mu \mathrm{g} / \mathrm{ml})$ put patients are risk for NPAEs. Hepatic metabolism is the principal mode of efavirenz clearance, with predominantly the 8-hydroxy efavirenz (78\%-92\%) and to a lesser extent 7-hydroxyefavirenz (8\%-22\%) being the primary metabolites in human plasma and urine (Mutlib et al., 1999; Ward et al., 2003; Ogburn et al., 2010). The 8-hydroxy metabolite of efavirenz is formed mainly by the action of the phase I metabolic enzyme CYP2B6 and to a lesser extent by CYP3A4, CYP3A5 CYP2A6, CYP1A2, and CYP2C9 (Ward et al., 2003; Desta et al., 2007; Arab-Alameddine et al., 2009; di Iulio et al., 2009; Kwara et al., 2009) and direct phase II N-glucuronidation by UDP-glucuronosyltransferase (UGT)2B7 (Belanger et al., 2009).

More than 50 different alleles for the CYP2B6 gene are known (https://www.pharmvar.org/gene/CYP2B6). The CYP2B6 gene is also highly polymorphic with numerous single nucleotide polymorphisms (SNP) associated with functional consequences, resulting in interindividual variability in different populations. Some of these SNPs are associated with elevated efavirenz plasma levels (Lang et al., 2001; Rodriguez-Novoa et al., 2005; Wyen et al., 2008), placing these individuals at an increased risk of experiencing NPAEs (Rotger et al., 2005; Zanger et al., 2007; Sarfo et al., 2014). A genome-wide association analysis of 856 HIV patients taking efavirenz-based medications found that only three CYP2B6 polymorphisms (i.e., G516T, T983C, C15582T) were independently associated with elevated efavirenz plasma concentrations (Holzinger et al., 2012). In a focused study of 113 patients consisting of only black South African children and adults, significant associations with efavirenz plasma concentrations were found for these same three polymorphisms (G516T, T983C, C15582T), with the composite of the three best describing efavirenz plasma exposure (Sinxadi et al., 2015).

NPAEs are the primary reason for discontinuation of efavirenz-based regimens (Scourfield et al., 2012; Leutscher et al., 2013; Walmsley et al., 2013). Although it has been reported that efavirenz plasma levels are not correlated with discontinuation (Read et al., 2009; van Luin et al., 2009b), a significant risk for discontinuing efavirenz-based treatments is only evident for cumulative SNP genotypes involving slow metabolizing mutations in CYP2B6, CYP2A6, and CYP3A4 (Powers et al., 2009;
Lubomirov et al., 2011; Cummins et al., 2015). This seems to suggest that only extremely high levels of efavirenz exposure would be associated with discontinuation.

a. CYP2B6 G516T polymorphism. The CYP2B6 G516T polymorphism is nonsynonymous, meaning that it occurs in a coding region (exon 4) and results in a change in the amino acid sequence $(\mathrm{Q} 172 \mathrm{H})$. The CYP2B6 G516T SNP has impaired functionality compared with wild-type CYP2B6 due primarily to aberrant splicing, leading to decreased levels of mRNA, protein, and activity, either alone (i.e., CYP2B $6 * 9$ allele) or in combination with another mutation (i.e., CYP2B6*6 allele, G516T+A785G) (Hofmann et al., 2008). In the context of the CYP2B $6 * 6$ haplotype, meaning a group of genes inherited together, the interactions with efavirenz in human liver microsomes are complex, having an increased affinity $\left(K_{\mathrm{m}}\right)$ for this substrate but a lower maximal activity $\left(V_{\max }\right)$ compared with the wild-type CYP2B6, leading to an overall sixfold reduction in intrinsic clearance $\left(V_{\max } / K_{\mathrm{m}}\right)$ (Xu et al., 2012). A number of other groups also found decreased intrinsic clearance relative to the wild type (CYP2B6*1) using purified enzymes generated with different types of nonmammalian overexpression systems (Ariyoshi et al., 2011; Zhang et al., 2011; Xu et al., 2012), whereas others have instead reported increased intrinsic clearance when overexpressing CYP2B $6 * 6$ in mammalian cells (Radloff et al., 2013) (Table 2). CYP2B6*6 also has a $>2.5$-fold increased potency of inhibition of efavirenz metabolism by voriconazole and clopidogrel compared with the wild type (Xu et al., 2012).

The CYP2B6 G516T polymorphism is the single best predictor of elevated efavirenz plasma concentrations (Holzinger et al., 2012; Swart et al., 2013; Sinxadi et al., 2015). The CYP2B6 G516T genotype is quite common among all ethnic populations studied (24\%-38\%), although on average the CYP2B6 G516T allele frequency varies between ethnicities and tends to be more prevalent in African and Hispanic compared with Caucasian and Asian populations (Fig. 2B; Table 1). GT heterozygotes, and in particular the TT homozygotes, metabolize efavirenz more slowly than GG homozygotes, and as a result, their efavirenz plasma levels are elevated (Fig. 2A) (Lang et al., 2001; Gatanaga et al., 2007; Xu et al., 2007; Nemaura et al., 2012; Manosuthi et al., 2013). Slower metabolizers thus have a greater risk of efavirenz-induced psychosis, including hallucinations, while these NPAEs dissipate when lower doses of efavirenz are administered in these patients (Foster et al., 2003; Hasse et al., 2005; Lowenhaupt et al., 2007; Cabrera Figueroa et al., 2010). Collectively, these studies suggest that a significant portion of different ethnic populations are pharmacogenetically predisposed to neuropsychiatric complications due to higher than expected plasma levels of efavirenz under standard dosing conditions (i.e., $600 \mathrm{mg}$ efavirenz daily). This also suggests that there is a relationship between efavirenz dose and the incidents and severity of NPAEs. Although CYP2B6 

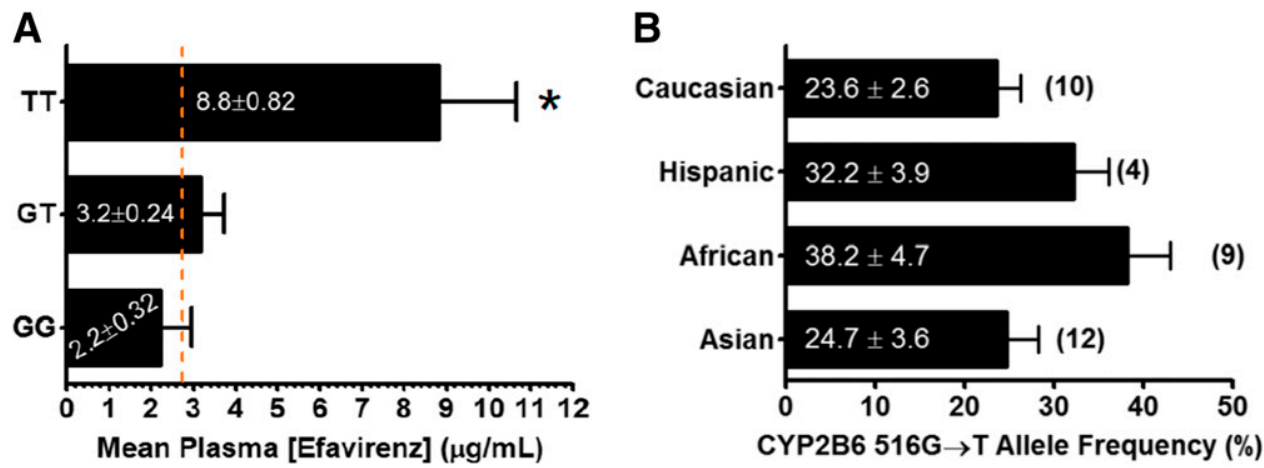

Fig. 2. Higher plasma concentrations are associated with slow metabolizing CYP2B6 516G $\rightarrow$ T allelic load. (A) Individuals homozygous for the slow metabolizing TT genotype have four times higher mean plasma concentrations of efavirenz than those homozygous for the fast metabolizing GG genotypes, and GT haplotypes have intermediate levels closer to the faster metabolizing GG genotype. $* P<0.05$ for the TT vs. GT and GG genotypes by one-way ANOVA and Bonferroni post hoc. The dashed orange line represents the $2.7 \mu \mathrm{g} / \mathrm{ml}$ cut-off above which there is increased risk for NPAE (see Fig. 1). The mean \pm S.E.M. plasma levels for efavirenz were calculated from values reported by Gatanga et al. (2007), Nemaura et al. (2012), Manosuthi et al. (2013). (B) CYP2B6 516G $\rightarrow$ T allele frequency varies as much as 1.6-fold as a function of major ethnic groups with Africans having the highest frequency and Caucasians the lowest. The Asian, Caucasian, African, and Hispanic ethnicity data (mean \pm S.E.M.) were compiled from reports in the literature (Gatanaga et al., 2007; Xu et al., 2007; Matimba et al., 2008; Nyakutira et al., 2008; Manosuthi et al., 2013). The numbers in parentheses over the bars represent the number of different studies for each ethnic group.

G516T is the most studied SNP concerning efavirenz, there are other SNPs, discussed below, that affect efavirenz plasma levels (Rotger et al., 2007; Manosuthi et al., 2013).

b. CYP2B6 T983C polymorphism. The CYP2B6 T983C is a nonsynonymous SNP occurring in exon 7 that results in a change in the amino acid sequence (I328T) (Table 1). The CYP2B6 T983C is reported to have impaired functionality compared with wild-type CYP2B6. In one study, impaired functionality of the human gene was attributed to both reduced expression and activity (as measured by bupropion hydroxylase activity) in insect cells but no detectable expression in mammalian cells (Klein et al., 2005). In another study using bupropion as the substrate to access activity, the primary effect was reduced protein expression in mammalian cells with little or no change in mRNA levels or enzyme properties (Wang et al., 2006). The T983C variant was initially reported as a relatively low frequency SNP in African Americans and Ghanaians $(4.4 \%-6.6 \%)$, but is not detected in Japanese, Taiwanese, Korean, and Caucasian populations (Klein et al., 2005). The finding that this SNP is generally absent from Caucasian and Asian populations has been replicated by others (Table 1) (Mehlotra et al., 2007; Rotger et al., 2007). The T983C SNP is also present at a low frequency in Hispanics (1.1\%) and Turks (4.1\%), but is absent in populations from Papua New Guinea or Sweden (Wang et al., 2006; Mehlotra et al., 2007).

In a study of patients whose plasma efavirenz levels were an average of threefold higher than expected, four of the five carried both an allele for G516T and T983C SNPs and the fifth was heterozygous for G516T (Wang et al., 2006). The remaining 16 G516T heterozygotes had 1.6-fold elevated plasma levels compared with 1.8fold for the four G516T homozygotes. The one patient heterozygous for T983C and lacking the G516T mutant had normal efavirenz plasma levels. In a study of 174 people living in Germany, none of the Caucasians and $14 \%$ of blacks were carriers of the T983C SNP (Wyen et al., 2008). All of these patients were on a stable HAART regimen for at least 3 months, and large $(>11$-fold) and significant differences in efavirenz plasma concentrations were observed in the $983 \mathrm{CC}$ homozygotes, who eventually discontinued their efavirenz based therapy due to CNS toxicity. Other studies have confirmed the gene effect of the T983C SNP to elevate plasma efavirenz levels (Ribaudo et al., 2010; Swart et al., 2013; Dhoro et al., 2015).

c. CYP2B6 C15582T polymorphism. The CYP2B6 $\mathrm{C} 15582 \mathrm{~T}$ is a SNP occurring in intron 3 within a branch site, and when combined with the exon 4 SNP G15631T located in an exonic splicing enhancer region, there are a greater proportion of transcripts skipping exons 4-6 (Lamba et al., 2003). In human female liver microsomes, C15582T heterozygotes had 1.5-fold and TT homozygotes had 1.9-fold lower levels of CYP2B6 protein (Lamba et al., 2003). Although the C15582T variant occurs frequently in most ethnic populations (32\%-44\%), it is much less common in Africans (8\%) (1000 genomes release 17). The lower prevalence of the $\mathrm{C} 15582 \mathrm{~T}$ allele in Africans has been a consistent finding across studies (6\%-9\%) (Evans et al., 2015; Sinxadi et al., 2015). However, in African Americans the frequency of this SNP was reported to be much higher (35\%) (Lamba et al., 2003).

In a clinical study of 856 individuals across a range of ethnicities (50\% white, $33 \%$ black, and $18 \%$ Hispanic) efavirenz plasma levels were 1.7-fold higher in individuals that are TT homozygotes for the C15582T polymorphism and lacked any polymorphic influence from G516T and T983C SNPs (Holzinger et al., 2012). By comparison, TT homozygotes for the G516T SNP and that lack the influence of T983C and C15582T had 5.4-fold elevated efavirenz plasma levels. A study of 113 black South Africans also found an independent association between elevated efavirenz plasma concentrations and 


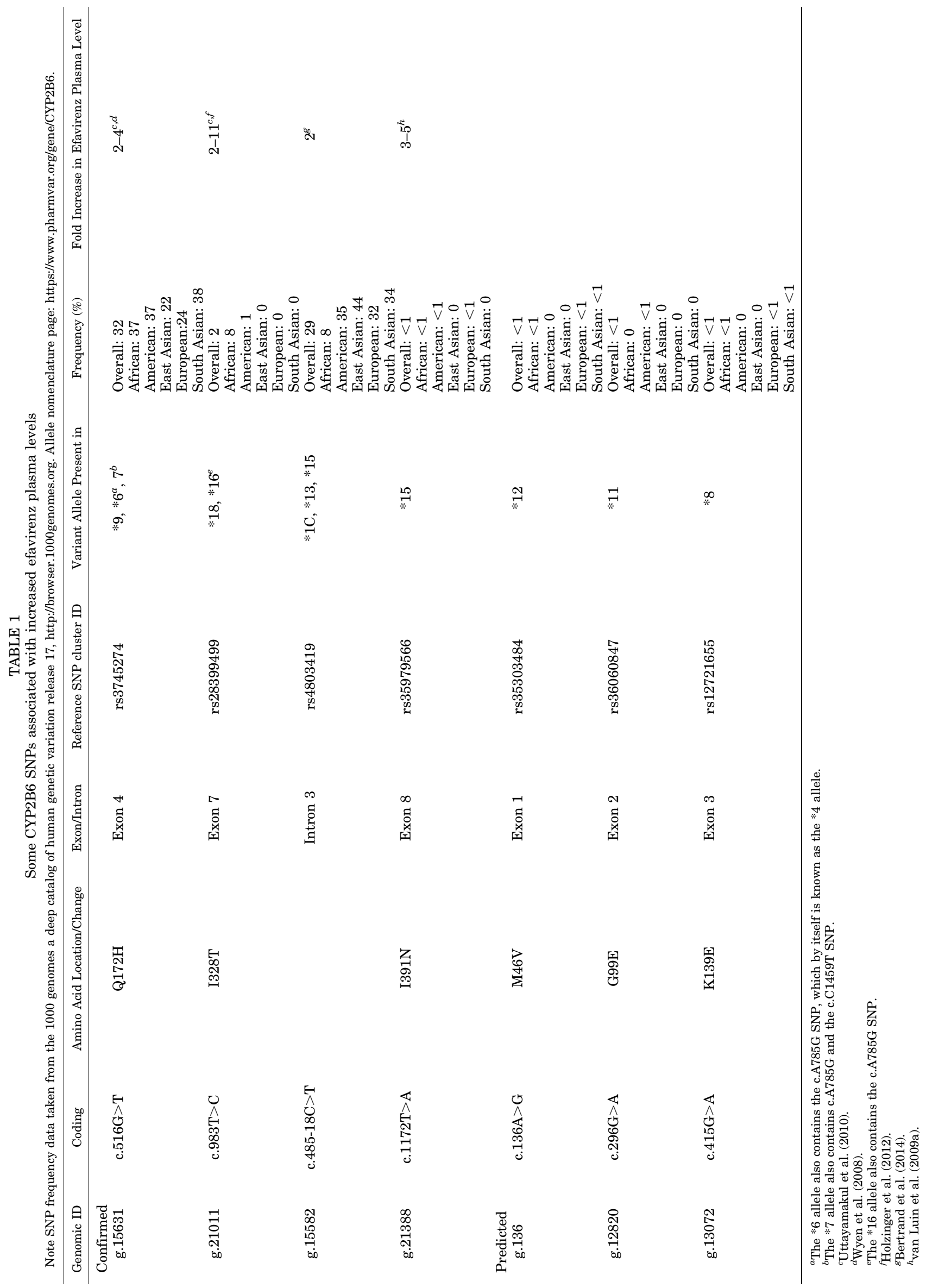


TABLE 2

Comparison of the relative reported intrinsic clearance $\left(\mathrm{CL}_{\mathrm{int}}, V_{\mathrm{max}} / K_{\mathrm{m}}\right)$ for CYP2B6*4 vs. CYP2B6*6

\begin{tabular}{|c|c|c|c|c|}
\hline Haplotype & System & $\mathrm{CL}_{\text {int }}(\%$ wild type) & Reference & Comments \\
\hline $2 \mathrm{~B} 6 * 4$ & E. coli & 170 & Bumpus et al. (2006) & N-terminally truncated transcripts \\
\hline $2 \mathrm{~B} 6 * 4$ & E. coli & 96 & Zhang et al. (2011) & N-terminally truncated transcripts \\
\hline $2 \mathrm{~B} 6 * 4$ & Sf9 cells & 142 & Ariyoshi et al. (2011) & \\
\hline Avg \pm S.E.M. & & $136 \pm 22$ & & \\
\hline $2 \mathrm{~B} 6 * 6$ & HLM & 17 & $\mathrm{Xu}$ et al. (2012) & \\
\hline $2 \mathrm{~B} 6 * 6$ & UES & 53 & Xu et al. (2012) & $\begin{array}{l}\text { No significant differences were observed in the presence } \\
\text { or absence of cyt } b \text { and thus the } \mathrm{CL}_{\text {int }} \text { value is an } \\
\text { average of the two measurements }\end{array}$ \\
\hline $2 \mathrm{~B} 6 * 6$ & E. coli & 20 & Zhang et al. (2011) & N-terminally truncated transcripts \\
\hline $2 \mathrm{~B} 6 * 6$ & Sf9 & 50 & Ariyoshi et al. (2011) & \\
\hline $2 \mathrm{~B} 6 * 6$ & COS-1 & 183 & Radloff et al. (2013) & \\
\hline Avg \pm S.E.M. & & $65 \pm 31$ & & \\
\hline
\end{tabular}

HLM, human liver microsomes from the specified haplotype; UES, unspecified expression system.

the C15582T genotype (Sinxadi et al., 2015). Only one patient was a TT homozygote for the C15582T SNP with a wild-type haplotype for both G516T and T983C allowing the $\mathrm{C} 15582 \mathrm{~T}$ variant to be assessed without the influence of these other two SNPs. In this one case, the plasma level of efavirenz was elevated 1.9-fold.

d. Other CYP2B6 polymorphisms. In a Caucasian study population, nonsynonymous CYP2B6 SNPs resulting in alleles expressing low levels of protein and having very low or null activity have been reported to occur at low frequency ( $\leq 1 \%$, Table 1) (Lang et al., 2004). These SNPs reside in exons $1,2,3$, or 8 with the following coding sequences and amino acid changes in parentheses: A136G (M46V), G296A (G99E), G415A (K139E), and T1172A (I391N). An additional nonsynonymous SNP, G419A (R140Q), had only a modest $18 \%$ reduction in expression compared with wild-type (CYP2B6*1) but an $88 \%$ reduction in intrinsic clearance $\left(V_{\max } / K_{\mathrm{m}}\right)$ activity. In the case of the $\mathrm{K} 139 \mathrm{E}$ variant, the loss of catalytic activity has been shown to impair the formation of a functional P450reductase complex (Zhang et al., 2011).

In a clinical case study, a Mauritanian male AA homozygous for the T1172A polymorphism (part of CYP2B6*15 allele) had high plasma levels of efavirenz $(7.1-10.6 \mu \mathrm{g} / \mathrm{ml})$ when given at a dose of $600 \mathrm{mg}$ or even $400 \mathrm{mg}(5.8 \mu \mathrm{g} / \mathrm{ml}$ ) (van Luin et al., 2009a). Moreover, concomitant NPAEs required further downward dose adjustment to $200 \mathrm{mg}(2.2 \mu \mathrm{g} / \mathrm{ml})$ to alleviate NPAEs (van Luin et al., 2009a). Although not yet confirmed by clinical studies, the seriously compromised or null phenotype of the other three missense mutations would lead to the prediction that homozygotes for these SNPs would also result in very high levels of efavirenz requiring dosage adjustment to avoid NPAEs.

The CYP2B $6 * 6$ haplotype, consisting of the combined G516T+A785G SNP in linkage disequilibrium, occurs frequently across ethnic populations (range 10\%-64\%), being lowest in Finnish and South China Han Chinese and highest in Papua New Guineans (Li et al., 2012). Across many clinical studies, the CYP2B6*6 haplotype has been associated with increases in efavirenz plasma concentration (Wang et al., 2006; Manosuthi et al., 2013;
Sukasem et al., 2013; Swart et al., 2013). However, it has also been reported that no independent associations between A785G and efavirenz plasma levels are apparent (Ribaudo et al., 2010) and no clinical studies of the CYP2B6*4 haplotype that consists of A785G alone have been reported to date. Although there is considerable variance between studies that likely represents the complexities of different expression systems and conditions (Zanger and Klein, 2013), studies of the intrinsic clearance properties comparing wild type (CYP2B6*1) with CYP2B6*4 and CYP2B*6 indicate that on average CYP2B6*4 SNP appears to have increased clearance (36\%) while the CYP2B6*6 SNP appears to have decreased clearance (35\%) (Table 2). These differences in activity are relatively modest, and thus it seems likely that drastically decreased expression of the CYP2B $6 * 6$ and CYP2B6*9 (>75\%), but not CYP2B6*4 (Hofmann et al., 2008), might account for the differences in clearance reported in clinical studies of CYP2B $6 * 6$ haplotypes. The constructing of haplotypes using CYP2B6 (G516T + A785G + T983C) in a longitudinal black pediatric cohort in South Africa provided evidence that the presence of the haplotype T-G-T predisposes a risk of efavirenz plasma levels $>4 \mu \mathrm{g} / \mathrm{ml}$ and thus also an increased risk for toxicity to develop (Reay et al., 2017).

e. Other polymorphisms leading to elevations in efavirenz levels. In the previous section, the focus was on CYP2B6, which is the enzyme primarily responsible for the phase I metabolism of efavirenz (Ward et al., 2003). SNPs in genes other than CYP2B6 have been reported also to contribute to the interindividual variations in efavirenz pharmacokinetics. These include CYP2A6, UGT2B7, CYP3A4, CYP3A5, and CAR, but their associations have yet to be replicated in vivo to strengthen their clinical impact (Holzinger et al., 2012). In this section, the focus will be on other enzymes and proteins playing a more minor role in the metabolism of efavirenz. These include other CYP P450 enzymes, efflux transporters such as adenosine triphosphate (ATP)-binding cassette (ABC) and multidrug resistance protein 1 (ABCD1/MDR1), nuclear receptors (NR) that function as ligand-activated transcription factors via orphan nuclear receptors, pregnane $\mathrm{X}$ receptors 
(PXR, NR1I2), and constitutive androstane receptors (CAR, NR1I3) (Telenti and Zanger, 2008).

i. CYP1A2 Polymorphisms. CYP1A2 metabolizes efavirenz to 8-hydroxyefavirenz (8-OH-EFV), although its overall role is minor (Ward et al., 2003; McDonagh et al., 2015). More than 40 SNPs for CYP1A2 are currently known (https://www.pharmvar.org/gene/CYP1A2), some of the most common ones are C163A, C729T, and T739G. No association was found between CYP1A2 and steadystate efavirenz plasma levels in $464 \mathrm{HIV}$-infected Bantuspeaking South Africans (Swart et al., 2013). In a Rawandan adult cohort, T739G heterozygotes were associated with 1.6-fold and GG homozygotes with 4.7-fold higher efavirenz plasma concentrations only when efavirenz was coadministered with rifampicin for the treatment of concomitant tuberculosis (Bienvenu et al., 2014). It would seem then that the clinical significance of the CYP1A2 polymorphisms on efavirenz plasma levels would be minimal, except under certain circumstances such as coadministration with rifampicin.

ii. CYP2A6 Polymorphisms. CYP2A6 is capable of biotransforming efavirenz to 8-OH-EFV and to 7-hydroxyefavirenz (7-OH-EFV) (Ogburn et al., 2010; McDonagh et al., 2015). It is a highly polymorphic gene with more than 70 SNPs presently known (https://www. pharmvar.org/gene/CYP2A6). Although CYP2A6 generally contributes less to the formation of the two primary metabolites (8-OH-EFV and 7-OH-EFV) compared with CYP2B6, the activity of CYP2A6 becomes relevant in individuals that have slow metabolizing variants of CYP2B6 (di Iulio et al., 2009). For example, elevated efavirenz levels have been found to occur in the presence of a slow metabolizing CYP2B6 variant co-occurring with the CYP2A6-T48G genotype (Haas et al., 2014) as well as other CYP2A6 genotypes (i.e., A745G, T6558C, G5065A) and each have half the activity of the wild-type enzyme (di Iulio et al., 2009). In the case of CYP2A6T48G, which defines the CYP2A6*9 haplotype, the polymorphism disrupts the cis-regulatory element TATA box promoter region, resulting in lower levels of expression (Pitarque et al., 2001; Yoshida et al., 2003). In another study in a Ghanaian population $(n=65)$, the carriers of CYP2A6*9B (CYP2A6 G1836T) and CYP2A6*17 (CYP2A6 G1093A), which also have the slow metabolism G516T variant of CYP2B6, had a 1.8 times higher median efavirenz plasma levels compared with noncarriers (Kwara et al., 2009). In the presence of rifampicin-based TB treatment in a Rwandan cohort $(n=35)$, the CYP2A6 G1093A genotype was predictive of higher efavirenz plasma concentrations (Bienvenu et al., 2014). Furthermore, in 84 adult subjects from different races (52.4\% black, $28.6 \%$ white, and $19.1 \%$ Hispanic), the CYP2A6 T48G genotype in all races was associated with significantly elevated efavirenz plasma levels (Haas et al., 2014). However, other studies have reported no clear association of CYP2A6 with efavirenz plasma levels. This includes one study of 464 Bantu-speaking South Africans with HIV infection (Swart et al., 2013) and another study with 143 individuals with HIV infection receiving either efavirenz or nevirapine (Heil et al., 2012).

iii. CYP3A4 and CYP3A5 Polymorphisms. The CYP3A subfamily is the predominant form in the human liver and encodes for four isoforms: CYP3A4, CYP3A5, CYP3A7, and CYP3A43 (Ward et al., 2003; Haas et al., 2004; Telenti and Zanger, 2008). CYP3A4 is the most abundant hepatic drug metabolizing enzyme, accounting for approximately $30 \%-40 \%$ of the total CYP content (Watkins et al., 1987), and participates in the metabolism of over $50 \%$ of all commercially available drugs (Wrighton et al., 2000; Telenti and Zanger, 2008), including efavirenz (Ward et al., 2003). Although both CYPs 3A4 and 3A5 are capable of metabolizing efavirenz to 8-OH-EFA, their efavirenz-metabolizing ability is much less than that of CYP2B6 (Ward et al., 2003; McDonagh et al., 2015). Several studies have reported on the pharmacogenetics of CYP3A4 and CYP3A5 activity on efavirenz exposure with contradictory outcomes. In 169 subjects with 393 plasma samples, the population pharmacokinetics for efavirenz was analyzed as a function of CYP2B6, CYP2A6, and CYP3A4/5 alleles. Both CYP2A6 and CYP3A4 prominently affected the clearance of efavirenz (Arab-Alameddine et al., 2009). However, retrospective analysis from the Adult AIDS Clinical Trials Group (ACTG) A5095/5097 by Haas and coworkers (2004, 2005) in subjects from different ethnic origins (genetic data on 157 study subjects) indicated no apparent statistically significant associations with CYP3A4 A392G and CYP3A5 G713A and a weak association with CYP3A5 A6986G and efavirenz plasma levels. Similarly, in a study of 159 Chinese individuals with HIV infection, the CYP3A4 A392G and CYP3A5 A6986G genotypes were found to have no significant effect on efavirenz plasma levels (Chen et al., 2010). Other studies involving 464 Bantu-speaking South Africans with HIV infection (Swart et al., 2013) or 143 individuals with HIV infection (Heil et al., 2012) also found no association between efavirenz levels and CYP3A4 and CYP3A5 genotypes, respectively.

iv. Efflux Transporter Polymorphisms. The solute carrier and ATP binding cassette (ABC) efflux transporters encompass two major gene superfamilies responsible for the transport of drugs across membrane barriers present in intestine, liver, kidney, and brain. The role of these efflux transporters is to export xenobiotics from the intracellular to the extracellular milieu. Efavirenz was shown to be a substrate for the multidrug resistance protein 1 (ABCB1/MDR1), but subsequent studies failed to reproduce the finding (Telenti and Zanger, 2008).

v. ATP Binding Cassette Subfamily B Member 1/Multidrug Resistance Protein 1 Polymorphisms. P-glycoprotein 1 (PgP), also known as ATP binding cassette subfamily B member 1 (ABCB1) or multidrug resistance protein 1 (MDR1), is an energy-dependent efflux transporter located at the intestinal wall, the 
blood-brain barrier, and on the plasma membranes of lymphocytes where they function to pump foreign substances out of the cellular lumen into the extracellular milieu. Although efavirenz is not a substrate for or inhibitor of MDR1 in vitro or in vivo (Stormer et al., 2002; Dirson et al., 2006), initial studies found an association between MDR1-C3435T polymorphisms and efavirenz plasma levels (Fellay et al., 2002; Csajka et al., 2003), as well as a greater rise in CD4cell counts at 6 months post-ART initiation (Fellay et al., 2002) and decreased virologic failure and decreased emergence of efavirenz-resistance (Haas et al., 2005). Responses to efavirenz-based ARV treatments in patients as a function of this polymorphism have been a fairly consistent finding across many studies [for a review, see Table 6 summary in McDonagh et al. (2015)]. However, the effects of this polymorphism on efavirenz plasma levels has not been a consistent finding (Cressey and Lallemant, 2007), including several studies with patients from different genetic backgrounds found no association with efavirenz exposure and several different ABCB1 variants (Heil et al., 2012), MDR1 G2677T/A, MDR1 C3435T (Winzer et al., 2003; Haas et al., 2004, 2005; Uttayamakul et al., 2012; Salem et al., 2014), ABCB1 C1236T, C3435T, G2677T/A (Ribaudo et al., 2010), ABCB1 G2677T/A, C3435T (Chen et al., 2010), and ABCB1 C1236T (Dhoro et al., 2013). Taken together, it would seem that ABCB1/ MDR1 SNPs, in particular the MDR1 C3435T SNP, plays no direct role in modifying efavirenz plasma levels.

Curiously, the MDR1-3435 CC homozygotes have higher, the $\mathrm{C} / \mathrm{T}$ heterozygotes intermediate, and the TT homozygotes the lowest levels of expression of duodenal MDR1 with a 4-fold difference in expression of CC versus TT homozygotes (Csajka et al., 2003). Functionally, the TT homozygote has reduced efflux activity for a rhodamine 123 substrate and lower MDR1 mRNA expression compared with the CC homozygotes (Hitzl et al., 2001). These factors may be relevant in the context of efavirenz, albeit indirectly, as there is precedent from MDR1 knockout studies that other transporters may be upregulated to compensate for reduced MDR1 activity (Smit et al., 1998; Schuetz et al., 2000). Although these other transporters have not been identified specifically, for this paradigm to work it would be presumed that one of them would be an efflux transporter for efavirenz.

vi. UDP-Glucuronosyltransferase Isoform $2 B 7$ Polymorphisms. The 8-OH-EFV and 7-OH-EFV metabolites of efavirenz are glucuronidated by the phase II enzyme UDP-glucuronosyltransferase isoform 2B7 (UGT2B7) (Mutlib et al., 1999; Ward et al., 2003), and efavirenz can also be directly converted to $N$-glucuronide-efavirenz $(N$ gln-EFV) by this same enzyme (Mutlib et al., 1999; Ward et al., 2003; Belanger et al., 2009). The strongest in vivo evidence of the independent effects of UGT2B7
(UGT2B7*1a carrier) on elevated efavirenz plasma levels was in a Ghanaian population $(n=94)$, in which the carriers had $36 \%$ higher efavirenz plasma levels compared with noncarriers (Kwara et al., 2009). Most other studies investigating several SNPs within UGT2B7 reported no significant association (McDonagh et al., 2015). However, in a study of 84 mixed race subjects that focused only on individuals with a slow metabolizing genotype (CYP2B6 516TT, 516T/983C, or 983CC), the median efavirenz levels were nearly double in the UGT2B7-735GG homozygotes compared with the 735AA homozygotes and AG heterozygotes (Haas et al., 2014). Thus, although homozygosity for UGT2B7-735GG alone appears to have no effect on efavirenz plasma levels, it can have a pronounced effect when co-occurring with other CYP2B6 SNPs that by themselves significantly affect efavirenz levels.

vii. Nuclear Receptor Polymorphisms. Both the pregnane $\mathrm{X}$ receptor $(\mathrm{PXR})$ and the constitutive androstane receptor (CAR) belong to the orphan nuclear receptor (NR) superfamily and are encoded by the genes NR1I2 and NR1I3, respectively. When activated by xenobiotics, they regulate a variety of overlapping sets of genes that encode for phase I and II drug metabolizing enzymes and transporters for xenobiotic detoxification and elimination. PXR and CAR are predominantly expressed in the liver where they induce the expression of CYP3A4, CYP2B6, CYP2C9, and CYP2C19 (Wang et al., 2012).

Several SNPs for NR1I2 and NR1I3 have been reported (Swart et al., 2012). Two studies reported no association between three different NR1I2 SNPs in relation to efavirenz plasma concentration, earlier switching from efavirenz to a different ARV drug or discontinuation of efavirenz treatment (Wyen et al., 2011; Swart et al., 2012). Five studies have quantified the effect of CAR (NR1I3) on efavirenz exposure. A German study (225 Caucasian and 146 black adult patients with HIV infection) reported that NR1I3 rs2307424 (540CC) wild-type homozygotes contributed to early discontinuation of efavirenz treatment due to self-reported CNS-related side effects [72 of $131(55 \%)$ in the early discontinuation group] (Wyen et al., 2011). A Chilean study $(n=208$ patients with HIV) observed a significant association between efavirenz plasma levels and exon 5 NR1I3-C540T, where TT homozygotes had significantly lower efavirenz plasma levels compared with the CC and CT genotype (Cortes et al., 2013). However, in a Ghanaian population $(n=521)$, no significant association between efavirenz plasma levels and NR1I3-C540 to $\mathrm{T}$ variants was observed, indicating that NR1I3 is not an important determinant for efavirenz plasma levels in this subpopulation (Sarfo et al., 2014). In a Bantu-speaking South African population $(n=163)$, intron 4 NR1I3-C8784 (rs3003596) CC and TC genotypes have been associated with reduced plasma efavirenz levels, with $48 \%$ of individuals with the TT genotype having efavirenz plasma levels above $4 \mu \mathrm{g} / \mathrm{ml}$ (Swart et al., 2012). In this same study, it was observed that NR1I3-C540T heterozygotes were associated with more 
patients switching from efavirenz-based treatment over a 12-month period. However, in a mixed race population study $(n=84)$, the reported associations of efavirenz exposure with either NR1I3-C540T or NR1I3-T8784C could not be replicated (Haas et al., 2014). On balance then, it appears that no consensus has been reached concerning the clinical relevance of NR1I3 on efavirenz exposure, necessitating further research.

\section{Dose Adjustment Algorithm}

Given the important role that sex, weight, and the CYP2B6-G516T SNP genotype plays in efavirenz's metabolism, an efavirenz dose-adjustment algorithm has been proposed (Nemaura et al., 2012). According to this algorithm, if the patient is homozygous for G516T (TT genotype), then the efavirenz dose is reduced to $200 \mathrm{mg}$, as opposed to a standard dose of $600 \mathrm{mg}$. If the patient is heterozygous (GT), then one should consider the patient's weight: If $\geq 62 \mathrm{~kg}$, then a dose of $600 \mathrm{mg}$ would suffice. However, for patients $<62 \mathrm{~kg}$, consider the sex. Men should be given a 600-mg dose and women a 400-mg dose. Earlier studies have suggested an even more tailor-made therapy by reducing efavirenz dose from the standard 600 to $400 \mathrm{mg}$ and even to $200 \mathrm{mg}$ in Japanese patients suffering from CNS side effects or in whom the CYP2B6-G51GT SNP was present (Tsuchiya et al., 2004; Gatanaga et al., 2007). Tailor-made therapies may be the future of HIV treatment in developed countries when such testing becomes the norm of HIV treatment. However, in developing countries, it is not a viable option due to cost, inadequate manpower, and a lack of availability of genotype testing facilities. Dose reduction strategies supported by therapeutic drug monitoring, meaning measurement of drug blood concentrations, appear to be beneficial for reducing toxicity-induced discontinuation and thus NPAEs associated with efavirenz (van Luin et al., 2009b).

\section{Efavirenz Drug-Drug Interactions Leading to Elevated Efavirenz Levels}

As discussed in sections above, efavirenz is primarily metabolized by CYP2B6 and to a lesser extent by CYP3A4 and other CYPs. On the one hand, efavirenz's autoinduction of CYP2B6 and CYP3A4 metabolic enzymes (Mouly et al., 2002; Faucette et al., 2004) serves to accelerate its own metabolism. On the other hand, inhibition of these enzymes by efavirenz (Xu and Desta, 2013) slows down its metabolism. Notably, the effect of autoinduction on efavirenz levels over long time periods is substantial for CYP2B6 fast metabolizers, but not those possessing the slower metabolizing CYP2B6 isotypes (Ngaimisi et al., 2010).

In addition to CYP genotype, weight, and sex, there are noteworthy drug-drug interactions that result in elevations in plasma efavirenz levels. Of clinical relevance are interactions with drugs that significantly inhibit CYP3A4, the most abundant CYP isoform in human liver. These include the HIV-1 protease inhibitor ritonavir used in booster therapy (Fiske et al., 1998) and the antifungal agents ketoconazole (Saadeddin and Peris, 2009) and voriconazole (Damle et al., 2008; Liu et al., 2008). Since efavirenz is mainly metabolized by CYP2B6 and secondarily by CYP3A4, it stands to reason that the sensitivity to CYP3A4 inhibiting drugs would be most prominent in those individuals with slower metabolizing CYP2B6 genotypes. Indeed, CYP3A4-mediated metabolism of efavirenz is pronounced in those with impaired CYP2B6 activity (Arab-Alameddine et al., 2009). Yet complex interactions may occur simultaneously, including that CYP3A4 induction in CYP2B6 slow metabolizers is more pronounced given the higher levels of efavirenz plasma exposure (Habtewold et al., 2013).

1. Protease Inhibitors. In the case of coadministration of ritonavir $(500 \mathrm{mg})$, a $21 \%$ increase in the plasma AUC for efavirenz (600 mg) and a $14 \%$ increase in $C_{\text {max }}$ has been reported (Fiske et al., 1998; Sustiva, 1998). This level of increase was associated with an increase in NPAEs (Sustiva, 1998). However, it is unclear whether lower boosting doses of ritonavir (e.g., 100-200 mg) would produce as pronounced an effect. It is important to keep in mind that ritonavir is a very potent inhibitor of CYP3A4 (Kumar et al., 1996; von Moltke et al., 1998), much more than other HIV protease inhibitors (Decker et al., 1998). This likely explains why in clinical studies efavirenz clearance is reported to be unaffected by CYP3A4-inhibiting protease inhibitor cocktails lacking ritonavir (Pfister et al., 2003; Ma et al., 2008).

2. Antifungals. Typically, drug-drug interactions involving ketoconazole and efavirenz focus on reductions in ketoconazole levels. Like efavirenz, ketoconazole is metabolized by CYP3A4 (Fitch et al., 2009). In patients with HIV, efavirenz lowers levels of ketoconazole by inducing the expression of CYP3A4 (Sriwiriyajan et al., 2007). Less appreciated is that ketoconazole can also elevate efavirenz plasma levels. Although it has yet to be confirmed in humans, coadministration of efavirenz and ketoconazole in rats results in a $45 \%$ increase in plasma AUC for efavirenz along with a $26 \%$ increase in the $C_{\max }$ (Saadeddin and Peris, 2009). This can be attributed to ketoconazole's ability to potently inhibit CYP3A4 (Stresser et al., 2004). Thus, at least initially, inhibition of CYP3A4 by ketoconazole appears to supercede efavirenz's CYP3A4inducing effect, although it is unclear whether under chronic dosing conditions elevations in CYP3A4 levels would lower levels of ketoconazole sufficiently to prevent increases in efavirenz plasma exposure.

Voriconazole has similarly strong CYP3A4 inhibiting potency as ketoconazole (Ohno et al., 2007). In patients being treated with $400 \mathrm{mg}$ efavirenz, the addition of voriconazole resulted in a $43 \%$ increase in plasma AUC for efavirenz as well as a $37 \%$ increase in $C_{\max }$ (Liu et al., 2008). Furthermore, the coadministration of voriconazole $(400 \mathrm{mg})$ plus efavirenz $(300 \mathrm{mg})$ produces an efavirenz level and $C_{\text {max }}$ similar to $600 \mathrm{mg}$ efavirenz 
alone (Damle et al., 2008). These studies indicate that voriconazole is capable of increasing efavirenz levels in humans. Although both voriconazole and fluconazole have been demonstrated to increase the blood/plasma concentrations of CYP3A4/5 substrates in vivo (Niwa et al., 2014) and fluconazole (200 mg) has been reported to increase efavirenz ( $400 \mathrm{mg}$ ) plasma by $16 \%$ (Sustiva, 1998), voriconazole is a much more potent CYP3A4 inhibitor than fluconazole, being only slightly less potent than ketoconazole (Ohno et al., 2007). This difference in inhibitor potencies for ketoconazole and voriconazole versus fluconazole parallels the magnitude of the increases in efavirenz plasma exposure observed upon coadministration. However, no significant increase was observed with itraconazole ( $200 \mathrm{mg} /$ day for 6 days) pretreatment, which is likely due to its significantly lower inhibitory potency (Jiang et al., 2013) that is approximately 10-fold lower than ketoconazole's (Kajita et al., 2000). Thus, it seems likely that only the antifungals that potently inhibit CYP3A4, such as ketoconazole and voriconazole, would elevate efavirenz levels to a degree that might result in elevations in efavirenz plasma levels sufficient to increase the incidence of NPAEs.

3. Antiplatelet Agents. The antiplatelet agent clopidogrel is a potent inhibitor of CYP2B6 derived from human liver microsomes, with a $>10$-fold higher potency than the next three most potent inhibitors: clotrimazole, itraconazole, and ticlopidine (Walsky et al., 2006). In a study with 17 healthy Korean males of mixed CYP2B6*1 and CYP2B $6 * 6$ genotypes, clopidogrel pretreatment (75 mg/day for 4 days) was found to significantly increase efavirenz $(200 \mathrm{mg})$ plasma AUC by $17 \%$ and $C_{\max }$ by $29 \%$ (Jiang et al., 2013). However, no significant increase was observed with itraconzaole ( $200 \mathrm{mg} /$ day for 6 days) pretreatment, which is likely due to its significantly lower inhibitory potency. By comparison, in the exclusively slow metabolizing CYP2B6*6 (G516T+A785G) homozygotes, the plasma AUC and $C_{\max }$ for efavirenz $(200 \mathrm{mg})$ was increased by $26 \%$ and $38 \%$, respectively, when pretreated with clopidogrel (Jiang et al., 2013). This is in contrast to much larger increases in plasma efavirenz concentrations (estimated as a 2.9-fold increase) reported in CYP2B6*6 homozygotes given only $600 \mathrm{mg}$ efavirenz (Rotger et al., 2007), and likely reflects the higher dose of efavirenz.

\section{Molecular Mechanisms and Receptor Pharmacology of Efavirenz}

There are many challenges associated with adequately treating the HIV pandemic, including the relative lack of readily accessible, effective, and affordable pharmacotherapies and adverse events associated with existing medications. The latter is especially problematic with regard to compliance. There is thus a dedicated effort to move away from a cytopathic viral model of HIV pathogenesis toward addressing its immunopathogenic features, i.e., generalized immune activation, and hence to more specifically investigate neutralizing and nonneutralizing antibodies as part of a therapeutic vaccine option (Cadogan and Dalgleish, 2008). At this time, however, anti-HIV strategies remain very much centralized around HAART with antiretroviral agents. As discussed in Historical Perspective of Antiretroviral Drugs and Highly Active Antiretroviral Therapy, efavirenz has been a mainstay of HAART, because it effectively suppresses HIV. Although efavirenz was recently downgraded by DHHS from a first line to an alternative treatment of treatment-naive patients due to NPAEs, both WHO and South African guidelines continue to recommend efavirenz as the preferred NNRTI for HAART in adults. Furthermore, its popularity as a component of first line HAART therapy is likely to continue now that generic forms are becoming available. Consequently, a better understanding of the molecular basis of NPAEs is essential.

Although a comprehensive understanding of the mechanisms responsible for efavirenz-mediated NPAEs and for its attractiveness as a recreational drug remain elusive, its narrow therapeutic window and ability to rapidly accumulate in brain are likely key contributing factors (for further details, see Efavirenz Therapeutic Index and Brain Exposure). Recent studies have begun investigating the receptor neuropharmacology underpinning NPAEs and the recreational use of efavirenz (Gatch et al., 2013; Dalwadi et al., 2016) (Fig. 3). By using a rationalized mechanistic approach and selection of targets known to interact with other drugs of abuse to narrow the receptor profiling effort, a number of CNS receptors were identified as possible targets for efavirenz. Specifically, efavirenz was discovered to interact with the $5-\mathrm{HT}_{2 \mathrm{~A}}, 5-\mathrm{HT}_{2 \mathrm{C}}, 5-\mathrm{HT}_{3}, 5-\mathrm{HT}_{6}, \mathrm{M}_{1}, \mathrm{M}_{3}$, and $\mathrm{GABA}_{\mathrm{A}}$ receptors, as well as with the dopamine transporter (DAT), the serotonin transporter, the vesicular monoamine transporter 2, and monoamine oxidase A (Gatch et al., 2013; Dalwadi et al., 2016; Huang et al., 2017). More precisely and within approximately the same concentration range, efavirenz functions as a $\mathrm{G}_{\mathrm{q}}$-signaling antagonist at the $5-\mathrm{HT}_{2 \mathrm{~A}}, 5-\mathrm{HT}_{2 \mathrm{C}}$, and $\mathrm{M}_{1}$ receptors. It also functions as a $\mathrm{G}_{\mathrm{s}}$-signaling inverse agonist at the $5-\mathrm{HT}_{6}$ receptor, $\mathrm{G}_{\mathrm{q}}$-signaling allosteric modulator of the $\mathrm{M}_{3}$ receptor, dual dose-dependent potentiator and inhibitor of the $\mathrm{GABA}_{\mathrm{A}}$ receptor, pore blocker at the $5-\mathrm{HT}_{3}$ receptor, and an inhibitor of DAT, serotonin transporter, and monoamine oxidase A. In vivo, efavirenz dose dependently suppresses novel open field locomotor activity in SwissWebster mice as does LSD (Gatch et al., 2013). Efavirenz can be trained as a discriminative stimulus in rats, and LSD partially substitutes for efavirenz in these efavirenztrained rats. Furthermore, in rats trained to discriminate LSD from saline, efavirenz partially substitutes for LSD, and this substitution is blocked by pretreatment with the $5-\mathrm{HT}_{2 \mathrm{~A}}$ receptor selective antagonist MDL100,907, thus delineating a role for serotonergic signaling in the psychoactive properties of efavirenz (Gatch et al., 2013). In a rodent head twitch assay, which is a proxy for 
hallucinogenic activity in humans (Halberstadt and Geyer, 2011), efavirenz produced head twitch responses in wild-type but not in the $5-\mathrm{HT}_{2 \mathrm{~A}}$-knockout mice; however, the response was far weaker than for LSD and initiated and dissipated much more quickly (Gatch et al., 2013). Overall, the predominate behavioral profile of efavirenz in rodents seems to be most consistent with an LSD-like effect mediated by the $5-\mathrm{HT}_{2 \mathrm{~A}}$ receptor (Gatch et al., 2013), and molecular mechanistic studies suggest that efavirenz competes for the same binding site on the $5-\mathrm{HT}_{2 \mathrm{~A}}$ receptor as the hallucinogens LSD and 2,5Dimethoxy-4-iodoamphetamine (DOI) (Dalwadi et al., 2016). Furthermore, support for involvement of the $5-\mathrm{HT}_{2 \mathrm{~A}}$ receptor in some of the neuropsychiatric manifestations of efavirenz, including hallucinations, come from studies in patients who are HIV positive, where the nonselective 5- $\mathrm{HT}_{2 \mathrm{~A}}$ receptor antagonist cyproheptadine has been shown to reverse the aforementioned effects (Dabaghzadeh et al., 2012, 2013). What remains puzzling, however, is that classic hallucinogens that act on the $5-\mathrm{HT}_{2 \mathrm{~A}}$ receptor [e.g., LSD, DOI, $\alpha$-methyl-5-HT, (4-Bromo3,6-dimethoxybenzocyclobuten-1-yl)methylamine hydrobromide (TCB-2)] behave as agonists or partial agonists of $\mathrm{G}_{\mathrm{q}}$ signaling, whereas efavirenz behaves as an antagonist of this signaling pathway (Dalwadi et al., 2016). This would seem to suggest that $G_{q}$ signaling may not be the only or most critical pathway responsible for $5-\mathrm{HT}_{2 \mathrm{~A}^{-}}$ mediated effects of hallucinogens, an idea supported in part by the finding that $\mathrm{G}_{\mathrm{q}}$-knockout mice have diminished but not abolished head twitch responses to DOI (Garcia et al., 2007).

Scopolamine is a centrally acting muscarinic receptor antagonist with hallucinogenic and delirium-inducing properties (Seo et al., 2009; Lin et al., 2011; Jalali et al., 2014). Notably, efavirenz also has scopolamine-like inhibitory effects on $\mathrm{M}_{1}$ and $\mathrm{M}_{3}$ muscarinic receptors (Dalwadi et al., 2016) that may contribute to its ability to precipitate hallucinations or vivid dreaming in some individuals. Central muscarinic systems appear to play a role in mood disorders (Barak, 2009; Carruthers et al., 2015; Delport et al., 2017). The cholinergic neurocircuitry responsible for antimuscarinic-induced psychosis may involve the action of acetylcholine on subcortical glutamate and striatal dopamine release, leading to attention and executive function difficulties, memory loss, multisensory hallucinations, and delusions (Barak, 2009). These effects are observed when antimuscarinics are administered acutely to healthy subjects, and a reduction in cortical $\mathrm{M}_{1}$ receptor expression may represent a defining feature of the pathophysiology of psychotic disorders such as schizophrenia (Carruthers et al., 2015). Consequently, a disruption of central monoaminergic systems in general and cholinergic systems specifically might contribute to NPAEs induced by efavirenz as well as its attractiveness for recreational use. A caveat though is that cyproheptadine, mentioned in the clinical studies above, is also a high affinity antagonist of all five muscarinic receptors (Stanton et al., 1993), so unless it acted as a more potent allosteric antagonist of efavirenz at muscarinic receptor binding sites, it would likely not prevent any behavioral scopolamine-like effect of efavirenz as cyproheptadine itself has been reported to induce hallucinations, albeit generally at higher doses (von Mühlendahl and Krienke, 1978; Watemberg et al., 1999).

Recent opinion has emphasized a potential contributory role of the mitochondrial-immune-inflammatoryredox cascade to the NPAEs associated with efavirenz, with oxidative stress and neuronal toxicity proposed as playing variable roles in the nature and severity of neuropsychiatric symptoms (Cavalcante et al., 2010; Decloedt and Maartens, 2013; Purnell and Fox, 2014; Apostolova et al., 2015; Funes et al., 2015). Mitochondrial and redox dysfunction set in motion by proinflammatory cytokines and disordered kynurenine metabolism apparently can directly alter monoaminergic transmission (Garcia-Cazorla et al., 2008; Möller et al., 2013a,b). In particular, disturbances in glutamate signaling leading to imbalances in cortical and subcortical dopamine signaling may be of particular relevance here when considering the neurobiology of depressive, anxiety, psychotic, and cognitive phenotypes (Brand et al., 2015; Möller et al., 2015). The kynurenine pathway metabolizes tryptophan via indoleamine 2,3-dioxygenase (IDO) and/or tryptophan 2,3-dioxygenase (TDO) to either kynurenic acid, a glycine site $N$-methyl-D-aspartate receptor antagonist with neuroprotective properties, or quinolinic acid, an $N$-methylD-aspartate receptor agonist with pro-oxidant and neurodegenerative properties (Möller et al., 2015). The resulting oxidative stress of the latter modifies dopamine release (Möller et al., 2013b), whereas the redirecting of tryptophan away from serotonin synthesis depletes neuronal stores of serotonin. Pro- and anti-inflammatory cytokines activate or inhibit IDO, respectively, thereby altering serotonin and dopamine levels in various limbic brain regions, leading to psychotic, mood, cognitive, and anxiety manifestations (Brand et al., 2015; Möller et al., 2015) (Fig. 3). However, efavirenz has been found to enhance serotonin levels in rats, an effect produced in parallel to a reduced activity of TDO (Cavalcante et al., 2010). While the reported reduction in $5-\mathrm{HT}_{2 \mathrm{~A}}$ receptor density upon repeated exposure to efavirenz (Dalwadi et al., 2016) may better explain depressive-like symptoms than the reported elevation of serotonin in the shorter term, the resulting disturbance in tryptophan-serotonin metabolism may have longer term consequences. Disturbances in kynurenine metabolism have been reported in patients with schizophrenia and depression (Möller et al., 2015) and disruption of the kynurenic acid/quinolinic acid balance may contribute to neurotoxicity in patients with HIV infection (Harvey et al., 2002).

Clinical evidence has linked oxidative stress to patients treated with efavirenz (Hulgan et al., 2003), and there is evidence that mitochondrial dysfunction is the primary source of such redox imbalance following efavirenz 


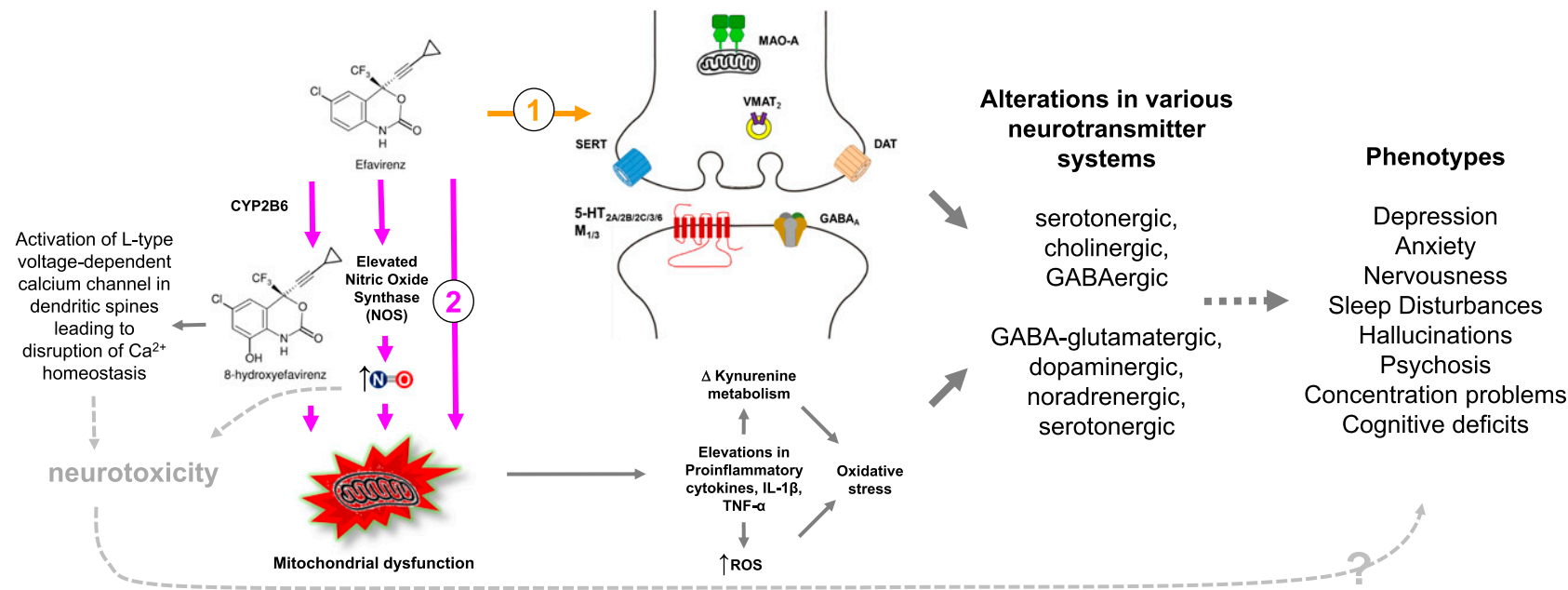

Fig. 3. Putative molecular mechanisms involved in the NPAEs and illicit use of efavirenz. Pathway 1 (orange arrow): By directly targeting $5-\mathrm{HT}_{2 \mathrm{~A}}, 5-\mathrm{HT}_{2 \mathrm{C}}, 5-\mathrm{HT}_{2 \mathrm{~B}}, 5-\mathrm{HT}_{3}, 5-\mathrm{HT}_{6}, \mathrm{M}_{1}, \mathrm{M}_{3}$, and $\mathrm{GABA}_{\mathrm{A}}$ receptors, and DAT, serotonin transporter (SERT), and vesicular monoamine transporter 2 (VMAT $\mathrm{VM}_{2}$, efavirenz may engender a range of possible psychotropic effects via actions on neurotransmitter systems known to be involved in regulating sleep, cognition, mood, and psychotic behavior. Pathway 2 (magenta arrows): Efavirenz can apparently upregulate inducible nitric oxide synthase, leading to mitochondrial-immune-inflammatory-redox dysfunction that indirectly modulates various key neurotransmitters like serotonin, dopamine, and norepinephrine, as well as GABA and glutamate. Efavirenz-induced mitochondrial dysfunction and altered bioenergetics leading to disturbances in pro- vs. anti-inflammatory cytokine release, altered kynurenine metabolism and oxidative stress may drive disturbances in monoamine signaling. Excessive and sustained elevation of nitric oxide may result in neurotoxicity. Metabolism of efavirenz by CYP450 results in the formation of 8-hydroxyefavirenz which can both induce mitochondrial dysfunction and activate L-type voltage-dependent calcium channels in dendritic spines, leading to the disruption of calcium homeostasis and subsequent neurotoxicity that may also contribute to phenotypic outcomes.

challenge (Apostolova et al., 2017). Both efavirenz and its 8-hydroxy metabolite provoke similar deleterious actions on mitochondrial respiration (Apostolova et al., 2017), while neurotoxicity associated with 8-hydroxyefavirenz has been reported to involve L-type calcium channels and a disruption of calcium homeostasis (Tovar-y-Romo et al., 2012) (Fig. 3). Although further work is needed, it appears that efavirenz and/or 8-OH efavirenz-mediated mitochondrial-redox disturbances may mobilize the kynurenine pathway via a proinflammatory action on IDO. Because altered redox and immune-inflammatory conditions are associated with altered regional brain monoamines (Möller et al., 2013a,b), such changes may contribute to the mood altering, psychogenic, and cognitive disruptive properties of efavirenz (Fig. 3).

Another component of the immune system, nitric oxide (NO), also plays a pathologic role in HIV infection where immunologic cell-derived NO is implicated in mediating $\mathrm{HIV}$-associated neurotoxicity via increased expression of inducible NO synthase (iNOS) (Harvey et al., 2002) (Fig. 3). Moreover, NO is a mediator of mitochondrial dysfunction associated with the CNS symptoms of HIV and efavirenz has been found to promote iNOS expression in cultured glial cells (Apostolova et al., 2015). The efavirenz-induced iNOS activation has been shown to interfere with mitochondrial function and bioenergetics in neurons and glia, an effect that was reversed by inhibiting NOS (Apostolova et al., 2015). NO is also recognized as a modulator of dopaminergic, serotonergic, noradrenergic, GABA-glutamate, and muscarinic pathways (Prast and Philippu, 2001), and as such is implicated in the neurobiology of mood, anxiety, and psychotic disorders (Brand et al., 2015). With both psychosis and depression associated with mitochondrial-immune-inflammatory-redox disturbances as well as altered NO homeostasis (Maes et al., 2011; Davis et al., 2014b; Brand et al., 2015), any disruption of these processes may contribute to neurotoxicity and NPAEs associated with efavirenz (Fig. 3). However, other factors such as creatine kinase, altered GABAglutamate balance and calcium homeostasis may play a role as well (Cavalcante et al., 2010; Apostolova et al., 2017).

In summary, it seems likely that alterations in monoamine signaling plays a major role in the NPAEs associated with efavirenz, either via a direct action of the drug on specific target receptors, ion channels, transporters, and enzymes (Fig. 3, pathway 1) or indirectly via actions on the immune-inflammatory-redox cascade (Fig. 3, pathway 2). Direct disruption of serotonergic, GABAergic, and muscarinic pathways (pathway 1), as well as mitochondrial-immune-inflammatory dysfunction and altered bioenergetics and their subsequent effects on monoamine pathways (pathway 2), may therefore represent efavirenz-mediated processes, giving rise to a host of psychopathological manifestations. With so many possible CNS targets, future work should be aimed at understanding the predominant pathways in terms of efavirenz's NPAEs and illicit use. This level of insight may ultimately allow for the coformulation of efavirenz with other drugs that might block its major untoward side effects or its potential for abuse. 


\section{Possible Association of Efavirenz with Human Immunodeficiency Virus-Associated Neurocognitive Disorder}

HIV-associated neurocognitive disorder (HAND) occurs when the HIV virus penetrates the nervous system and induces inflammatory and neurotoxic responses that directly impact the health of neurons and glia. This ultimately impacts cognitive functions such as language, memory, attention, problem-solving, and decisionmaking. While HAND is more common during advanced stages of the disease (i.e., AIDS), it can also occur during the medically asymptomatic stage of the HIV infection, and there is evidence that these milder forms of HAND are increasing likely as a consequence of the success of HAART in suppressing HIV and improving immune function (Heaton et al., 2011). Recently, however, long-term efavirenz use in HIV patients has been shown to worsen neurocognitive function (Ma et al., 2016). Since efavirenz is associated with NPAEs, penetrates the brain at concentrations relevant to the interaction with a number of neuroreceptors and immune-inflammatory-redox cascades, and can impact neurocognitive function, it is logical to speculate that efavirenz might possibly have synergizing actions with HAND.

A cross-sectional single cohort study involving 146 asymptomatic HIV patients found that efavirenz use was associated with a high prevalence of HAND in asymptomatic HIV patients (Ciccarelli et al., 2011). A different 48-week randomized controlled study involving treatment-naive patients with HIV found similar results (Winston et al., 2010). Thirty patients participated in this study and initiated HAART, consisting of tenofoviremtricitabine plus either efavirenz (group 1), atazanavirritonavir (group 2), or zidovudine-abacavir (group 3). Over a 48-week period, groups 2 and 3 showed greater improvement from baseline in their executive function and rate of information processing compared with group 1 (Winston et al., 2010). In this study, the $N$-acetylaspartate (NAA)/ creatine $(\mathrm{Cr})$ ratio was a measure of neuronal integrity with a decreased ratio generally associated with neuronal loss or dysfunction. Patients receiving efavirenz-based HAART showed a significant increase in $\mathrm{NAA} / \mathrm{Cr}$ ratio compared with the other two groups (Winston et al., 2010). This finding is of interest because patients taking efavirenz did not show marked improvement in their cerebral function, despite exhibiting greater neuronal recovery assessed by NAA/Cr ratio compared with patients in other groups. It is expected that an increase in neuronal recovery would correlate with improved CNS function, yet it did not in this study, suggesting that either NAA/Cr ratio is not a good measure of neuronal recovery or neuronal integrity per se does not correlate with neurocognitive function. One could argue that suboptimal dosing could be responsible for HAND, but a cross-sectional study in Malawian adults suggests this is not the case, as asymptomatic HAND was reported in $55 \%$ of patients who had therapeutic plasma levels of efavirenz (Kelly et al., 2014). Furthermore, patients with subtherapeutic levels of plasma efavirenz had a global deficit score $<0.6$, which is consistent with normal neuropsychological function (Kelly et al., 2014). Overall, it can be inferred from these studies that there is increased incidence of mild HAND in the HAART era and that efavirenz may be involved in the worsening of neurocognitive function.

\section{Summary of Key Points}

People are living longer with HIV and neuropsychiatric adverse events (NPAE) associated with efavirenz have been shown to persist in some patients even out to two years, the longest time point investigated. NPAEs are more common with efavirenz than with other ARV drugs and are associated with high efavirenz plasma levels. CYP2B6-G516T is a common polymorphism accounting for slow metabolism of efavirenz and resulting in elevated efavirenz plasma levels especially when co-occurring with other fairly common slow-metabolizing CYP2B6 polymorphisms (T983C and C15582T). SNPs in other genes that appear to influence efavirenz pharmacokinetics include CYP2A6, UGT2B7, CYP3A4, CYP3A5, and CAR, though the in vivo data is lacking in many cases. Modifiable factors can influence efavirenz plasma levels with elevated plasma levels being associated with low BMI, high fat meals that lead to increased absorption, ingestion of grapefruit or sweet orange juice which contain components that potently inhibit the ABCCG2 transporter, and use of medications that potently inhibit the efavirenz metabolizing enzymes CYP3A4 (e.g., the protease inhibitor ritonavir and antifungals ketoconazole, voriconazole) and CYP2B6 (e.g., the antiplatelet agent clopidogrel). Nonmodifiable factors that can influence efavirenz plasma levels include age, with adults having slower clearance and thus longer half-lives than children, and ethnicity due to a range of SNPs resulting in Caucasians and Asians having on average lower plasma levels than Hispanics which have intermediate levels and blacks which have the highest levels. At the receptor level, efavirenz has been shown to interact directly with $5-\mathrm{HT}_{2 \mathrm{~A}}$, $5-\mathrm{HT}_{2 \mathrm{C}}, 5-\mathrm{HT}_{3}, 5-\mathrm{HT}_{6}, \mathrm{M}_{1}, \mathrm{M}_{3}$, and $\mathrm{GABA}_{\mathrm{A}}$ receptors, as well as with DAT, SERT, and VMAT $\mathrm{VM}_{2}$ transporters, and to a lesser extent MAO-A and the 5- $\mathrm{HT}_{2 \mathrm{~B}}$ receptor, which may not only account for its propensity to produced NPAEs but also its attractiveness for recreational use. The predominate behavioral profile of efavirenz is most consistent with interactions at the serotonin $5-\mathrm{HT}_{2 \mathrm{~A}}$ receptor and a hallucinogen-like profile. Efavirenz or its 8-hydroxymetabolite may indirectly modulate monoaminergic neurotransmission by altering mitochondrial function and inducing immune-inflammatory-redox dysfunction. Over the long-term efavirenz appears to worsen neurocognitive function in HIV patients and may be associated with a high prevalence of HAND in asymptomatic HIV patients. 


\section{Authorship Contributions}

Wrote or contributed to the writing of the manuscript: Dalwadi, Ozuna, Harvey, Viljoen, Schetz.

\section{References}

Allavena C, Le Moal G, Michau C, Chiffoleau A, and Raffi F (2006) Neuropsychiatric adverse events after switching from an antiretroviral regimen containing efavirenz without tenofovir to an efavirenz regimen containing tenofovir: a report of nine cases. Antivir Ther 11:263-265.

Apostolova N, Blas-Garcia A, Galindo MJ, and Esplugues JV (2017) Efavirenz: what is known about the cellular mechanisms responsible for its adverse effects. Eur $J$ Pharmacol 812:163-173.

Apostolova N, Funes HA, Blas-Garcia A, Alegre F, Polo M, and Esplugues JV (2015) Involvement of nitric oxide in the mitochondrial action of efavirenz: a differential effect on neurons and glial cells. J Infect Dis 211:1953-1958.

Arab-Alameddine M, Di Iulio J, Buclin T, Rotger M, Lubomirov R, Cavassini M, Fayet A, Décosterd LA, Eap CB, Biollaz J, et al.; Swiss HIV Cohort Study (2009) Pharmacogenetics-based population pharmacokinetic analysis of efavirenz in HIV 1-infected individuals. Clin Pharmacol Ther 85:485-494.

Arenas-Pinto A, Grund B, Sharma S, Martinez E, Cummins N, Fox J, Klingman K, Sedlacek D, Collins S, Flynn P, et al. (2016) Increased risk of suicidal behaviour with use of efavirenz: results from START trial, in 21st World AIDS Conferences; July 18-22 2016; Durban, South Africa.

Ariyoshi N, Ohara M, Kaneko M, Afuso S, Kumamoto T, Nakamura H, Ishii I, Ishikawa T, and Kitada M (2011) Q172H replacement overcomes effects on the metabolism of cyclophosphamide and efavirenz caused by CYP2B6 variant with Arg262. Drug Metab Dispos 39:2045-2048.

Avery LB, Sacktor N, McArthur JC, and Hendrix CW (2013) Protein-free efavirenz concentrations in cerebrospinal fluid and blood plasma are equivalent: applying the law of mass action to predict protein-free drug concentration. Antimicrob Agents Chemother 57:1409-1414.

Barak S (2009) Modeling cholinergic aspects of schizophrenia: focus on the antimuscarinic syndrome. Behav Brain Res 204:335-351.

Bélanger AS, Caron P, Harvey M, Zimmerman PA, Mehlotra RK, and Guillemette C (2009) Glucuronidation of the antiretroviral drug efavirenz by UGT2B7 and an in vitro investigation of drug-drug interaction with zidovudine. Drug Metab Dispos 37:1793-1796.

Benedek I, Joshi A, Fiske W, White S, Stevenson D, and Banerjee G (1998) Pharmacokinetic interaction between efavirenz (EFV) and rifampicin (RIF) in healthy volunteers, in XII International Conference on AIDS; June 28 to July 3; Geneva, Switzerland. Abstract 42280 .

Bertrand J, Verstuyft C, Chou M, Borand L, Chea P, Nay KH, Blanc FX, Mentré F, and Taburet AM; CAMELIA (ANRS 1295-CIPRA KH001) Study Group (2014) Dependence of efavirenz- and rifampicin-isoniazid-based antituberculosis treatment drug-drug interaction on CYP2B6 and NAT2 genetic polymorphisms: ANRS 12154 study in Cambodia. J Infect Dis 209:399-408.

Best BM, Koopmans PP, Letendre SL, Capparelli EV, Rossi SS, Clifford DB, Collier AC, Gelman BB, Mbeo G, McCutchan JA, et al.; CHARTER Group (2011) Efaviren concentrations in CSF exceed IC50 for wild-type HIV. J Antimicrob Chemother 66: 354-357.

Bienvenu E, Swart M, Dandara C, and Ashton M (2014) The role of genetic polymorphisms in cytochrome P450 and effects of tuberculosis co-treatment on the predictive value of CYP2B6 SNPs and on efavirenz plasma levels in adult HIV patients. Antiviral Res 102:44-53.

Brand SJ, Moller M, and Harvey BH (2015) A review of biomarkers in mood and psychotic disorders: a dissection of clinical vs. preclinical correlates. Curr Neuropharmacol 13:324-368.

Brook I (1987) Approval of zidovudine (AZT) for acquired immunodeficiency syndrome. A challenge to the medical and pharmaceutical communities. JAMA 258:1517.

Bumpus NN, Kent UM, and Hollenberg PF (2006) Metabolism of efavirenz and 8-hydroxyefavirenz by $\mathrm{P} 4502 \mathrm{~B} 6$ leads to inactivation by two distinct mechanisms. $J$ Pharmacol Exp Ther 318:345-351.

Burger D, van der Heiden I, la Porte C, van der Ende M, Groeneveld P, Richter C, Koopmans P, Kroon F, Sprenger H, Lindemans J, et al. (2006) Interpatient variability in the pharmacokinetics of the HIV non-nucleoside reverse transcriptase inhibitor efavirenz: the effect of gender, race, and CYP2B6 polymorphism. $\mathrm{Br} J$ Clin Pharmacol 61:148-154.

Buti M, Gane E, Seto WK, Chan HL, Chuang WL, Stepanova T, Hui AJ, Lim YS, Mehta R, Janssen HL, et al.; GS-US-320-0108 Investigators (2016) Tenofovir alafenamide versus tenofovir disoproxil fumarate for the treatment of patients with HBeAg-negative chronic hepatitis B virus infection: a randomised, double-blind, phase 3, non-inferiority trial [published correction appears in Lancet Gastroenterol Hepatol (2016)]. Lancet Gastroenterol Hepatol 1:196-206.

Cabrera SE, Santos D, Valverde MP, Domínguez-Gil A, González F, Luna G, and García MJ (2009) Influence of the cytochrome P450 $2 \mathrm{~B} 6$ genotype on population pharmacokinetics of efavirenz in human immunodeficiency virus patients. Antimicrob Agents Chemother 53:2791-2798.

Cabrera Figueroa S, Iglesias Gómez A, Sánchez Martín A, de la Paz Valverde Merino M, Domínguez-Gil Hurlé A, and Cordero Sánchez M (2010) Long-term efficacy and safety of efavirenz dose reduction to $200 \mathrm{mg}$ once daily in a Caucasian patient with HIV. Clin Drug Investig 30:405-411.

Cadogan M and Dalgleish AG (2008) HIV immunopathogenesis and strategies for intervention. Lancet Infect Dis 8:675-684.

Carruthers SP, Gurvich CT, and Rossell SL (2015) The muscarinic system, cognition and schizophrenia. Neurosci Biobehav Rev 55:393-402.

Catalan J, Harding R, Sibley E, Clucas C, Croome N, and Sherr L (2011) HIV in fection and mental health: suicidal behaviour-systematic review. Psychol Health Med 16:588-611.
Cavalcante GI, Capistrano VL, Cavalcante FS, Vasconcelos SM, Macêdo DS, Sousa FC, Woods DJ, and Fonteles MM (2010) Implications of efavirenz for neuropsychiatry: a review. Int $J$ Neurosci 120:739-745.

Chan HL, Fung S, Seto WK, Chuang WL, Chen CY, Kim HJ, Hui AJ, Janssen HL, Chowdhury A, Tsang TY, et al.; GS-US-320-0110 Investigators (2016) Tenofovir alafenamide versus tenofovir disoproxil fumarate for the treatment of $\mathrm{HBeAg}$ positive chronic hepatitis B virus infection: a randomised, double-blind, phase 3 , non-inferiority trial [published correction appears in Lancet Gastroenterol Hepatol (2016)]. Lancet Gastroenterol Hepatol 1:185-195.

Chen J, Sun J, Ma Q, Yao Y, Wang Z, Zhang L, Li L, Sun F, and Lu H (2010) CYP2B6 polymorphism and nonnucleoside reverse transcriptase inhibitor plasma concentrations in Chinese HIV-infected patients. Ther Drug Monit 32:573-578.

Ciccarelli N, Fabbiani M, Di Giambenedetto S, Fanti I, Baldonero E, Bracciale L, Tamburrini E, Cauda R, De Luca A, and Silveri MC (2011) Efavirenz associated with cognitive disorders in otherwise asymptomatic HIV-infected patients. Neurology 76:1403-1409.

Clifford DB, Evans S, Yang Y, Acosta EP, Goodkin K, Tashima K, Simpson D, Dorfman D, Ribaudo H, and Gulick RM (2005) Impact of efavirenz on neuropsychological performance and symptoms in HIV-infected individuals. Ann Intern Med 143:714-721.

Coffie PA, Tonwe-Gold B, Tanon AK, Amani-Bosse C, Bédikou G, Abrams EJ, Dabis F, and Ekouevi DK (2010) Incidence and risk factors of severe adverse events with nevirapine-based antiretroviral therapy in HIV-infected women. MTCT-Plus program, Abidjan, Côte d'Ivoire. BMC Infect Dis 10:188.

Cohen C, Wohl D, Arribas JR, Henry K, Van Lunzen J, Bloch M, Towner W, Wilkins E, Ebrahimi R, Porter D, et al. (2014) Week 48 results from a randomized clinical trial of rilpivirine/emtricitabine/tenofovir disoproxil fumarate vs. efavirenz/ emtricitabine/tenofovir disoproxil fumarate in treatment-naive HIV-1-infected adults. AIDS 28:989-997.

Cohen K, Grant A, Dandara C, McIlleron H, Pemba L, Fielding K, Charalombous S, Churchyard G, Smith P, and Maartens G (2009) Effect of rifampicin-based antitubercular therapy and the cytochrome P450 2B6 516G $>$ T polymorphism on efavirenz concentrations in adults in South Africa. Antivir Ther 14:687-695.

Colebunders R, Hilbrands R, De Roo A, and Pelgrom J (2002) Neuropsychiatric reaction induced by abacavir. Am J Med 113:616.

Cortes CP, Siccardi M, Chaikan A, Owen A, Zhang G, and la Porte CJ (2013) Correlates of efavirenz exposure in Chilean patients affected with human immunodeficiency virus reveals a novel association with a polymorphism in the constitutive androstane receptor. Ther Drug Monit 35:78-83.

Cressey TR and Lallemant M (2007) Pharmacogenetics of antiretroviral drugs for the treatment of HIV-infected patients: an update. Infect Genet Evol 7:333-342.

Csajka C, Marzolini C, Fattinger K, Décosterd LA, Fellay J, Telenti A, Biollaz J, and Buclin T (2003) Population pharmacokinetics and effects of efavirenz in patients with human immunodeficiency virus infection. Clin Pharmacol Ther 73:20-30.

Cummins NW, Neuhaus J, Chu H, Neaton J, Wyen C, Rockstroh JK, Skiest DJ, Boyd MA, Khoo S, Rotger M, et al.; INSIGHT Study Group (2015) Investigation of efavirenz discontinuation in multi-ethnic populations of $\mathrm{HIV}$-positive individuals by genetic analysis. EBioMedicine 2:706-712.

Dabaghzadeh F, Ghaeli P, Khalili H, Alimadadi A, Jafari S, Akhondzadeh S, and Khazaeipour Z (2013) Cyproheptadine for prevention of neuropsychiatric adverse effects of efavirenz: a randomized clinical trial. AIDS Patient Care STDS 27:146-154.

Dabaghzadeh F, Khalili H, Ghaeli P, and Dashti-Khavidaki S (2012) Potential benefits of cyproheptadine in HIV-positive patients under treatment with antiretroviral drugs including efavirenz. Expert Opin Pharmacother 13:2613-2624

Dalwadi DA, Kim S, Amdani SM, Chen Z, Huang RQ, and Schetz JA (2016) Molecular mechanisms of serotonergic action of the HIV-1 antiretroviral efavirenz. Pharmacol Res 110:10-24.

Damle B, LaBadie R, Crownover P, and Glue P (2008) Pharmacokinetic interactions of efavirenz and voriconazole in healthy volunteers. Br J Clin Pharmacol 65:523-530.

Davis GP, Surratt HL, Levin FR, and Blanco C (2014a) Antiretroviral medication: an emerging category of prescription drug misuse. Am $J$ Addict 23:519-525.

Davis J, Moylan S, Harvey BH, Maes M, and Berk M (2014b) Neuroprogression in schizophrenia: pathways underpinning clinical staging and therapeutic corollaries. Aust N Z J Psychiatry 48:512-529.

Decker CJ, Laitinen LM, Bridson GW, Raybuck SA, Tung RD, and Chaturvedi PR (1998) Metabolism of amprenavir in liver microsomes: role of CYP3A4 inhibition for drug interactions. J Pharm Sci 87:803-807.

Decloedt EH and Maartens G (2013) Neuronal toxicity of efavirenz: a systematic review. Expert Opin Drug Saf 12:841-846.

Delport A, Harvey BH, Petzer A, and Petzer JP (2017) Methylene blue and its analogues as antidepressant compounds. Metab Brain Dis 32:1357-1382.

Desta Z, Saussele T, Ward B, Blievernicht J, Li L, Klein K, Flockhart DA, and Zanger UM (2007) Impact of CYP2B6 polymorphism on hepatic efavirenz metabolism in vitro. Pharmacogenomics 8:547-558.

DHHS (2017) Guidelines for the use of antiretroviral agents in HIV-1-infected adults and adolescents. Panel on Antiretroviral Guidelines for Adults and Adolescents.

Dhoro M, Ngara B, Kadzirange G, Nhachi C, and Masimirembwa C (2013) Genetic variants of drug metabolizing enzymes and drug transporter (ABCB1) as possible biomarkers for adverse drug reactions in an HIV/AIDS cohort in Zimbabwe. Curr HIV Res 11:481-490.

Dhoro M, Zvada S, Ngara B, Nhachi C, Kadzirange G, Chonzi P, and Masimirembwa C (2015) CYP2B6*6, CYP2B6*18, Body weight and sex are predictors of efavirenz pharmacokinetics and treatment response: population pharmacokinetic modeling in an HIV/AIDS and TB cohort in Zimbabwe. BMC Pharmacol Toxicol 16:4

di Iulio J, Fayet A, Arab-Alameddine M, Rotger M, Lubomirov R, Cavassini M, Furrer H, Günthard HF, Colombo S, Csajka C, et al.; Swiss HIV Cohort Study (2009) In vivo analysis of efavirenz metabolism in individuals with impaired CYP2A6 function. Pharmacogenet Genomics 19:300-309.

Dirson G, Fernandez C, Hindlet P, Roux F, German-Fattal M, Gimenez F, and Farinotti R (2006) Efavirenz does not interact with the ABCB1 transporter at the blood-brain barrier. Pharm Res 23:1525-1532. 
Dooley KE, Denti P, Martinson N, Cohn S, Mashabela F, Hoffmann J, Haas DW, Hull J, Msandiwa R, Castel S, et al; TSHEPISO Study Team (2015) Pharmacokinetics of efavirenz and treatment of HIV-1 among pregnant women with and without tuberculosis coinfection. J Infect Dis 211:197-205.

Dresser GK, Bailey DG, Leake BF, Schwarz UI, Dawson PA, Freeman DJ, and Kim RB (2002) Fruit juices inhibit organic anion transporting polypeptide-mediated drug uptake to decrease the oral availability of fexofenadine. Clin Pharmacol Ther 71:11-20.

Dueweke TJ, Poppe SM, Romero DL, Swaney SM, So AG, Downey KM, Althaus IW, Reusser F, Busso M, Resnick L, et al. (1993) U-90152, a potent inhibitor of human immunodeficiency virus type 1 replication. Antimicrob Agents Chemother 37: $1127-1131$.

Eiden C, Peyriere H, Peytavin G, and Reynes J (2011) Severe insomnia related to high concentrations of raltegravir. AIDS 25:725-727.

Evans J, Swart M, Soko N, Wonkam A, Huzair F, and Dandara C (2015) A global health diagnostic for personalized medicine in resource-constrained world settings: a simple PCR-RFLP method for genotyping CYP2B6 g.15582C $>\mathrm{T}$ and science and policy relevance for optimal use of antiretroviral drug efavirenz. OMICS 19: $332-338$

Faucette SR, Wang H, Hamilton GA, Jolley SL, Gilbert D, Lindley C, Yan B, Negishi M, and LeCluyse EL (2004) Regulation of CYP2B6 in primary human hepatocytes by prototypical inducers. Drug Metab Dispos 32:348-358.

Fellay J, Marzolini C, Meaden ER, Back DJ, Buclin T, Chave JP, Decosterd LA, Furrer H, Opravil M, Pantaleo G, et al.; Swiss HIV Cohort Study (2002) Response to antiretroviral treatment in HIV-1-infected individuals with allelic variants of the multidrug resistance transporter 1: a pharmacogenetics study. Lancet 359:30-36.

Fettiplace A, Stainsby C, Winston A, Givens N, Puccini S, Vannappagari V, Hsu R, Fusco J, Quercia R, Aboud M, et al. (2017) Psychiatric symptoms in patients receiving dolutegravir. J Acquir Immune Defic Syndr 74:423-431.

Fischl MA, Richman DD, Hansen N, Collier AC, Carey JT, Para MF, Hardy WD, Dolin R, Powderly WG, Allan JD, et al.; The AIDS Clinical Trials Group (1990) The safety and efficacy of zidovudine (AZT) in the treatment of subjects with mildly symptomatic human immunodeficiency virus type 1 (HIV) infection. A doubleblind, placebo-controlled trial. Ann Intern Med 112:727-737.

Fiske W, Benedek IH, Joseph JL, Dennis S, O’Dea R, Hsu A, and Kornhauser DM (1998) Pharmacokinetics of efavirenz (EFV) and ritonavir (RIT) after multiple oral doses in healthy volunteers, in 12th World AIDS Conference; June 28 to July 3 Geneva, Switzerland. Abstract 42269.

Fitch WL, Tran T, Young M, Liu L, and Chen Y (2009) Revisiting the metabolism of ketoconazole using accurate mass. Drug Metab Lett 3:191-198.

Fleisher B, Unum J, Shao J, and An G (2015) Ingredients in fruit juices interact with dasatinib through inhibition of BCRP: a new mechanism of beverage-drug interaction. J Pharm Sci 104:266-275.

Fletcher CV, Brundage RC, Fenton T, Alvero CG, Powell C, Mofenson LM, and Spector SA (2008) Pharmacokinetics and pharmacodynamics of efavirenz and nelfinavir in HIV-infected children participating in an area-under-the-curve controlled trial. Clin Pharmacol Ther 83:300-306.

Flexner C (2000) Dual protease inhibitor therapy in HIV-infected patients: pharmacologic rationale and clinical benefits. Annu Rev Pharmacol Toxicol 40:649-674.

Flexner C (2011) Antiretroviral agents and treatment of HIV infection, in Goodman \& Gilman's The Pharmacological Basis of Therapeutics (Brunton LC, Chabner BA, and Knollmann BC eds) pp 2084, McGraw-Hill Medical Publishing Division, New York

Ford N, Mofenson L, Kranzer K, Medu L, Frigati L, Mills EJ, and Calmy A (2010) Safety of efavirenz in first-trimester of pregnancy: a systematic review and metaanalysis of outcomes from observational cohorts. AIDS 24:1461-1470.

Foster R, Olajide D, and Everall IP (2003) Antiretroviral therapy-induced psychosis: case report and brief review of the literature. HIV Med 4:139-144.

Foster R, Taylor C, and Everall IP (2004) More on abacavir-induced neuropsychiatric reactions. AIDS 18:2449.

Friedland G, Khoo S, Jack C, and Lalloo U (2006) Administration of efavirenz $(600 \mathrm{mg} /$ day) with rifampicin results in highly variable levels but excellent clinical outcomes in patients treated for tuberculosis and HIV. J Antimicrob Chemother 58: 1299-1302.

Fumaz CR, Munoz-Moreno JA, Molto J, Negredo E, Ferrer MJ, Sirera G, PerezAlvarez N, Gomez G, Burger D, and Clotet B (2005) Long-term neuropsychiatric disorders on efavirenz-based approaches: quality of life, psychologic issues, and adherence. J Acquir Immune Defic Syndr 38:560-565.

Fumaz CR, Tuldrà A, Ferrer MJ, Paredes R, Bonjoch A, Jou T, Negredo E, Romeu J, Sirera G, Tural C, et al. (2002) Quality of life, emotional status, and adherence of HIV-1-infected patients treated with efavirenz versus protease inhibitorcontaining regimens. J Acquir Immune Defic Syndr 29:244-253.

Funes HA, Blas-Garcia A, Esplugues JV, and Apostolova N (2015) Efavirenz alters mitochondrial respiratory function in cultured neuron and glial cell lines. $J$ Antimicrob Chemother 70:2249-2254.

Gandhi M, Benet LZ, Bacchetti P, Kalinowski A, Anastos K, Wolfe AR, Young M, Cohen M, Minkoff H, Gange SJ, et al.; Women's Interagency HIV Study (2009) Nonnucleoside reverse transcriptase inhibitor pharmacokinetics in a large unselected cohort of HIV-infected women. J Acquir Immune Defic Syndr 50:482-491.

Gandhi M, Greenblatt RM, Bacchetti P, Jin C, Huang Y, Anastos K, Cohen M, Dehovitz JA, Sharp GB, Gange SJ, et al.; Women's Interagency HIV Study (2012) A single-nucleotide polymorphism in CYP2B6 leads to $>3$-fold increases in efavirenz concentrations in plasma and hair among HIV-infected women. J Infect Dis 206 1453-1461.

Garcia EE, Smith RL, and Sanders-Bush E (2007) Role of G(q) protein in behavioral effects of the hallucinogenic drug 1-(2,5-dimethoxy-4-iodophenyl)-2-aminopropane Neuropharmacology 52:1671-1677.

Garcia-Cazorla A, Duarte S, Serrano M, Nascimento A, Ormazabal A, Carrilho I, Briones P, Montoya J, Garesse R, Sala-Castellvi P, et al. (2008) Mitochondrial diseases mimicking neurotransmitter defects. Mitochondrion 8:273-278.
Gatanaga H, Hayashida T, Tsuchiya K, Yoshino M, Kuwahara T, Tsukada H, Fujimoto K, Sato I, Ueda M, Horiba M, et al. (2007) Successful efavirenz dose reduction in HIV type 1 -infected individuals with cytochrome P450 2B6*6 and *26. Clin Infect Dis 45:1230-1237.

Gatch MB, Kozlenkov A, Huang RQ, Yang W, Nguyen JD, Gonzalez-Maeso J, Rice KC, France CP, Dillon GH, Forster MJ, et al. (2013) The HIV antiretroviral drug efavirenz has LSD-like properties. Neuropsychopharmacology 38:2373-2384.

Gounden V, van Niekerk C, Snyman T, and George JA (2010) Presence of the CYP2B6 516G $>$ T polymorphism, increased plasma Efavirenz concentrations and early neuropsychiatric side effects in South African HIV-infected patients. AIDS Res Ther 7:32.

Gray J and Young B (2009) Acute onset insomnia associated with the initiation of raltegravir: a report of two cases and literature review. AIDS Patient Care STDS 23:689-690.

Grelotti DJ, Closson EF, and Mimiaga MJ (2013) Pretreatment antiretroviral exposure from recreational use. Lancet Infect Dis 13:10-12.

Gulick RM, Mellors JW, Havlir D, Eron JJ, Gonzalez C, McMahon D, Richman DD, Valentine FT, Jonas L, Meibohm A, et al. (1997) Treatment with indinavir, zidovudine, and lamivudine in adults with human immunodeficiency virus infection and prior antiretroviral therapy. $N$ Engl J Med 337:734-739.

Gulick RM, Ribaudo HJ, Shikuma CM, Lustgarten S, Squires KE, Meyer WA III, Acosta EP, Schackman BR, Pilcher CD, Murphy RL, et al. AIDS Clinical Trials Group Study A5095 Team (2004) Triple-nucleoside regimens versus efavirenzcontaining regimens for the initial treatment of HIV-1 infection. $N$ Engl J Med 350: $1850-1861$

Gutiérrez F, Navarro A, Padilla S, Antón R, Masiá M, Borrás J, and Martín-Hidalgo A (2005) Prediction of neuropsychiatric adverse events associated with long-term efavirenz therapy, using plasma drug level monitoring. Clin Infect Dis 41:1648-1653.

Haas DW, Kwara A, Richardson DM, Baker P, Papageorgiou I, Acosta EP, Morse GD, and Court MH (2014) Secondary metabolism pathway polymorphisms and plasma efavirenz concentrations in HIV-infected adults with CYP2B6 slow metabolizer genotypes. J Antimicrob Chemother 69:2175-2182.

Haas DW, Ribaudo HJ, Kim RB, Tierney C, Wilkinson GR, Gulick RM, Clifford DB, Hulgan T, Marzolini C, and Acosta EP (2004) Pharmacogenetics of efavirenz and central nervous system side effects: an adult AIDS clinical trials group study. AIDS 18:2391-2400

Haas DW, Smeaton LM, Shafer RW, Robbins GK, Morse GD, Labbe L, Wilkinson GR Clifford DB, D'Aquila RT, De Gruttola V, et al. (2005) Pharmacogenetics of longterm responses to antiretroviral regimens containing efavirenz and/or nelfinavir: an adult aids clinical trials group study. J Infect Dis 192:1931-1942.

Habtewold A, Amogne W, Makonnen E, Yimer G, Nylén H, Riedel KD, Aderaye G, Bertilsson L, Burhenne J, Diczfalusy U, et al. (2013) Pharmacogenetic and pharmacokinetic aspects of CYP3A induction by efavirenz in HIV patients. Pharmacogenomics $J$ 13:484-489.

Halberstadt AL and Geyer MA (2011) Multiple receptors contribute to the behavioral effects of indoleamine hallucinogens. Neuropharmacology 61:364-381.

Hammer SM, Squires KE, Hughes MD, Grimes JM, Demeter LM, Currier JS, Eron JJ Jr, Feinberg JE, Balfour HH Jr, Deyton LR, et al. (1997) A controlled trial of two nucleoside analogues plus indinavir in persons with human immunodeficiency virus infection and CD4 cell counts of 200 per cubic millimeter or less. AIDS clinica trials group 320 study team. N Engl J Med 337:725-733.

Harris M, Larsen G, and Montaner JS (2008) Exacerbation of depression associated with starting raltegravir: a report of four cases. AIDS 22:1890-1892.

Harvey BH, Meyer CL, Gallichio VS, and Manji HK (2002) Lithium salts in AIDS and AIDS-related dementia. Psychopharmacol Bull 36:5-26.

Hasse B, Günthard HF, Bleiber G, and Krause M (2005) Efavirenz intoxication due to slow hepatic metabolism. Clin Infect Dis 40:e22-e23.

Heaton RK, Franklin DR, Ellis RJ, McCutchan JA, Letendre SL, Leblanc S, Corkran SH, Duarte NA, Clifford DB, Woods SP, et al.; CHARTER Group; HNRC Group (2011) HIV-associated neurocognitive disorders before and during the era of combination antiretroviral therapy: differences in rates, nature, and predictors. $J$ Neurovirol 17:3-16.

Heil SG, van der Ende ME, Schenk PW, van der Heiden I, Lindemans J, Burger D, and van Schaik RH (2012) Associations between ABCB1, CYP2A6, CYP2B6, CYP2D6, and CYP3A5 alleles in relation to efavirenz and nevirapine pharmacokinetics in HIV-infected individuals. Ther Drug Monit 34:153-159.

Hirt D, Urien S, Olivier M, Peyrière H, Nacro B, Diagbouga S, Zoure E, Rouet F, Hien $\mathrm{H}$, Msellati $\mathrm{P}$, et al. (2009) Is the recommended dose of efavirenz optimal in young West African human immunodeficiency virus-infected children? Antimicrob Agents Chemother 53:4407-4413.

Hitzl M, Drescher S, van der Kuip H, Schäffeler E, Fischer J, Schwab M, Eichelbaum M, and Fromm MF (2001) The C3435T mutation in the human MDR1 gene is associated with altered efflux of the P-glycoprotein substrate rhodamine 123 from CD56+ natural killer cells. Pharmacogenetics 11:293-298.

Ho DD (1995) Time to hit HIV, early and hard. N Engl J Med 333:450-451.

Hofmann MH, Blievernicht JK, Klein K, Saussele T, Schaeffeler E, Schwab M, and Zanger UM (2008) Aberrant splicing caused by single nucleotide polymorphism c.516G $>$ T $[\mathrm{Q} 172 \mathrm{H}]$, a marker of CYP2B6*6, is responsible for decreased expression and activity of CYP2B6 in liver. $J$ Pharmacol Exp Ther 325:284-292.

Holzinger ER, Grady B, Ritchie MD, Ribaudo HJ, Acosta EP, Morse GD, Gulick RM, Robbins GK, Clifford DB, Daar ES, et al. (2012) Genome-wide association study of plasma efavirenz pharmacokinetics in AIDS clinical trials group protocols implicates several CYP2B6 variants. Pharmacogenet Genomics 22:858-867.

Honda Y, Ushigome F, Koyabu N, Morimoto S, Shoyama Y, Uchiumi T, Kuwano M, Ohtani H, and Sawada Y (2004) Effects of grapefruit juice and orange juice components on P-glycoprotein- and MRP2-mediated drug efflux. $\mathrm{Br} J$ Pharmacol 143 : 856-864

Huang R, Chen Z, Dolan S, Schetz JA, and Dillon GH (2017) The dual modulatory effects of efavirenz on GABA $\mathrm{A}_{\mathrm{A}}$ receptors are mediated via two distinct sites. Neuropharmacology 121:167-178. 
Hulgan T, Morrow J, D'Aquila RT, Raffanti S, Morgan M, Rebeiro P, and Haas DW (2003) Oxidant stress is increased during treatment of human immunodeficiency virus infection. Clin Infect Dis 37:1711-1717.

Inciardi JA, Surratt HL, Kurtz SP, and Cicero TJ (2007) Mechanisms of prescription drug diversion among drug-involved club- and street-based populations. Pain Med 8:171-183.

Jalali F, Afshari R, and Babaei A (2014) Smoking crushed hyoscine/scopolamine tablets as drug abuse. Subst Use Misuse 49:793-797.

Janneh O, Chandler B, Hartkoorn R, Kwan WS, Jenkinson C, Evans S, Back DJ, Owen A, and Khoo SH (2009) Intracellular accumulation of efavirenz and nevirapine is independent of P-glycoprotein activity in cultured CD4 T cells and primary human lymphocytes. J Antimicrob Chemother 64:1002-1007.

Jiang F, Desta Z, Shon JH, Yeo CW, Kim HS, Liu KH, Bae SK, Lee SS, Flockhart DA, and Shin JG (2013) Effects of clopidogrel and itraconazole on the disposition of efavirenz and its hydroxyl metabolites: exploration of a novel CYP2B6 phenotyping index. Br J Clin Pharmacol 75:244-253.

Joly V and Yeni P (2000) New trends in antiretroviral therapy for HIV infection. Eur J Intern Med 11:301-308.

Kajita J, Kuwabara T, Kobayashi H, and Kobayashi S (2000) CYP3A4 is mainly responsibile for the metabolism of a new vinca alkaloid, vinorelbine, in human liver microsomes. Drug Metab Dispos 28:1121-1127.

Kappelhoff BS, van Leth F, Robinson PA, MacGregor TR, Baraldi E, Montella F, Uip DE, Thompson MA, Russell DB, Lange JM, et al.; 2NN Study Group (2005) Are adverse events of nevirapine and efavirenz related to plasma concentrations? Antivir Ther 10:489-498.

Karalliedde LD, Clarke S, Collignon U, and Karalliedde J (2010) Drugs to treat infections, antivirals and antiretrovirals, Adverse Drug Interactions: A Handbook for Prescribers, CRC Press, Francis \& Taylor Group, Boca Raton, FL.

Kaul S, Ji P, Lu M, Nguyen KL, Shangguan T, and Grasela D (2010) Bioavailability in healthy adults of efavirenz capsule contents mixed with a small amount of food. Am J Health Syst Pharm 67:217-222.

Kelly CM, van Oosterhout JJ, Ngwalo C, Stewart RC, Benjamin L, Robertson KR, Khoo S, Allain TJ, and Solomon T (2014) HIV associated neurocognitive disorders (HAND) in Malawian adults and effect on adherence to combination anti-retroviral therapy: a cross sectional study. PLoS One 9:e98962.

Kinloch-De Loës S, Hirschel BJ, Hoen B, Cooper DA, Tindall B, Carr A, Saurat JH, Clumeck N, Lazzarin A, Mathiesen L, et al. (1995) A controlled trial of zidovudine in primary human immunodeficiency virus infection. $N$ Engl J Med 333:408-413.

Klein K, Lang T, Saussele T, Barbosa-Sicard E, Schunck WH, Eichelbaum M, Schwab M, and Zanger UM (2005) Genetic variability of CYP2B6 in populations of African and Asian origin: allele frequencies, novel functional variants, and possible implications for anti-HIV therapy with efavirenz. Pharmacogenet Genomics 15:861-873.

Koudriakova T, Iatsimirskaia E, Utkin I, Gangl E, Vouros P, Storozhuk E, Orza D, Marinina J, and Gerber N (1998) Metabolism of the human immunodeficiency virus protease inhibitors indinavir and ritonavir by human intestinal microsomes and expressed cytochrome P4503A4/3A5: mechanism-based inactivation of cytochrome P4503A by ritonavir. Drug Metab Dispos 26:552-561.

Kumar GN, Rodrigues AD, Buko AM, and Denissen JF (1996) Cytochrome P450 mediated metabolism of the HIV-1 protease inhibitor ritonavir (ABT-538) in human liver microsomes. J Pharmacol Exp Ther 277:423-431.

Kwara A, Lartey M, Sagoe KW, Kenu E, and Court MH (2009) CYP2B6, CYP2A6 and UGT2B7 genetic polymorphisms are predictors of efavirenz mid-dose concentration in HIV-infected patients. AIDS 23:2101-2106.

Kwara A, Tashima KT, Dumond JB, Poethke P, Kurpewski J, Kashuba AD, Court MH, and Greenblatt DJ (2011) Modest but variable effect of rifampin on steadystate plasma pharmacokinetics of efavirenz in healthy African-American and Caucasian volunteers. Antimicrob Agents Chemother 55:3527-3533.

Lafay-Chebassier C, Chavant F, Favrelière S, Pizzoglio V, and Pérault-Pochat MC; French Association of Regional Pharmacovigilance Centers (2015) Drug-induced depression: a case/non case study in the French pharmacovigilance database. Therapie 70:425-432.

Lamba V, Lamba J, Yasuda K, Strom S, Davila J, Hancock ML, Fackenthal JD, Rogan PK, Ring B, Wrighton SA, et al. (2003) Hepatic CYP2B6 expression: gender and ethnic differences and relationship to CYP2B6 genotype and CAR (constitutive androstane receptor) expression. J Pharmacol Exp Ther 307:906-922.

Lamorde M, Byakika-Kibwika P, Tamale WS, Kiweewa F, Ryan M, Amara A, Tjia J, Back D, Khoo S, Boffito M, et al. (2012) Effect of food on the steady-state pharmacokinetics of tenofovir and emtricitabine plus efavirenz in Ugandan adults. Aids Res Treat 2012:105980.

Lang JP, Halleguen O, Picard A, Lang JM, and Danion JM (2001) Apropos of atypical melancholia with Sustiva (efavirenz). Encephale 27:290-293.

Lang T, Klein K, Richter T, Zibat A, Kerb R, Eichelbaum M, Schwab M, and Zanger UM (2004) Multiple novel nonsynonymous CYP2B6 gene polymorphisms in Caucasians: demonstration of phenotypic null alleles. J Pharmacol Exp Ther 311: 34-43.

la Porte CJ, Sabo JP, Elgadi M, and Cameron DW (2009) Interaction studies of tipranavir-ritonavir with clarithromycin, fluconazole, and rifabutin in healthy volunteers. Antimicrob Agents Chemother 53:162-173.

Larkan F, Wyk V, and Saris J (2010) Of remedies and poisons: recreational use of antiretroviral drugs in the social imagination of South African carers. Afr Sociol Rev 14:62-73.

Larru B, Eby J, and Lowenthal ED (2014) Antiretroviral treatment in HIV-1 infected pediatric patients: focus on efavirenz. Pediatric Health Med Ther 5:29-42.

Letendre S, Marquie-Beck J, Capparelli E, Best B, Clifford D, Collier AC, Gelman BB, McArthur JC, McCutchan JA, Morgello S, et al.; CHARTER Group (2008) Validation of the CNS penetration-effectiveness rank for quantifying antiretrovira penetration into the central nervous system. Arch Neurol 65:65-70.

Leutscher PD, Stecher C, Storgaard M, and Larsen CS (2013) Discontinuation of efavirenz therapy in HIV patients due to neuropsychiatric adverse effects. Scand $J$ Infect Dis 45:645-651.
Li J, Menard V, Benish RL, Jurevic RJ, Guillemette C, Stoneking M, Zimmerman PA, and Mehlotra RK (2012) Worldwide variation in human drug-metabolism enzyme genes CYP2B6 and UGT2B7: implications for HIV/AIDS treatment. Pharmacogenomics 13:555-570.

Lin HL, Kent UM, and Hollenberg PF (2005) The grapefruit juice effect is not limited to cytochrome P450 (P450) 3A4: evidence for bergamottin-dependent inactivation, heme destruction, and covalent binding to protein in $\mathrm{P} 450 \mathrm{~s} 2 \mathrm{~B} 6$ and $3 \mathrm{~A} 5 . J$ Pharmacol Exp Ther 313:154-164.

Lin YG, Chen PH, Chang FY, Wu LT, Liao KY, and Wu TC (2011) Delirium due to scopolamine patch in a 4-year-old boy. J Formos Med Assoc 110:208-211.

Lindbäck S, Vizzard J, Cooper DA, and Gaines H (1999) Long-term prognosis following zidovudine monotherapy in primary human immunodeficiency virus type 1 infection. J Infect Dis 179:1549-1552.

Lindfelt T, O'Brien J, Song JC, Patel R, and Winslow DL (2010) Efavirenz plasma concentrations and cytochrome 2B6 polymorphisms. Ann Pharmacother 44: 1572-1578.

Liu P, Foster G, LaBadie RR, Gutierrez MJ, and Sharma A (2008) Pharmacokinetic interaction between voriconazole and efavirenz at steady state in healthy male subjects. J Clin Pharmacol 48:73-84.

Lochet P, Peyrière H, Lotthé A, Mauboussin JM, Delmas B, and Reynes J (2003) Long-term assessment of neuropsychiatric adverse reactions associated with efavirenz. HIV Med 4:62-66

López-Cortés LF, Ruiz-Valderas R, Viciana P, Alarcón-González A, Gómez-Mateos J, León-Jimenez E, Sarasanacenta M, López-Pua Y, and Pachón J (2002) Pharmacokinetic interactions between efavirenz and rifampicin in HIV-infected patients with tuberculosis. Clin Pharmacokinet 41:681-690.

Lowenhaupt EA, Matson K, Qureishi B, Saitoh A, and Pugatch D (2007) Psychosis in a 12-year-old HIV-positive girl with an increased serum concentration of efavirenz. Clin Infect Dis 45:e128-e130.

Lubomirov R, Colombo S, di Iulio J, Ledergerber B, Martinez R, Cavassini M, Hirschel B, Bernasconi E, Elzi L, Vernazza P, et al.; Swiss HIV Cohort Study (2011) Association of pharmacogenetic markers with premature discontinuation of firstline anti-HIV therapy: an observational cohort study. J Infect Dis 203:246-257.

Ma Q, Forrest A, Rosenkranz SL, Para MF, Yarasheski KE, Reichman RC, and Morse GD; ACTG A5043 Protocol Team, DAIDS, NIH (2008) Pharmacokinetic interaction between efavirenz and dual protease inhibitors in healthy volunteers. Biopharm Drug Dispos 29:91-101.

Ma Q, Vaida F, Wong J, Sanders CA, Kao YT, Croteau D, Clifford DB, Collier AC, Gelman BB, Marra CM, et al.; CHARTER Group (2016) Long-term efavirenz use is associated with worse neurocognitive functioning in HIV-infected patients. $J$ Neurovirol 22:170-178

Maes M, Galecki P, Chang YS, and Berk M (2011) A review on the oxidative and nitrosative stress (O\&NS) pathways in major depression and their possible contribution to the (neuro)degenerative processes in that illness. Prog Neuropsychopharmacol Biol Psychiatry 35:676-692.

Mahy M, Autenrieth CS, Stanecki K, and Wynd S (2014) Increasing trends in HIV prevalence among people aged 50 years and older: evidence from estimates and survey data. AIDS 28 (Suppl 4):S453-S459.

Mallal S, Phillips E, Carosi G, Molina JM, Workman C, Tomazic J, Jägel-Guedes E, Rugina S, Kozyrev O, Cid JF, et al.; PREDICT-1 Study Team (2008) HLA-B*5701 screening for hypersensitivity to abacavir. N Engl J Med 358:568-579.

Manosuthi W, Sukasem C, Lueangniyomkul A, Mankatitham W, Thongyen S, Nilkamhang S, Manosuthi S, and Sungkanuparph S (2013) Impact of pharmacogenetic markers of CYP2B6, clinical factors, and drug-drug interaction on efavirenz concentrations in HIV/tuberculosis-coinfected patients. Antimicrob Agents Chemother 57:1019-1024.

Manosuthi W, Sungkanuparph S, Tantanathip P, Mankatitham W, Lueangniyomkul A, Thongyen S, Eampokarap B, Uttayamakul S, Suwanvattana P, Kaewsaard S, et al.; N2R Study Team (2009) Body weight cutoff for daily dosage of efavirenz and 60 -week efficacy of efavirenz-based regimen in human immunodeficiency virus and tuberculosis coinfected patients receiving rifampin. Antimicrob Agents Chemother 53:4545-4548.

Marzolini C, Telenti A, Decosterd LA, Greub G, Biollaz J, and Buclin T (2001) Efavirenz plasma levels can predict treatment failure and central nervous system side effects in HIV-1-infected patients. AIDS 15:71-75.

Matimba A, Oluka MN, Ebeshi BU, Sayi J, Bolaji OO, Guantai AN, and Masimirembwa CM (2008) Establishment of a biobank and pharmacogenetics database of African populations. Eur J Hum Genet 16:780-783.

Maxwell S, Scheftner WA, Kessler HA, and Busch K (1988) Manic syndrome associated with zidovudine treatment. JAMA 259:3406-3407.

McCance-Katz EF, Gruber VA, Beatty G, Lum PJ, and Rainey PM (2013) Interactions between alcohol and the antiretroviral medications ritonavir or efavirenz. $J$ Addict Med 7:264-270

McDonagh EM, Lau JL, Alvarellos ML, Altman RB, and Klein TE (2015) PharmGKB summary: efavirenz pathway, pharmacokinetics. Pharmacogenet Genomics 25:363-376

McLeod GX and Hammer SM (1992) Zidovudine: five years later. Ann Intern Med 117:487-501

Mehlotra RK, Bockarie MJ, and Zimmerman PA (2007) CYP2B6 983T $>$ C polymorphism is prevalent in West Africa but absent in Papua New Guinea: implications for HIV/AIDS treatment. Br J Clin Pharmacol 64:391-395.

Merry C, Barry M, Gibbons S, Mulcahy F, and Back D (1996) Improved tolerability of ritonavir derived from pharmacokinetic principles. Br J Clin Pharmacol 42:787.

Mills AM, Antinori A, Clotet B, Fourie J, Herrera G, Hicks C, Madruga JV, Vanveggel S, Stevens M, and Boven K; ECHO and THRIVE study groups (2013) Neurological and psychiatric tolerability of rilpivirine (TMC278) vs. efavirenz in treatment-naïve, HIV-1-infected patients at 48 weeks. HIV Med 14:391-400.

Mogatle S, Skinner M, Mills E, and Kanfer I (2008) Effect of African potato (Hypoxis hemerocallidea) on the pharmacokinetics of efavirenz. S Afr Med $J$ 98:945-949.

Molina JM, Ferchal F, Rancinan C, Raffi F, Rozenbaum W, Sereni D, Morlat P, Journot V, Decazes JM, and Chêne G (2000) Once-daily combination therapy with 
emtricitabine, didanosine, and efavirenz in human immunodeficiency virusinfected patients. J Infect Dis 182:599-602.

Mollan KR, Smurzynski M, Eron JJ, Daar ES, Campbell TB, Sax PE, Gulick RM, Na L, O'Keefe L, Robertson KR, et al. (2014) Association between efavirenz as initial therapy for HIV-1 infection and increased risk for suicidal ideation or attempted or completed suicide: an analysis of trial data. Ann Intern Med 161:1-10.

Möller M, Du Preez JL, Viljoen FP, Berk M, Emsley R, and Harvey BH (2013a) Social isolation rearing induces mitochondrial, immunological, neurochemical and behavioural deficits in rats, and is reversed by clozapine or $\mathrm{N}$-acetyl cysteine. Brain Behav Immun 30:156-167.

Möller M, Du Preez JL, Viljoen FP, Berk M, and Harvey BH (2013b) N-Acetyl cysteine reverses social isolation rearing induced changes in cortico-striatal monoamines in rats. Metab Brain Dis 28:687-696.

Möller M, Swanepoel T, and Harvey BH (2015) Neurodevelopmental animal models reveal the convergent role of neurotransmitter systems, inflammation, and oxidative stress as biomarkers of schizophrenia: implications for novel drug development. ACS Chem Neurosci 6:987-1016.

Moreno A, Labelle C, and Samet JH (2003) Recurrence of post-traumatic stress disorder symptoms after initiation of antiretrovirals including efavirenz: a report of two cases. HIV Med 4:302-304.

Morlese JF, Qazi NA, Gazzard BG, and Nelson MR (2002) Nevirapine-induced neuropsychiatric complications, a class effect of non-nucleoside reverse transcriptase inhibitors? AIDS 16:1840-1841.

Mouly S, Lown KS, Kornhauser D, Joseph JL, Fiske WD, Benedek IH, and Watkins PB (2002) Hepatic but not intestinal CYP3A4 displays dose-dependent induction by efavirenz in humans. Clin Pharmacol Ther 72:1-9.

Mukonzo JK, Röshammar D, Waako P, Andersson M, Fukasawa T, Milani L, Svensson JO, Ogwal-Okeng J, Gustafsson LL, and Aklillu E (2009) A novel polymorphism in $\mathrm{ABCB} 1$ gene, CYP2B $6 * 6$ and sex predict single-dose efavirenz population pharmacokinetics in Ugandans. Br J Clin Pharmacol 68:690-699.

Muñoz-Moreno JA, Fumaz CR, Ferrer MJ, González-García M, Moltó J, Negredo E, and Clotet B (2009) Neuropsychiatric symptoms associated with efavirenz: prevalence, correlates, and management. A neurobehavioral review. AIDS Rev 11:103-109.

Mutlib AE, Chen H, Nemeth GA, Markwalder JA, Seitz SP, Gan LS, and Christ DD (1999) Identification and characterization of efavirenz metabolites by liquid chromatography/mass spectrometry and high field NMR: species differences in the metabolism of efavirenz. Drug Metab Dispos 27:1319-1333.

Nadal D, Steiner F, Cheseaux JJ, Lazarevitch CA, Aebi C, Kind C, and Rudin C; Pediatric AIDS Group of Switzerland (2000) Long-term responses to treatment including ritonavir or nelfinavir in HIV-1-infected children. Infection 28:287-296.

Napoli AA, Wood JJ, Coumbis JJ, Soitkar AM, Seekins DW, and Tilson HH (2014) No evident association between efavirenz use and suicidality was identified from a disproportionality analysis using the FAERS database. J Int AIDS Soc 17:19214

National Department of Health (2015) National Consolidated Guidelines for the Prevention of Mother-To-Child Transmission of HIV (PMTCT) and the Management of HIV in Children, Adolescents and Adults, National Department of Health, Pretoria, South Africa.

Nelson MR, Elion RA, Cohen CJ, Mills A, Hodder SL, Segal-Maurer S, Bloch M, Garner W, Guyer B, Williams S, et al. (2013) Rilpivirine versus efavirenz in HIV-1infected subjects receiving emtricitabine/tenofovir DF: pooled 96-week data from ECHO and THRIVE studies. HIV Clin Trials 14:81-91.

Nemaura T, Nhachi C, and Masimirembwa C (2012) Impact of gender, weight and CYP2B6 genotype on efavirenz exposure in patients on HIV/AIDS and TB treatment: implications for individualising therapy. Afr $J$ Pharm Pharmacol 6: $2188-2193$

Ngaimisi E, Mugusi S, Minzi OM, Sasi P, Riedel KD, Suda A, Ueda N, Janabi M, Mugusi F, Haefeli WE, et al. (2010) Long-term efavirenz autoinduction and its effect on plasma exposure in HIV patients. Clin Pharmacol Ther 88:676-684.

Nguyen A, Calmy A, Delhumeau C, Mercier I, Cavassini M, Mello AF, Elzi L, Rauch A, Bernasconi E, Schmid P, et al. (2011) A randomized cross-over study to compare raltegravir and efavirenz (SWITCH-ER study). AIDS 25:1481-1487.

Nitta K, Okada K, Yanai M, and Takahashi S (2013) Aging and chronic kidney disease. Kidney Blood Press Res 38:109-120.

Niu MT, Bethel J, Holodniy M, Standiford HC, and Schnittman SM; Division of AIDS Treatment Research Initiative (1998) Zidovudine treatment in patients with primary (acute) human immunodeficiency virus type 1 infection: a randomized, doubleblind, placebo-controlled trial. DATRI 002 study group. J Infect Dis 178:80-91.

Niwa T, Imagawa Y, and Yamazaki H (2014) Drug interactions between nine antifungal agents and drugs metabolized by human cytochromes P450. Curr Drug Metab 15:651-679.

Nkhoma ET, Coumbis J, Farr AM, Johnston SS, Chu BC, Rosenblatt LC, Seekins D, and Villasis-Keever A (2016) No evidence of an association between efavirenz exposure and suicidality among HIV patients initiating antiretroviral therapy in a retrospective cohort study of real world data. Medicine (Baltimore) 95:e2480

Nunez M, Gonzalez de Requena D, Gallego L, Jimenez-Nacher I, Gonzalez-Lahoz J, and Soriano V (2001) Higher efavirenz plasma levels correlate with development of insomnia. J Acquir Immune Defic Syndr 28:399-400.

Nyakutira C, Röshammar D, Chigutsa E, Chonzi P, Ashton M, Nhachi C, and Masimirembwa C (2008) High prevalence of the CYP2B6 516G->T(*6) variant and effect on the population pharmacokinetics of efavirenz in HIV/AIDS outpatients in Zimbabwe. Eur J Clin Pharmacol 64:357-365.

O'Dowd M and McKegney F (1988) Manic syndrome associated with zidovudine. JAMA 260:3587-3588.

Ogburn ET, Jones DR, Masters AR, Xu C, Guo Y, and Desta Z (2010) Efavirenz primary and secondary metabolism in vitro and in vivo: identification of novel metabolic pathways and cytochrome P450 2A6 as the principal catalyst of efavirenz 7-hydroxylation. Drug Metab Dispos 38:1218-1229.

Ohno Y, Hisaka A, and Suzuki H (2007) General framework for the quantitative prediction of CYP3A4-mediated oral drug interactions based on the AUC increase by coadministration of standard drugs. Clin Pharmacokinet 46:681-696.
Orrell C, Cohen K, Conradie F, Zeinecker J, Ive P, Sanne I, and Wood R (2011) Efavirenz and rifampicin in the South African context: is there a need to doseincrease efavirenz with concurrent rifampicin therapy? Antivir Ther 16:527-534.

Palella FJ Jr, Delaney KM, Moorman AC, Loveless MO, Fuhrer J, Satten GA, Aschman DJ, and Holmberg SD; HIV Outpatient Study Investigators (1998) Declining morbidity and mortality among patients with advanced human immunodeficiency virus infection. $N$ Engl $J$ Med 338:853-860.

Panos G, Samonis G, Alexiou VG, Kavarnou GA, Charatsis G, and Falagas ME (2008) Mortality and morbidity of HIV infected patients receiving HAART: a cohort study. Curr HIV Res 6:257-260.

Pedrol E, Llibre JM, Tasias M, Currán A, Guardiola JM, Deig E, Guelar A, MartínezMadrid O, Tikhomirova L, and Ramírez R; RELAX Study Group (2015) Outcome of neuropsychiatric symptoms related to an antiretroviral drug following its substitution by nevirapine: the RELAX study. HIV Med 16:628-634.

Peroni RN, Di Gennaro SS, Hocht C, Chiappetta DA, Rubio MC, Sosnik A, and Bramuglia GF (2011) Efavirenz is a substrate and in turn modulates the expression of the efflux transporter ABCG2/BCRP in the gastrointestinal tract of the rat. Biochem Pharmacol 82:1227-1233.

Pfister M, Labbé L, Hammer SM, Mellors J, Bennett KK, Rosenkranz S, and Sheiner LB; Adult AIDS Clinical Trial Group Study 398 (2003) Population pharmacokinetics and pharmacodynamics of efavirenz, nelfinavir, and indinavir: adult AIDS clinical trial group study 398. Antimicrob Agents Chemother 47:130-137.

Pham PA (2009) Antiretroviral adherence and pharmacokinetics: review of their roles in sustained virologic suppression. AIDS Patient Care STDS 23:803-807.

Phungula S (2013) Nyaope Addicts Increase in Ermelo, Health-E News, The South African Health News Service, South Africa.

Pitarque M, von Richter O, Oke B, Berkkan H, Oscarson M, and Ingelman-Sundberg $\mathrm{M}$ (2001) Identification of a single nucleotide polymorphism in the TATA box of the CYP2A6 gene: impairment of its promoter activity. Biochem Biophys Res Commun 284:455-460.

Poeta J, Linden R, Antunes MV, Real L, Menezes AM, Ribeiro JP, and Sprinz E (2011) Plasma concentrations of efavirenz are associated with body weight in HIVpositive individuals. J Antimicrob Chemother 66:2601-2604.

Porter K, Johnson AM, Phillips AN, and Darbyshire JH (1999) The practical significance of potential biases in estimates of the AIDS incubation period distribution in the UK register of HIV seroconverters. AIDS 13:1943-1951.

Powers V, Ward J, and Gompels M (2009) CYP2B6 G516T genotyping in a UK cohort of HIV-positive patients: polymorphism frequency and influence on efavirenz discontinuation. HIV Med 10:520-523.

Prast H and Philippu A (2001) Nitric oxide as modulator of neuronal function. Prog Neurobiol 64:51-68.

Purnell PR and Fox HS (2014) Efavirenz induces neuronal autophagy and mitochondrial alterations. J Pharmacol Exp Ther 351:250-258.

Puthanakit T, Kerr S, Ananworanich J, Bunupuradah T, Boonrak P, and Sirisanthana V (2009a) Pattern and predictors of immunologic recovery in human immunodeficiency virus-infected children receiving non-nucleoside reverse transcriptase inhibitor-based highly active antiretroviral therapy. Pediatr Infect Dis $J \mathbf{2 8}$ : 488-492.

Puthanakit T, Tanpaiboon P, Aurpibul L, Cressey TR, and Sirisanthana V (2009b) Plasma efavirenz concentrations and the association with CYP2B6-516G > T polymorphism in HIV-infected Thai children. Antivir Ther 14:315-320.

Rachlis A and Fanning MM (1993) Zidovudine toxicity. Clinical features and management. Drug Saf 8:312-320.

Radloff R, Gras A, Zanger UM, Masquelier C, Arumugam K, Karasi JC, Arendt V, Seguin-Devaux C, and Klein K (2013) Novel CYP2B6 enzyme variants in a Rwandese population: functional characterization and assessment of in silico prediction tools. Hum Mutat 34:725-734.

Ramachandran G, Hemanth Kumar AK, Rajasekaran S, Kumar P, Ramesh K, Anitha S, Narendran G, Menon P, Gomathi C, and Swaminathan S (2009a) CYP2B6 G516T polymorphism but not rifampin coadministration influences steady-state pharmacokinetics of efavirenz in human immunodeficiency virus-infected patients in South India. Antimicrob Agents Chemother 53:863-868.

Ramachandran G, Ramesh K, Hemanth Kumar AK, Jagan I, Vasantha M, Padmapriyadarsini C, Narendran G, Rajasekaran S, and Swaminathan S (2009b) Association of high T allele frequency of CYP2B6 G516T polymorphism among ethnic south Indian HIV-infected patients with elevated plasma efavirenz and nevirapine. J Antimicrob Chemother 63:841-843.

Read TR, Carey D, Mallon P, Mijch A, Goodall R, Hudson F, Wand H, and Emery S (2009) Efavirenz plasma concentrations did not predict cessation of therapy due to neuropsychiatric symptoms in a large randomized trial. AIDS 23:2222-2223.

Reay R, Dandara C, Viljoen M, and Rheeders M (2017) CYP2B6 haplotype predicts efavirenz plasma concentration in black South African HIV-1-infected children: a longitudinal pediatric pharmacogenomic study. OMICS 21:465-473.

Ribaudo HJ, Haas DW, Tierney C, Kim RB, Wilkinson GR, Gulick RM, Clifford DB, Marzolini C, Fletcher CV, Tashima KT, et al.; Adult AIDS Clinical Trials Group Study (2006) Pharmacogenetics of plasma efavirenz exposure after treatment discontinuation: an adult AIDS clinical trials group study. Clin Infect Dis $\mathbf{4 2}$ 401-407.

Ribaudo HJ, Liu H, Schwab M, Schaeffeler E, Eichelbaum M, Motsinger-Reif AA Ritchie MD, Zanger UM, Acosta EP, Morse GD, et al. (2010) Effect of CYP2B6, $\mathrm{ABCB} 1$, and CYP3A5 polymorphisms on efavirenz pharmacokinetics and treatment response: an AIDS clinical trials group study. J Infect Dis 202:717-722.

Richman D, Rosenthal AS, Skoog M, Eckner RJ, Chou TC, Sabo JP, and Merluzzi VJ (1991) BI-RG-587 is active against zidovudine-resistant human immunodeficiency virus type 1 and synergistic with zidovudine. Antimicrob Agents Chemother 35: 305-308.

Riddler SA, Haubrich R, DiRienzo AG, Peeples L, Powderly WG, Klingman KL, Garren KW, George T, Rooney JF, Brizz B, et al.; AIDS Clinical Trials Group Study A5142 Team (2008) Class-sparing regimens for initial treatment of HIV-1 infection. N Engl J Med 358:2095-2106. 
Rihs TA, Begley K, Smith DE, Sarangapany J, Callaghan A, Kelly M, Post JJ, and Gold J (2006) Efavirenz and chronic neuropsychiatric symptoms: a crosssectional case control study. HIV Med 7:544-548.

Rodriguez-Novoa S, Barreiro P, Rendón A, Jiménez-Nacher I, González-Lahoz J, and Soriano V (2005) Influence of 516G $>$ T polymorphisms at the gene encoding the CYP450-2B6 isoenzyme on efavirenz plasma concentrations in HIV-infected subjects. Clin Infect Dis 40:1358-1361.

Romão PR, Lemos JC, Moreira J, de Chaves G, Moretti M, Castro AA, Andrade VM, Boeck CR, Quevedo J, and Gavioli EC (2011) Anti-HIV drugs nevirapine and efavirenz affect anxiety-related behavior and cognitive performance in mice. Neurotox Res 19:73-80.

Rotger M, Colombo S, Furrer H, Bleiber G, Buclin T, Lee BL, Keiser O, Biollaz J, Décosterd L, and Telenti A; Swiss HIV Cohort Study (2005) Influence of CYP2B6 polymorphism on plasma and intracellular concentrations and toxicity of efavirenz and nevirapine in HIV-infected patients. Pharmacogenet Genomics 15:1-5.

Rotger M, Tegude H, Colombo S, Cavassini M, Furrer H, Décosterd L, Blievernicht J, Saussele T, Günthard HF, Schwab M, et al. (2007) Predictive value of known and novel alleles of CYP2B6 for efavirenz plasma concentrations in HIV-infected individuals. Clin Pharmacol Ther 81:557-566.

Saadeddin A and Peris JE (2009) Pharmacokinetic interaction between efavirenz and ketoconazole in rats. Xenobiotica 39:135-139.

Saito M, Hirata-Koizumi M, Matsumoto M, Urano T, and Hasegawa R (2005) Undesirable effects of citrus juice on the pharmacokinetics of drugs: focus on recent studies. Drug Saf 28:677-694.

Saitoh A, Fletcher CV, Brundage R, Alvero C, Fenton T, Hsia K, and Spector SA (2007) Efavirenz pharmacokinetics in HIV-1-infected children are associated with CYP2B6-G516T polymorphism. J Acquir Immune Defic Syndr 45:280-285.

Salem AH, Fletcher CV, and Brundage RC (2014) Pharmacometric characterization of efavirenz developmental pharmacokinetics and pharmacogenetics in HIVinfected children. Antimicrob Agents Chemother 58:136-143.

Sarfo FS, Zhang Y, Egan D, Tetteh LA, Phillips R, Bedu-Addo G, Sarfo MA, Khoo S, Owen A, and Chadwick DR (2014) Pharmacogenetic associations with plasma efavirenz concentrations and clinical correlates in a retrospective cohort of Ghanaian HIV-infected patients. J Antimicrob Chemother 69:491-499.

Schaerf FW, Miller R, Pearlson GD, Kaminsky MJ, and Weaver D (1988) Manic syndrome associated with zidovudine. JAMA 260:3587-3588.

Schmiedlin-Ren P, Edwards DJ, Fitzsimmons ME, He K, Lown KS, Woster PM, Rahman A, Thummel KE, Fisher JM, Hollenberg PF, et al. (1997) Mechanisms of enhanced oral availability of CYP3A4 substrates by grapefruit constituents. Decreased enterocyte CYP3A4 concentration and mechanism-based inactivation by furanocoumarins. Drug Metab Dispos 25:1228-1233.

Schuetz EG, Umbenhauer DR, Yasuda K, Brimer C, Nguyen L, Relling MV, Schuetz JD, and Schinkel AH (2000) Altered expression of hepatic cytochromes P-450 in mice deficient in one or more mdr1 genes. Mol Pharmacol 57:188-197.

Schwarz UI, Johnston PE, Bailey DG, Kim RB, Mayo G, and Milstone A (2006) Impact of citrus soft drinks relative to grapefruit juice on ciclosporin disposition. $\mathrm{Br}$ $J$ Clin Pharmacol 62:485-491.

Scourfield A, Zheng J, Chinthapalli S, Waters L, Martin T, Mandalia S, and Nelson M (2012) Discontinuation of Atripla as first-line therapy in HIV-1 infected individuals. AIDS 26:1399-1401.

Seo SW, Suh MK, Chin J, and Na DL (2009) Mental confusion associated with scopolamine patch in elderly with mild cognitive impairment (MCI). Arch Gerontol Geriatr 49:204-207.

Shubber Z, Calmy A, Andrieux-Meyer I, Vitoria M, Renaud-Théry F, Shaffer N, Hargreaves S, Mills EJ, and Ford N (2013) Adverse events associated with nevirapine and efavirenz-based first-line antiretroviral therapy: a systematic review and meta-analysis. AIDS 27:1403-1412

Sinxadi PZ, Leger PD, McIlleron HM, Smith PJ, Dave JA, Levitt NS, Maartens G, and Haas DW (2015) Pharmacogenetics of plasma efavirenz exposure in HIV infected adults and children in South Africa. Br J Clin Pharmacol 80:146-156.

Smit JW, Schinkel AH, Weert B, and Meijer DK (1998) Hepatobiliary and intestinal clearance of amphiphilic cationic drugs in mice in which both mdr1a and mdr1b genes have been disrupted. $\mathrm{Br} J$ Pharmacol 124:416-424.

Smith C, Ryom L, Monforte Ad, Reiss P, Mocroft A, El-Sadr W, Weber R, Law M, Sabin C, and Lundgren J (2014) Lack of association between use of efavirenz and death from suicide: evidence from the D:A:D study. J Int AIDS Soc 17 (4 Suppl 3): 19512

Soler Palacin P, Aramburo A, Moraga FA, Cabañas MJ, and Figueras C (2006) Neuropsychiatric reaction induced by abacavir in a pediatric human immunodeficiency virus-infected patient. Pediatr Infect Dis $J$ 25:382.

Sriwiriyajan S, Mahatthanatrakul W, Ridtitid W, and Jaruratanasirikul S (2007) Effect of efavirenz on the pharmacokinetics of ketoconazole in HIV-infected patients. Eur J Clin Pharmacol 63:479-483.

Stanton T, Bolden-Watson C, Cusack B, and Richelson E (1993) Antagonism of the five cloned human muscarinic cholinergic receptors expressed in CHO-K1 cells by antidepressants and antihistaminics. Biochem Pharmacol 45:2352-2354.

Starr SE, Fletcher CV, Spector SA, Yong FH, Fenton T, Brundage RC, Manion D, Ruiz N, Gersten M, Becker M, et al. (1999) Combination therapy with efavirenz, nelfinavir, and nucleoside reverse-transcriptase inhibitors in children infected with human immunodeficiency virus type 1. Pediatric AIDS clinical trials group 382 team. $N$ Engl J Med 341:1874-1881.

Staszewski S, Morales-Ramirez J, Tashima KT, Rachlis A, Skiest D, Stanford J, Stryker R, Johnson P, Labriola DF, Farina D, et al. (1999) Efavirenz plus zidovudine and lamivudine, efavirenz plus indinavir, and indinavir plus zidovudine and lamivudine in the treatment of HIV-1 infection in adults. Study 006 Team. $N$ Engl J Med 341:1865-1873.

Stöhr W, Back D, Dunn D, Sabin C, Winston A, Gilson R, Pillay D, Hill T, Ainsworth J, Pozniak A, et al.; Liverpool TDM Database; UK CHIC Study (2008) Factors influencing efavirenz and nevirapine plasma concentration: effect of ethnicity, weight and co-medication. Antivir Ther 13:675-685.
Störmer E, von Moltke LL, Perloff MD, and Greenblatt DJ (2002) Differential modulation of P-glycoprotein expression and activity by non-nucleoside HIV-1 reverse transcriptase inhibitors in cell culture. Pharm Res 19:1038-1045.

Stresser DM, Broudy MI, Ho T, Cargill CE, Blanchard AP, Sharma R, Dandeneau AA, Goodwin JJ, Turner SD, Erve JC, et al. (2004) Highly selective inhibition of human CYP3Aa in vitro by azamulin and evidence that inhibition is irreversible. Drug Metab Dispos 32:105-112.

Sukasem C, Chamnanphon M, Koomdee N, Puangpetch A, Santon S, Jantararoungtong T, Prommas S, Chantratita W, and Manosuthi W (2013) High plasma efavirenz concentration and CYP2B6 polymorphisms in Thai HIV-1 infections. Drug Metab Pharmacokinet 28:391-397.

Sustiva (1998) Sustiva product insert: highlights of prescribing information. BristolMyers Squibb, Princeton, NJ.

Swart M, Skelton M, Ren Y, Smith P, Takuva S, and Dandara C (2013) High predictive value of CYP2B6 SNPs for steady-state plasma efavirenz levels in South African HIV/AIDS patients. Pharmacogenet Genomics 23:415-427.

Swart M, Whitehorn H, Ren Y, Smith P, Ramesar RS, and Dandara C (2012) PXR and CAR single nucleotide polymorphisms influence plasma efavirenz levels in South African HIV/AIDS patients. BMC Med Genet 13:112.

Takahashi M, Ibe S, Kudaka Y, Okumura N, Hirano A, Suzuki T, Mamiya N, Hamaguchi M, and Kaneda T (2007) No observable correlation between central nervous system side effects and EFV plasma concentrations in Japanese HIV type 1-infected patients treated with EFV containing HAART. AIDS Res Hum Retroviruses 23:983-987.

Takanaga H, Ohnishi A, Yamada S, Matsuo H, Morimoto S, Shoyama Y, Ohtani H, and Sawada Y (2000) Polymethoxylated flavones in orange juice are inhibitors of P-glycoprotein but not cytochrome P450 3A4. J Pharmacol Exp Ther 293:230-236.

Tanaka R, Hanabusa H, Kinai E, Hasegawa N, Negishi M, and Kato S (2008) Intracellular efavirenz levels in peripheral blood mononuclear cells from human immunodeficiency virus-infected individuals. Antimicrob Agents Chemother 52: $782-785$.

Tashima KT, Caliendo AM, Ahmad M, Gormley JM, Fiske WD, Brennan JM, and Flanigan TP (1999) Cerebrospinal fluid human immunodeficiency virus type 1 (HIV-1) suppression and efavirenz drug concentrations in HIV-1-infected patients receiving combination therapy. J Infect Dis 180:862-864.

Telenti A and Zanger UM (2008) Pharmacogenetics of anti-HIV drugs. Annu Rev Pharmacol Toxicol 48:227-256.

ter Heine R, Scherpbier HJ, Crommentuyn KM, Bekker V, Beijnen JH, Kuijpers TW, and Huitema $\mathrm{AD}$ (2008) A pharmacokinetic and pharmacogenetic study of efavirenz in children: dosing guidelines can result in subtherapeutic concentrations. Antivir Ther 13:779-787.

Tovar-y-Romo LB, Bumpus NN, Pomerantz D, Avery LB, Sacktor N, McArthur JC, and Haughey NJ (2012) Dendritic spine injury induced by the 8-hydroxy metabolite of efavirenz. J Pharmacol Exp Ther 343:696-703.

Tozzi V, Balestra P, Salvatori MF, Vlassi C, Liuzzi G, Giancola ML, Giulianelli M, Narciso P, and Antinori A (2009) Changes in cognition during antiretroviral therapy: comparison of 2 different ranking systems to measure antiretroviral drug efficacy on HIV-associated neurocognitive disorders [published correction appears in J Acquir Immune Defic Syndr (2009) 52(4):529]. J Acquir Immune Defic Syndr 52:56-63.

Tsuchiya K, Gatanaga H, Tachikawa N, Teruya K, Kikuchi Y, Yoshino M, Kuwahara T, Shirasaka T, Kimura S, and Oka S (2004) Homozygous CYP2B6 *6 (Q172H and K262R) correlates with high plasma efavirenz concentrations in HIV-1 patients treated with standard efavirenz-containing regimens. Biochem Biophys Res Commun 319:1322-1326.

Uttayamakul S, Likanonsakul S, Manosuthi W, Wichukchinda N, Kalambaheti T, Nakayama EE, Shioda T, and Khusmith S (2010) Effects of CYP2B6 G516T polymorphisms on plasma efavirenz and nevirapine levels when co-administered with rifampicin in HIV/TB co-infected Thai adults. AIDS Res Ther 7:8.

Uttayamakul S, Likanonsakul S, Manosuthi W, Wichukchinda N, Shioda T, and Khusmith S (2012) Influence of ABCB-1 C3435T polymorphisms on plasma nevirapine and efavirenz levels and their effects on virologic and immunological outcomes in HIV/TB co-infected Thai adults under anti-retroviral therapy. Southeast Asian J Trop Med Public Health 43:78-88.

van Leth F, Phanuphak P, Ruxrungtham K, Baraldi E, Miller S, Gazzard B, Cahn P, Lalloo UG, van der Westhuizen IP, Malan DR, et al.; 2NN Study team (2004) Comparison of first-line antiretroviral therapy with regimens including nevirapine, efavirenz, or both drugs, plus stavudine and lamivudine: a randomised open-labe trial, the 2NN study. Lancet 363:1253-1263.

van Luin M, Brouwer AM, van der Ven A, de Lange W, van Schaik RH, and Burger $\mathrm{DM}$ (2009a) Efavirenz dose reduction to $200 \mathrm{mg}$ once daily in a patient treated with rifampicin. AIDS 23:742-744

van Luin M, Gras L, Richter C, van der Ende ME, Prins JM, de Wolf F, Burger DM, and Wit FW (2009b) Efavirenz dose reduction is safe in patients with high plasma concentrations and may prevent efavirenz discontinuations. J Acquir Immune Defic Syndr 52:240-245.

Vazquez E (1999) Sustiva flashbacks. Posit Aware 10:17.

Viljoen M, Gous H, Kruger HS, Riddick A, Meyers TM, and Rheeders M (2010) Efavirenz plasma concentrations at 1,3 , and 6 months post-antiretroviral therapy initiation in HIV type 1-infected South African children. AIDS Res Hum Retroviruses 26:613-619.

Viljoen M, Karlsson MO, Meyers TM, Gous H, Dandara C, and Rheeders M (2012) Influence of CYP2B6 516G $>\mathrm{T}$ polymorphism and interoccasion variability (IOV) on the population pharmacokinetics of efavirenz in HIV-infected South African children. Eur J Clin Pharmacol 68:339-347.

von Giesen HJ, Köller H, de Nocker D, Haslinger BA, and Arendt G (2003) Long-term safety and efficacy of NNRTI within the central nervous system. HIV Clin Trials 4:382-390.

von Hentig N, Koenigs C, Elanjikal S, Linde R, Dunsch D, Kreuz W, and Funk MB (2006) Need for therapeutic drug monitoring in HIV-1 infected children receiving efavirenz doses according to international guidelines. Eur J Med Res 11:377-380. 
von Moltke LL, Greenblatt DJ, Grassi JM, Granda BW, Duan SX, Fogelman SM, Daily JP, Harmatz JS, and Shader RI (1998) Protease inhibitors as inhibitors of human cytochromes P450: high risk associated with ritonavir. J Clin Pharmacol 38:106-111.

von Mühlendahl KE and Krienke EG (1978) Toxicity of cyproheptadine. Side effects and accidental overdosage (author's transl). Monatsschr Kinderheilkd 126:123-126.

Walmsley SL, Antela A, Clumeck N, Duiculescu D, Eberhard A, Gutiérrez F, Hocqueloux L, Maggiolo F, Sandkovsky U, Granier C, et al.; SINGLE Investigators (2013) Dolutegravir plus abacavir-lamivudine for the treatment of HIV-1 infection. N Engl J Med 369:1807-1818.

Walsky RL, Astuccio AV, and Obach RS (2006) Evaluation of 227 drugs for in vitro inhibition of cytochrome P450 2B6. J Clin Pharmacol 46:1426-1438.

Wang J, Sönnerborg A, Rane A, Josephson F, Lundgren S, Ståhle L, and IngelmanSundberg M (2006) Identification of a novel specific CYP2B6 allele in Africans causing impaired metabolism of the HIV drug efavirenz. Pharmacogenet Genomics 16:191-198.

Wang YM, Ong SS, Chai SC, and Chen T (2012) Role of CAR and PXR in xenobiotic sensing and metabolism. Expert Opin Drug Metab Toxicol 8:803-817.

Ward BA, Gorski JC, Jones DR, Hall SD, Flockhart DA, and Desta Z (2003) The cytochrome P450 2B6 (CYP2B6) is the main catalyst of efavirenz primary and secondary metabolism: implication for HIV/AIDS therapy and utility of efavirenz as a substrate marker of CYP2B6 catalytic activity. J Pharmacol Exp Ther 306: 287-300.

Watanabe M, Matsumoto N, Takeba Y, Kumai T, Tanaka M, Tatsunami S, Takenoshita-Nakaya S, Harimoto Y, Kinoshita Y, and Kobayashi S (2011) Orange juice and its component, hesperidin, decrease the expression of multidrug resistanceassociated protein 2 in rat small intestine and liver. J Biomed Biotechnol 2011: 502057.

Watemberg NM, Roth KS, Alehan FK, and Epstein CE (1999) Central anticholinergic syndrome on therapeutic doses of cyproheptadine. Pediatrics 103:158-160.

Waters L, Fisher M, Winston A, Higgs C, Hadley W, Garvey L, Mandalia S, Perry N, Nicola M, and Nelson M (2011) A phase IV, double-blind, multicentre, randomized, placebo-controlled, pilot study to assess the feasibility of switching individuals receiving efavirenz with continuing central nervous system adverse events to etravirine. AIDS 25:65-71.

Watkins PB, Wrighton SA, Schuetz EG, Molowa DT, and Guzelian PS (1987) Identification of glucocorticoid-inducible cytochromes P-450 in the intestinal mucosa of rats and man. J Clin Invest 80:1029-1036.

Weiss J, Herzog M, König S, Storch CH, Ketabi-Kiyanvash N, and Haefeli WE (2009) Induction of multiple drug transporters by efavirenz. J Pharmacol Sci 109:242-250.

WHO (2016) Consolidated Guidelines on the Use of Antiretroviral Drugs for Treating and Preventing HIV Infection Recommendations for a Public Health Approach, 2nd ed, World Health Organization, Geneva.

Wilson WH, Schenkein DP, Jernigan CL, Woodcock J, and Schilsky RL (2013) Reevaluating the accelerated approval process for oncology drugs. Clin Cancer Res 19:2804-2809.

Winston A, Duncombe C, Li PC, Gill JM, Kerr SJ, Puls R, Petoumenos K, TaylorRobinson SD, Emery S, and Cooper DA; Altair Study Group (2010) Does choice of combination antiretroviral therapy (cART) alter changes in cerebral function testing after 48 weeks in treatment-naive, HIV-1-infected individuals commencing cART? A randomized, controlled study [published correction appears in Clin Infect Dis (2010) 51:638]. Clin Infect Dis 50:920-929.

Winston A, Jose S, Gibbons S, Back D, Stohr W, Post F, Fisher M, Gazzard B, Nelson M, Gilson R, et al.; UK Collaborative HIV Cohort Study (2013) Effects of age on antiretroviral plasma drug concentration in HIV-infected subjects undergoing routine therapeutic drug monitoring. J Antimicrob Chemother 68:1354-1359.

Wintergerst U, Hoffmann F, Jansson A, Notheis G, Huss K, Kurowski M, and Burger D (2008) Antiviral efficacy, tolerability and pharmacokinetics of efavirenz in an unselected cohort of HIV-infected children. J Antimicrob Chemother 61:1336-1339.
Winzer R, Langmann P, Zilly M, Tollmann F, Schubert J, Klinker H, and Weissbrich B (2003) No influence of the P-glycoprotein genotype (MDR1 C3435T) on plasma levels of lopinavir and efavirenz during antiretroviral treatment. Eur J Med Res 8: 531-534.

Wise ME, Mistry K, and Reid S (2002) Drug points: neuropsychiatric complications of nevirapine treatment. BMJ 324:879.

Woodhouse KW and Wynne HA (1988) Age-related changes in liver size and hepatic blood flow. The influence on drug metabolism in the elderly. Clin Pharmacokinet 15:287-294.

Wright JM, Sachdev PS, Perkins RJ, and Rodriguez P (1989) Zidovudine-related mania. Med J Aust 150:339-341.

Wrighton SA, Schuetz EG, Thummel KE, Shen DD, Korzekwa KR, and Watkins PB (2000) The human CYP3A subfamily: practical considerations. Drug Metab Rev 32: 339-361.

Wyen C, Hendra H, Siccardi M, Platten M, Jaeger H, Harrer T, Esser S, Bogner JR, Brockmeyer NH, Bieniek B, et al; German Competence Network for HIV/AIDS Coordinators (2011) Cytochrome P450 2B6 (CYP2B6) and constitutive androstane receptor (CAR) polymorphisms are associated with early discontinuation of efavirenz-containing regimens. J Antimicrob Chemother 66:2092-2098.

Wyen C, Hendra H, Vogel M, Hoffmann C, Knechten H, Brockmeyer NH, Bogner JR, Rockstroh J, Esser S, Jaeger H, et al.; German Competence Network for HIV/AIDS (2008) Impact of CYP2B6 983T $>$ C polymorphism on non-nucleoside reverse transcriptase inhibitor plasma concentrations in HIV-infected patients. J Antimicrob Chemother 61:914-918.

Wyles DL and Gerber JG (2005) Antiretroviral drug pharmacokinetics in hepatitis with hepatic dysfunction [published correction appears in Clin Infect Dis (2005) 40: 913]. Clin Infect Dis 40:174-181.

Xu BY, Guo LP, Lee SS, Dong QM, Tan Y, Yao H, Li LH, Lin CK, Kung HF, and He ML (2007) Genetic variability of CYP2B6 polymorphisms in four southern Chinese populations. World J Gastroenterol 13:2100-2103.

$\mathrm{Xu} C$ and Desta Z (2013) In vitro analysis and quantitative prediction of efavirenz inhibition of eight cytochrome P450 (CYP) enzymes: major effects on CYPs 2B6, 2C8, 2C9 and 2C19. Drug Metab Pharmacokinet 28:362-371.

Xu C, Ogburn ET, Guo Y, and Desta Z (2012) Effects of the CYP2B6*6 allele on catalytic properties and inhibition of CYP2B6 in vitro: implication for the mechanism of reduced efavirenz metabolism and other CYP2B6 substrates in vivo. Drug Metab Dispos 40:717-725.

Yilmaz A, Watson V, Dickinson L, and Back D (2012) Efavirenz pharmacokinetics in cerebrospinal fluid and plasma over a 24-hour dosing interval. Antimicrob Agents Chemother 56:4583-4585.

Yoshida R, Nakajima M, Nishimura K, Tokudome S, Kwon JT, and Yokoi T (2003) Effects of polymorphism in promoter region of human CYP2A6 gene (CYP2A6*9) on expression level of messenger ribonucleic acid and enzymatic activity in vivo and in vitro. Clin Pharmacol Ther 74:69-76.

Young SD, Britcher SF, Tran LO, Payne LS, Lumma WC, Lyle TA, Huff JR, Anderson PS, Olsen DB, Carroll SS, et al. (1995) L-743, 726 (DMP-266): a novel, highly potent nonnucleoside inhibitor of the human immunodeficiency virus type 1 reverse transcriptase. Antimicrob Agents Chemother 39:2602-2605.

Zanger UM and Klein K (2013) Pharmacogenetics of cytochrome P450 2B6 (CYP2B6): advances on polymorphisms, mechanisms, and clinical relevance. Front Genet 4:24. Zanger UM, Klein K, Saussele T, Blievernicht J, Hofmann MH, and Schwab M (2007) Polymorphic CYP2B6: molecular mechanisms and emerging clinical significance. Pharmacogenomics 8:743-759.

Zhang H, Sridar C, Kenaan C, Amunugama H, Ballou DP, and Hollenberg PF (2011) Polymorphic variants of cytochrome P450 2B6 (CYP2B6.4-CYP2B6.9) exhibit altered rates of metabolism for bupropion and efavirenz: a charge-reversal mutation in the K139E variant (CYP2B6.8) impairs formation of a functional cytochrome p450-reductase complex. J Pharmacol Exp Ther 338:803-809. 